\title{
How To Do Things With Fish and MacIntyre: Speech Act Theory, Dramatic Narrative, And \\ The Interpretation Of Moral Utterance
}

\author{
By Jason Hannan, B. Sc.
}

\author{
A thesis submitted to \\ the Faculty of Graduate Studies \\ in partial fulfillment of \\ the requirements for the degree of \\ Master of Arts
}

School of Journalism and Communication

Carleton University

Ottawa, ON

August 29, 2005

(C) 2005, Jason Hannan 


$\begin{array}{ll}\begin{array}{l}\text { Library and } \\ \text { Archives Canada }\end{array} & \begin{array}{l}\text { Bibliothèque et } \\ \text { Archives Canada }\end{array} \\ \begin{array}{l}\text { Published Heritage } \\ \text { Branch }\end{array} & \begin{array}{l}\text { Direction du } \\ \text { Patrimoine de l'édition }\end{array} \\ \begin{array}{l}\text { 395 Wellington Street } \\ \text { Ottawa ON K1A ON4 }\end{array} & \begin{array}{l}\text { 395, rue Wellington } \\ \text { Ottawa ON K1A ON4 } \\ \text { Canada }\end{array}\end{array}$

Your file Votre référence

ISBN: 0-494-10048-6

Ourfile Notre référence

ISBN: 0-494-10048-6

NOTICE:

The author has granted a nonexclusive license allowing Library and Archives Canada to reproduce, publish, archive, preserve, conserve, communicate to the public by telecommunication or on the Internet, loan, distribute and sell theses worldwide, for commercial or noncommercial purposes, in microform, paper, electronic and/or any other formats.

The author retains copyright ownership and moral rights in this thesis. Neither the thesis nor substantial extracts from it may be printed or otherwise reproduced without the author's permission.
AVIS:

L'auteur a accordé une licence non exclusive permettant à la Bibliothèque et Archives Canada de reproduire, publier, archiver, sauvegarder, conserver, transmettre au public par télécommunication ou par l'Internet, prêter, distribuer et vendre des thèses partout dans le monde, à des fins commerciales ou autres, sur support microforme, papier, électronique et/ou autres formats.

L'auteur conserve la propriété du droit d'auteur et des droits moraux qui protège cette thèse. $\mathrm{Ni}$ la thèse ni des extraits substantiels de celle-ci ne doivent être imprimés ou autrement reproduits sans son autorisation.
In compliance with the Canadian

Privacy Act some supporting forms may have been removed from this thesis.

While these forms may be included in the document page count, their removal does not represent any loss of content from the thesis.
Conformément à la loi canadienne sur la protection de la vie privée, quelques formulaires secondaires ont été enlevés de cette thèse.

Bien que ces formulaires aient inclus dans la pagination, il n'y aura aucun contenu manquant.

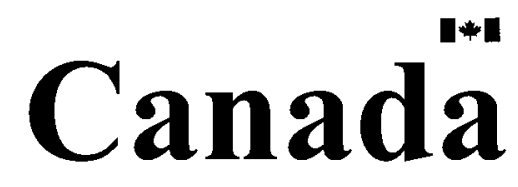




\begin{abstract}
The present thesis concerns the interpretation of moral utterance by members of alien cultures. It is based on Alasdair MacIntyre's theory of the narrative constitution of moral identity and J. L. Austin and John Searle's theory of the speech-act. The methodology is based on an essay by the postmodern literary critic Stanley Fish, who applies speech-act theory to a literary text to unpack the social and cultural conventions that govern the use of language. The present thesis attempts a similar task by likewise applying speech-act theory to a literary text. However, whereas the object of Fish's analysis is the speech-acts constitutive of a formal institution, I have examined the speech-acts constitutive of a particular social tradition. The question of illocutionary force is an ongoing preoccupation in my analysis. It is my contention that the illocutionary force of the non-institutional speech-act derives from the authority of socially embodied narratives. Whereas the procedural force of "ought" statements issued in institutional settings derives from the legitimating structure of the institution itself, I argue that the moral force of "ought" statements issued in non-institutional settings derives from the collective narratives of which a moral agent is a part. Speech-act theory is invaluable to the study of communication, for it concerns the social and cultural conditions of intelligibility in a given community of meaning, the price one must pay for membership in that community, and the price one pays for defying its conventions. More importantly, it concerns the communicative foundations of moral meaning.
\end{abstract}




\section{ACKNOWLEDGEMENTS}

I would like to thank my supervisor, Professor Karim H. Karim. I am grateful to my second reader, Professor Michael Dorland, for his encouraging feedback concerning my initial thesis proposal. I am likewise grateful to Professor Barry Rutland of the Department of English Language and Literature at Carleton University for his constructive criticisms concerning the initial proposal. I would like to thank Professor Sheryl Hamilton, whose comments on the original draft of my thesis proposal and an earlier essay have influenced the writing of the present work considerably. Professor Paul Attallah was kind enough to comment on two versions of my thesis proposal. It was due in part to his insightful remarks that the first version eventually gave way to a second version. I am grateful to Carole Craswell for kindly helping me through a small, albeit agonizing, bureaucratic nightmare concerning summer registration, as well as for her patience while I harassed her with countless questions concerning administrative matters. Finally, I would like to thank my fellow graduate students at the Department of Communication at Carleton University. Our unofficial consolation club provided me with an essential outlet for sharing my anxieties over the process of thesis writing. Had it not been for their generous sympathies, that process would doubtless have generated a great deal more anxiety. 


\section{TABLE OF CONTENTS}

CHAPTER 1: INTRODUCTION................................................................................................... 3

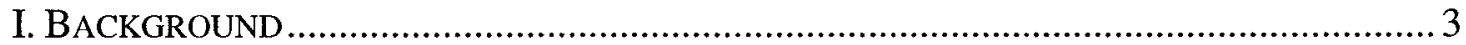

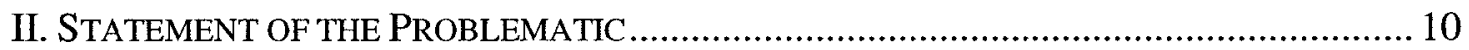

III. EXPLICATION OF RESEARCH APPROACH................................................... 12

IV. JUSTIFICATION AND APPLICATION................................................................ 18

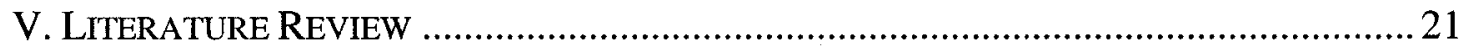

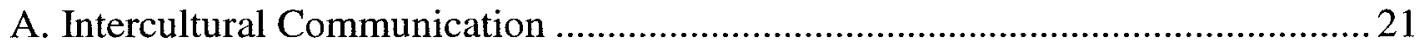

B. On Language, Utterances and Meaning .......................................................... 22

C. Practical Rationality, Moral Interpretive Schemas and Moral Experience .......... 22

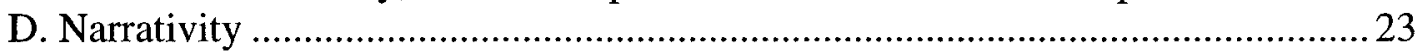

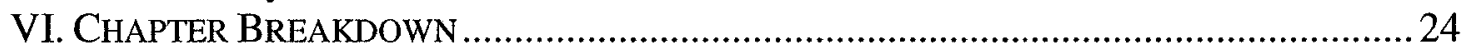

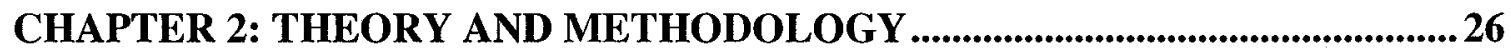

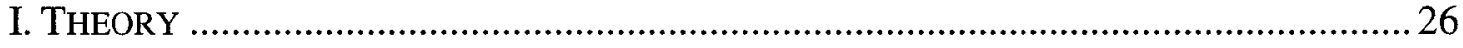

A. On Moral Experience and Practical Rationality .................................................26

B. A Narrative Conception of Culture ................................................................ 33

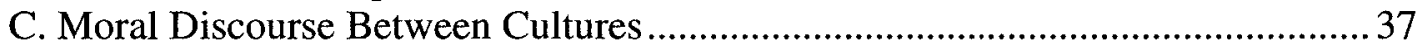

D. Background to Speech Act Theory: Austin, Searle, and Fish ...........................41

II. METHODOLOGY: HOW TO DO THINGS WITH STANLEY FISH ................................. 51

CHAPTER THREE: A SPEECH-ACT READING OF BRICK LANE....................56

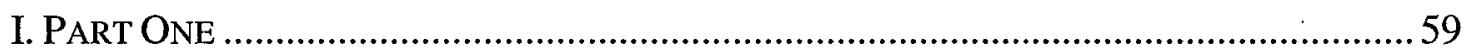

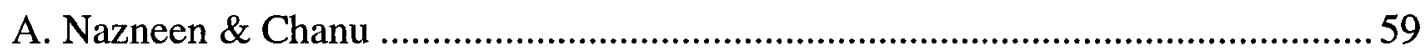

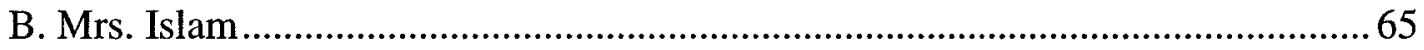

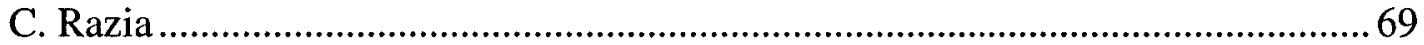

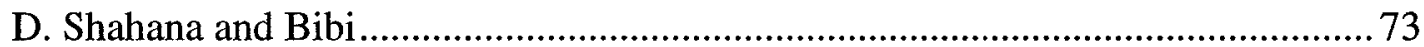

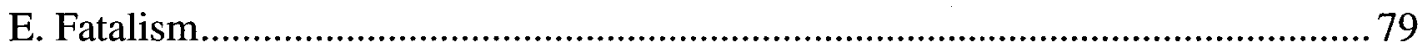

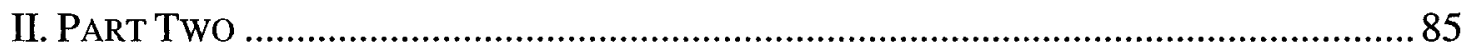

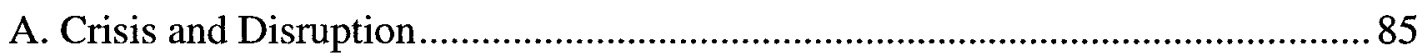

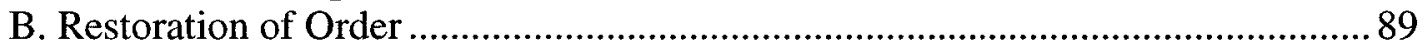

C. Discovery of alternative social roles .............................................................. 91

D. Coercion and Control ......................................................................................... 93

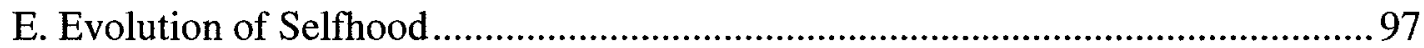

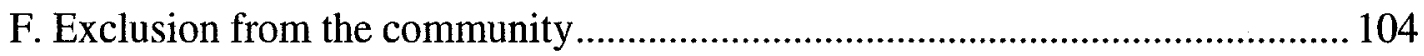

G. Incommensurability and Narrative Rupture ................................................ 105

H. The Final Moments of Transformation ...................................................... 106

CHAPTER 4: NARRATIVE CONTEXTS OF JUSTIFICATION: ........................113

SUPPLEMENT TO THE THEORY OF THE SPEECH-ACT ................................ 113

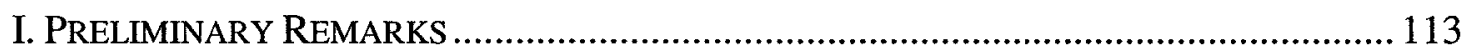

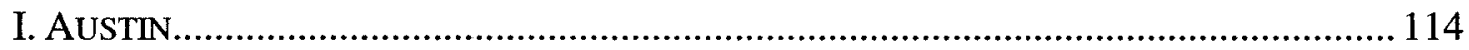

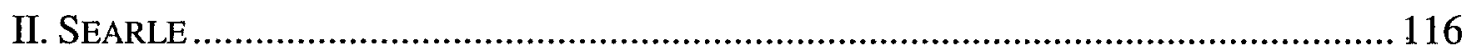




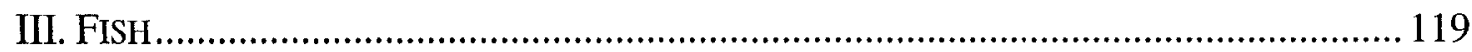

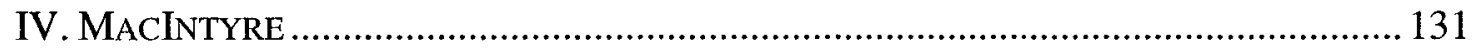

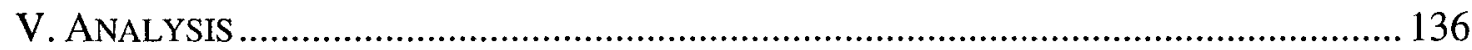

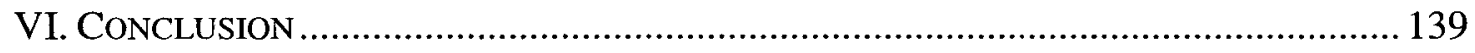

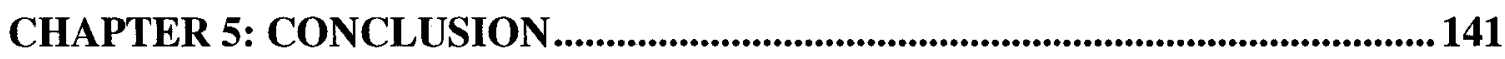

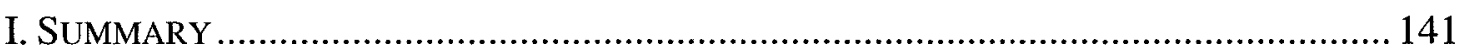

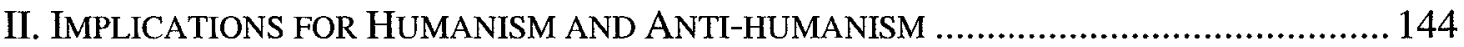

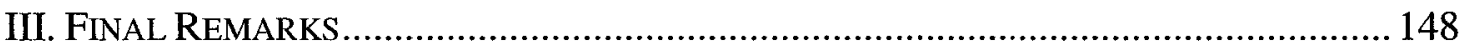

A. Speech-Act Analysis in the Field of Communication .................................... 148

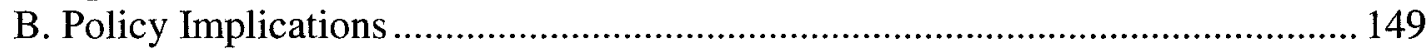

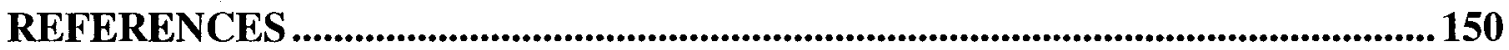




\section{CHAPTER 1: INTRODUCTION}

\section{Background}

In The Unfinished Project: Toward a Postmetaphysical Humanism (2001), the communitarian philosopher Lorenzo C. Simpson seeks to reconstruct a viable theory of humanism for the present age and offers a model for intercultural understanding and moral discourse. Like many other socially observant intellectuals, Simpson argues that a number of features characteristic of the modern era, including globalization, the mass media, transcultural migration and the concomitant rise of culturally diverse societies, are increasingly resulting in "sites of cultural confrontation and difference" (2001: 1). Although attempts are currently being undertaken in certain states to accommodate cultural differences, both for reasons pertaining to the pursuit of the enduring ideal of political equality and the more pragmatic concern of avoiding potentially explosive cultural tensions, the "struggles for social and racial justice" have yet to be won (2). In the face of moral and political challenges posed by cultural differences, Simpson rightly inquires into the legacy of secular humanism, once celebrated for its "universal aspirations valid for the species as a whole" (ibid). As Simpson points out, the European humanist tradition maintained a particular "philosophy of man," central to which was a metaphysical belief in "man's" uniqueness among the species for possessing the tripartite faculties of reason, language, and morality. Unlike other species, "man" was free to determine his own destiny - no doubt a source of inspiration for the prospect of a better future. Given the encouraging presumption of a common basis for humanity, it would seem reasonable to inquire into the possible philosophical resources at humanism's disposal for addressing the haunting specter of intercultural conflict in the present age. 
However, humanism as a movement and intellectual orientation is no longer tenable in many contemporary philosophical circles - and for a number of reasons. Chief among these is the dismissal of the dogmatic belief that "there is some interesting shared feature or metaphysical essence that embraces us all" (4). The most influential attack upon this belief came from Martin Heidegger, who argued that what humanists took to be the ultimate nature of human beings was in fact only a working approximation of the everelusive nature of Being. Heidegger's anti-metaphysical critique of humanism eventually gained much currency in Continental philosophy, particularly in French intellectual circles. It was an important influence upon the thought of such figures as Louis Althusser, Michel Foucault, and Jacques Derrida. In the United States, the pragmatist philosopher Richard Rorty became an influential critic of humanism as well. Any and all attempts to formulate what Rorty referred to as a "final vocabulary" for capturing human reality was bound to be inadequate, offering only a sadly wanting description whose philosophical purchase was confined to "a particular and provisional framework of intelligibility" (5). Humanism, its bitter critics maintained, presented us only with the illusion of possessing an ultimate, "transhistorical and transcultural" description of an allegedly universal human nature (ibid).

The demystification of humanism eventually resulted in the phenomenon of antihumanism, a counter paradigm prominently upheld by postmodernist and poststructuralist intellectuals at least since the 1966 publication of Foucault's Les Mots et Les Choses (The Order of Things). Here, Foucault advanced his famous "death of man" thesis, which argued that "man" was an ephemeral category produced by an intellectual structure or "episteme," the epistemological foundations of which have long been rendered obsolete. 
The legacy of humanism was thus something akin to the legacy of a geocentric cosmology.

Moreover, despite having once served as the prime mover behind the Enlightenment, humanism has come to be regarded by many as a moral abomination, a cultural and philosophical disaster to be resisted at all costs. Anti-humanists argued that, by maintaining a dogmatic belief in a universal human essence, humanism has had the insidious effect of suppressing differences. The European humanist tradition, for example, has defined the essence of humanity in very Eurocentric terms, thus indirectly belying its own conviction in a common humanity and providing an intellectual license for cultural bigotry and even genocidal racism. This admonitory attitude toward humanist discourse is reflective of a newfound respect for difference - a hugely important fact of human societies and one that has come to be problematized, celebrated and vigorously defended by postmodern philosophy and cultural anthropology.

Simpson observes that there have been two general ways of "responding to difference in our public world" (9). The first of these is to ignore difference by appealing, in characteristically humanistic fashion, to commonalities across cultures. In this way, whatever is in fact distinctive and hence different about a particular culture is regarded as inessential and therefore not worthy of engagement. The second response is to essentialize difference; to regard difference as "so fundamental that the search for commonalities or universal descriptions that bind persons is seen as wrongheaded" (9). Simpson regards the latter response as hinging upon an unjustified dichotomy between the ideal of community and the ideal of diversity, a dichotomy that necessarily defines community and diversity in mutually exclusive terms. According to this dichotomy, one 
is faced with a rather fateful choice: either one can embrace the former ideal, in which case advocates of the latter would level charges of provincialism and ethnocentrism, or one can embrace the latter ideal, in which case advocates of the former would level charges of relativism, political quietism, and complicity in intercultural conflict.

Although Simpson rejects this dichotomy, arguing instead that it is possible to have both community and diversity in mutually harmonizing ways, he acknowledges that there is some truth to each of these accusations. On the one hand, communitarianism does indeed run the risk of regressing into provincialism and exclusivist membership. On the other hand, the rejection of a "common grid" for mutual understanding "does expose us to the threat of relativism, social incoherence, and irreconcilable conflict" (11; emphasis in the original). He is especially concerned with the last threat, at least as it is posed by certain postmodern philosophers and cultural anthropologists who have been led by the staunch defense of difference to embrace what he believes are morally and philosophically untenable extremes. For example, Iris Marion Young and Robert Bernasconi, both important philosophers in their own right, have been chiefly concerned with the "phenomenon of alterity" and have put forth accounts of communicative understanding that severely limit the possibilities for mutual intelligibility. Simpson also sees a dramatic change of attitude in the work of postmodern cultural anthropologists, who have understandably been affected by the so-called crisis of representations. Universally suspicious of the potential threat posed by power to faithful representations of the other, this newer generation of anthropologists has come to despair of achieving cross-cultural understanding. "And this," Simpson observes, "from people whose very 
business is cross-cultural understanding" (119). He believes that, in the main, both groups are

...vulnerable to an illusory 'objectivist' ideal of representation, one informed by so implausible a criterion of authentic intersubjective knowledge that they are logically forced into the untenable position that mutual understanding, even among those who are similarly situated socially and culturally, is impossible.

(Simpson, 2001: 14)

In response to this exceedingly bleak view of the possibility of mutual

understanding, Simpson offers a model of "hermeneutic dialogue" aimed at achieving both mutual understanding and a critical engagement with the cultural other's moral point of view. His project seeks to establish a postmetaphysical, noninvidious theory of humanism that "involves practices of forging commensurable or mutually enriched vocabularies for identifying and discussing differences" (12). Such a vocabulary would ideally support "a mutually critical and respectful dialogue about matters of common concern" (ibid).

The above account of Simpson's central theoretical inquiry is useful in establishing the problematic of the present thesis. As was made clear in the above, Simpson's project is divided according to two fundamental, albeit interrelated, points of concern: moral understanding and moral negotiation. The present thesis will be an extended meditation on the first of these concerns. Accepting Simpson's contentions that moral conflict is a hard and bitter fact of culturally diverse societies and that the latterday "hermeneutics of suspicion" can yield a disheartening unwillingness to even attempt

\footnotetext{
${ }^{1}$ The phrase "hermeneutics of suspicion" was coined by Paul Ricoeur (see Grondin, 1994: 15). It refers to that absolute cynicism, perhaps most acutely represented by Nietzsche, towards all prima facie meaning. The hermeneutics of suspicion is predicated on the assumption (an assumption that ironically requires unconditional faith) that all truth-claims are driven by the will to power. Hence, the face value of any given utterance is rendered suspect, if not rejected outright. For Simpson's remarks on the hermeneutics of suspiciton, see Simpson, 2001: 49, 122-124.
} 
to understand the cultural other, I will be inquiring into the possibilities for the mutual intelligibility of moral utterances by members of alien cultures. ${ }^{2}$ However, whereas Simpson explores the possibility of mutual understanding through a model of secondorder rationality and "situated metalanguages," the latter being a hermeneutic reconstruction of Jürgen Habermas's model of discourse ethics, I will pursue the question of mutual intelligibility according to a very different theoretical scheme, one driven by a different set of questions and foundational assumptions. Thus, although our problematic remains the same, my approach to that problematic marks a departure in a number of ways.

Missing from Simpson's treatment of moral discourse between cultures, and in particular, from his reflections on what is constitutive of culture itself, is a serious engagement with what has come to be called narrativity. By this, I am referring to narrative as an ontological phenomenon of human consciousness, culture, and communication. ${ }^{3}$ Simpson treats narrative in rather cursory fashion, summarizing Iris Young's emphasis on the value of storytelling for intercultural understanding, but only to the extent that her emphasis on narrative bears upon his primary argument. He does not address the much broader topic of narrativity, especially as it has been prominently theorized by a diverse range of influential thinkers in such fields as philosophy, psychology, history, anthropology and, of course, within literary theory itself. By way of example, I might mention Alasdair MacIntyre, Charles Taylor, Paul Ricoeur, Roland Barthes, Tzvetvan Todorov, Gerard Genette, Jerome Bruner, Clifford Geertz, and Hayden

\footnotetext{
${ }^{2}$ The term "alien culture" is taken from MacIntyre (1984).

${ }^{3}$ As Walter Fisher puts it, narrativity "stresses ontology rather than epistemology, which is not to say that knowledge does not exist, but that it does not have an absolute foundation in ordinary discourse" (Fischer: 1987, 93).
} 
White, all of whom have rendered narrativity a topic worthy of serious critical engagement. I regard the absence of such serious critical engagement as a fundamental weakness in Simpson's overall argument, and especially in his treatment of culture. For how we think about culture will necessarily determine how we think about moral discourse and conflict between cultures. It is my opinion that Simpson's project of intercultural moral dialogue rests on certain inadequate notions of culture, communication, and moral consciousness, due in no small measure to his neglect of the narrative phenomenon. This, then, provides an appropriate starting point for understanding the basic thrust of the present thesis. It is my attempt to support the project of moral discourse between cultures, not by challenging Simpson's central objectives (which I happen to regard with considerable esteem), but rather by sublating that branch of his project devoted to intercultural understanding by incorporating the theory of narrative.

It is critical at this point to acknowledge that moral negotiation presupposes a significant personal investment in a moral scheme of some kind or other. Given that my focus will be on moral understanding only and not moral negotiation, the present thesis will not work through a humanist paradigm, such as the one constructed by Simpson. However, my commitment to moral understanding implies my belief in the possibility of such understanding. As the Marxist literary critic Terry Eagleton has noted, "[o]nly someone with whom you can communicate can affirm their [sic] difference from you. Only within some kind of common framework is conflict possible. [...] Difference presupposes affinity" (2003: 159; emphasis mine). Likewise, Brice Watcherhauser, a contemporary commentator on the philosophical hermeneutics of Hans-Georg Gadamer, 
has argued that, "Even to be aware of others as occupying a different normative space of inquiry requires that their space and ours not be completely sealed off from one another" (Watcherhauser, 2002: 64).

However, this thesis will not work through an anti-humanist paradigm that generically endorses the thesis of radical incommensurability and short-circuits the commitment to intercultural understanding. To the extent that anti-humanism tends toward an indiscriminate and absolute rejection of cross-cultural commonality, it regresses into the very essentialism it purports to condemn. ${ }^{4}$ An indiscriminate hermeneutics of suspicion does not strike me as intellectually viable. I am, rather, much more inclined to endorse Paul Ricoeur's "hermeneutics of confidence," which emphasizes possibilities over impossibilities in the pursuit of interpretation and understanding (Grondin, 1994: 15). The use of narratives to interpret moral utterances by members of alien cultures is guided by precisely this principle.

\section{Statement of the Problematic}

The driving question behind the present thesis is simply this: can the study of narratives play a constructive role in the interpretation of moral utterances made by members of an alien culture? For the purposes of this inquiry, I define narrative as a movement from a starting point to an ending point, with digressions and detours in

\footnotetext{
${ }^{4}$ This is a minor, but nonetheless important, proviso that does not have much bearing upon the general content of the present thesis. For a fuller treatment of the philosophical paradox inherent in anti-humanism, see MacIntyre (1990: 32-58, 196-215).
} 
between, driven by the showing, telling, or living of events linked by an underlying chain or system of causation. ${ }^{5}$

The present thesis is structured around the following set of assumptions: 1) A culture can be understood as an intersubjectively sustained narrative that gives each of its members a personal identity and sense of meaning or purpose; 2) a culture consists of a moral interpretive scheme, or rationality, without which communication would be meaningless; and 3) no utterance is value neutral. Even if an utterance is not overtly moral in content, it must nonetheless be interpreted against the moral interpretive scheme particular to the culture in which it was made. 4) The moral point of view of an individual agent is informed by practical experience and only sometimes by formal principles of ethics. The extent to which formal principles of ethics inform the point of view of a moral agent differs from agent to agent. For this reason, it is insufficient to merely inquire into a formal code of ethics dominant in a particular culture in order to interpret moral utterances made by a member of that culture. 5) Narratives have within them rational structures, of which a system of norms is constitutive, and through which narratives are rendered meaningful. 6) Narratives are more than just stories for entertainment; they are the products of a cultural context or environment and are, in some sense, a "fingerprint" of the lifeworld in which they were constructed. Reading narratives can give outsiders some sense of the rationality or moral interpretive scheme that prevails in a given culture. 7) Finally, narratives can provide the reader with a taste of the moral experience typical of an agent from another culture. By inviting the reader to provisionally adopt an alien point of view, the reader can discover the type of phronesis, or practical wisdom, required to thrive in an alien culture, thereby placing the

\footnotetext{
${ }^{5}$ This definition is based on Paul Cobley's definitions of narrative, plot, and story $(2003: 236,239,243)$.
} 
reader in a better position to interpret moral utterances that might otherwise be unintelligible. These assumptions will be developed further in Chapter Two.

\section{Explication of Research Approach}

In his recent book, After Theory, Terry Eagleton provocatively argues that " $\mathrm{t}] \mathrm{he}$ golden age of cultural theory is long past" (2003: 1). Against the backdrop of what he interprets as the demise of high theory and the imminent death of postmodernism itself, Eagleton envisions the future of cultural studies as preoccupied with those domains hitherto neglected by cultural theorists: love, evil, death, metaphysics, religion, and-of particular significance for the present thesis-morality. "For a long time," says Eagleton, "cultural theorists avoided the question of morality as something of an embarrassment. It seemed preachy, unhistorical, priggish and heavy-handed. For the harder-nosed kind of theorist, it was also soppy and unscientific" (140). This view of morality, he insists, is quite unfortunate. Whereas morality for the ancient Greeks was wholly indistinct from politics, "[q]uestions of good and bad" had at some historical turning point been "falsely abstracted from their social contexts," so as to regress into an overbearing moralism. The relevance of that moralism to practical experience was suspect at best (143). However, despite the profound distaste induced by this highly abstract view of morality, "cultural theorists eventually realized that you could not live without moral discourse altogether" (148). Politics, after all, was not possible without the assumption of a moral standpoint. Morality should therefore, on Eagleton's view, be retied to politics and rendered fundamentally practical in character, as it had once been for the Greeks. The problem, however, concerns the communication of moral differences between people of disparate 
cultures. Eagleton, as mentioned earlier, insightfully observes that cultures are not hermetically sealed off from one another, going so far as to advance the metaphysical argument that humans are a "universally communicative species," thereby guaranteeing a basis for commonality and understanding (160). However, Eagleton does not pursue this logic further so as to address the far more daunting question of how precisely moral understanding between cultures is to proceed.

Douglas Kellner, a leading figure in contemporary cultural studies, has similarly argued that cultural studies has either downplayed or entirely ignored the question of ethics (Kellner, 2001). Although from its inception British cultural studies was largely political in nature, ethics was later "subordinated to politics," such that "the moral dimension of culture" was "underemphasized or downplayed" (145). Kellner thus proposes a new direction for cultural studies, which "more explicitly stresses the importance of ethical/moral analysis, scrutinizing cultural texts for the specific ethical norms portrayed and evaluating the work accordingly" (145-146). Because culture is "a major transmitter and generator of values," it is crucial to take stock of "the ethical and moral dimension" of culture (146). For this reason, the "concern with ethics" and the way in which morality is captured by a particular text should become a "central and fundamental consideration of cultural studies" (ibid). Kellner insists that cultural studies is increasingly becoming stale, not least because it has not kept up with "new theoretical and historical developments" (150). Much like the Frankfurt School and the Birmingham School, contemporary cultural studies must "continually modify [its] work in response to new theoretical and historical developments," especially during a "period of rapid socio-historical change and the proliferation of new theories, cultural practices, 
and forms of political struggle" (ibid). Although Kellner goes further than Eagleton by laying specific emphasis on the ethical analysis of cultural texts, he does not endorse any specific methodological approach, insisting only that a "bold vision" is required to "capture the novelties of the present moment" (ibid).

One such methodological approach is proposed by the psychologist Jerome Bruner in his book Acts of Meaning (1990). Bruner argues that culture should be viewed as the chief organizing principle of both individual and collective action; that culture gives meaning to action by situating its underlying intentional states within an overarching interpretive system. That system can best be described as a socially embodied narrative. He further suggests that literary narratives, given their representative character of the cultures in which they are produced, furnish an appropriate basis for the understanding of culture.

Narrative, as Bruner points out, is more than mere "plot structure, dramatism, historicity, and diachronicity" (60). It is also principally about the use of language. It relies on "metaphor, metonymy, synecdoche, and implicature" to "explore the full range of connections between the exceptional and the ordinary" (ibid). However, one key issue that inevitably arises is that of interpretation, which Bruner insists cannot proceed according to the procedures of inference and deduction - the defining approach of the Anglo-American analytic philosophy of language. Rather, narratives must be interpreted according to their "verisimilitude", "truth likeness", and "lifelikeness" (61).

Bruner notes that interpretive meanings are "very sensitive to context" (ibid). The principal challenge once posed before analytic philosophy concerned how to "determine the meanings of sentences or propositions as written" (ibid; emphasis in the original). 
Gottlob Frege and Bertrand Russell's interpretive method of sense and reference assumed that meaning inhered in language; that it had an objective character, which belonged to nobody in particular. ${ }^{6}$ This interpretive approach, Bruner observes, ignored the communicative context. By contrast, Bruner sides with speech-act theorists J. L. Austin and John Searle, who have been committed to

restoring the communicative context back into discussions of meaning. While utterances were treated in the classical tradition as decontextualized or unsponsored locutions, they could also be treated in a principled way as expressing a speaker's communicative intention. And, in the same spirit, one could then inquire whether the speaker's meaning was grasped or "taken up" by a hearer and what determined that uptake. As we all know, uptake depends upon the speaker and listener's sharing a set of conventions for communicating different types of meaning.

(Bruner, 1990: 62-63)

What the Frege-Russell approach was for the most part blind to were the felicity conditions that grounded interpretive meaning; that is, the unwritten and often unacknowledged social and cultural conventions that govern the use of language. ${ }^{7}$ Bruner argues that the interpretation of meaning must focus on the "web of conventions that constitute a culture" (64). And, hence, the interpretation of narrative-and, by extension, of culture itself - can only proceed to the extent that we can "specify the structure and coherence of the larger contexts in which specific meanings are created and transmitted" (ibid).

Another prominent psychologist, Kenneth Gergen, likewise argues that narratives "do more than create conversational realities; they are themselves constituents of ongoing

\footnotetext{
${ }^{6}$ This view of language and meaning, it should be observed, has not quite expired. It may be found in the work of the literary critic, Meyer Abrams, and the moral philosophy of Jürgen Habermas. Both regard language as bearing neutral, stable, and constituting norms, upon which meaning ultimately resides. For Abrams, this view of language permits objective interpretation and criticism. For Habermas, it permits objective morality and the possibility of an impartial evaluation of rival moral standpoints. On their respective views on language, see Fish (1980: 303-321) and Habermas (1990). Although Habermas is reputed to be a speech-act theorist of sorts, his ideas are highly unorthodox relative to Austin and Searle. ${ }^{7}$ The notion of felicity conditions will be discussed in greater detail in Chapter II.
} 
and often institutionalized patterns of social conduct" (1998, online). That is, they "generate and sustain...cultural traditions" by reinforcing the web of conventions that govern the use of language. Gergen, too, cites the authority of J. L. Austin in emphasizing that "we must not only pay attention to the constative character of narrative discourse (its portrayal of the world)," but also to "its performative aspects-what it achieves in the very act of expression" (ibid).

Bruner and Gergen make a compelling case for according central importance to speech-act theory for the interpretation of meaning. The obvious question, however, concerns the specific application of the theory so as to extract interpretive meaning in the manner they suggest. The answer, I believe, lies in a pioneering essay entitled, "How To Do Things with Austin and Searle: Speech-Act Theory and Literary Criticism," by the postmodern literary critic Stanley Fish (1980: 197-245). Accomplishing precisely what Bruner and Gergen have suggested, Fish applies speech-act theory as a method of textual criticism in the interpretation of a classic literary text: Shakespeare's Coriolanus. Speech-act theory, as it was originally developed by Austin and Searle, is devoted to the study of the social and cultural conventions that govern the use of performative language; that is, language that not only conveys information, but also constitutes the performance of an act. Fish demonstrates that speech-act theory can be applied to a literary text to unpack the social and cultural conventions depicted in narrative form. By applying the theory in this fashion, he argues, it is possible retrieve the speech-act conventions that prevailed in an alien context.

The present thesis will build upon Fish's innovative use of speech-act theory to examine the social and cultural conventions that govern the use of moral utterances as 
depicted in narrative form. By moral utterance, I am referring to something more than what Jean-François Lyotard (1984) identifies as the key "moves" that constitute legitimate or intelligible instances of action and communication in a language game. Those moves consist of the denotative utterance, prescriptive utterance, and evaluative utterance. For the purposes of my argument, I will be adopting a much broader definition of moral utterances. I maintain that denotative, prescriptive, and evaluative statements are but three types of speech-act. It is specifically to speech-acts that we should turn to identify the legitimate moves and basic units of moral expression in the illocutionary game of a given culture or speech-act community. ${ }^{8}$ The guiding assumption behind my analysis is that, because morality functions within the narrative experience that is constitutive of cultures, it is therefore reasonable to regard literary narratives as legitimate objects of study for the interpretation of moral utterances by members of an alien culture.

Because of the considerable degree of analytical detail involved in the application of speech-act theory to literary texts, I will only have space within the present thesis to analyze one text. This will be Monica Ali's Brick Lane (2003), a story about a Bengali housewife, Nazneen, who migrates with her husband to the United Kingdom. The contrast between Bengali cultural norms, epitomized by the narrative portrait of Nazneen's family, and the norms of the multiple English cultures Nazneen encounters in her experience as an immigrant, offers a very compelling case for the value of the novel as a resource for cross-cultural moral understanding. The speech-acts characteristic of Bengali culture are saliently, if unfavorably, presented as the epitome of what constitutes

\footnotetext{
${ }^{8}$ The theory of the speech-act and the notion of illocutionary games will be discussed in much greater detail in Chapter Two.
} 
the moral identities of the Bengali wife, husband, daughter, etc. The novel is rife with situations in which the characters engage in speech-acts that function according to Bengali cultural norms. Like many other novelists who write about cultures largely foreign to a Western audience, Monica Ali delivers insider access to the moral experience of a people from a foreign culture. Taken in isolation, such speech-acts would likely be unintelligible to an English-speaking audience. Their moral significance could not be unpacked by the principles of logical deduction and inference. However, when presented in a narrative context, not only are these utterances intelligible, we also have a textual basis for undertaking a speech-act analysis.

\section{Justification and Application}

Fish justifies his particular application of speech-act theory by noting that Coriolanus is a speech-act play (Fish 1980: 221). That is, Coriolanus "is about what the theory is 'about,' the conditions for the successful performance of certain conventional acts and the commitments one enters into or avoids by performing or refusing to perform those acts" (ibid; emphasis in the original). Hence, speech-act theory does not necessarily apply to all literary texts. It is therefore imperative to justify my choice of texts for a speech-act analysis.

What qualifies Brick Lane for a speech-act analysis is that it is a realist or naturalistic novel. "Fictional genres," as John Searle argues, are partly "defined by the nonfictional commitments involved in the work of fiction. The difference, say, between the naturalistic novel, fairy tales, works of science fiction, surrealistic stories, is in part defined by the extent of the author's commitment to represent facts" (Searle quoted in 
Fish, 1980: 235-236; emphasis added). ${ }^{9}$ That degree of commitment is not only considerably greater in the case of the naturalistic novel, but definitive of the genre itself. Realist representation, as Paul Cobley notes, refers to "a mode of depiction which is putatively truer to the common-sense realities of life than other modes of depiction, such as those pejoratively called 'romantic', 'idealized' or 'sentimental'" (2001: 240). First popularized in the English-speaking world during the eighteenth century, realism has since become the "dominant and paradigmatic genre" of contemporary literature (92). Many commentators regard the novel as "a noble attempt to place in narrative form the complexity of the social world and its contemporary flux" (89). For the distinguished cultural critic, Raymond Williams, the realist novel

...offers to show people and their relationships in essentially knowable and communicable ways. Much of the confidence of this method depends on a particular kind of social confidence and experience. In its simplest form this amounts to saying...that the knowable and therefore known relationships compose and are part of a wholly known social structure, and that in and through the relationships the persons themselves can become wholly known.

(Williams, 1970: 13)

Cobley observes that nineteenth-century realism focused primarily on milieu. The "attempt to place complex historical and personal relations within a narrative frame" not only required considerable narrative technique, but also "a confidence in the ability to know common persons through the web of their relations within a social structure" (ibid; emphasis mine). Citing Williams and Eric Auerbach, Cobley further observes that realist novels concerned "common characters and the everyday instead of the sublime," and

\footnotetext{
${ }^{9}$ The notion of "fact" here should not present an occasion to enter into a debate about ontology. Rather, the use of the term "facts" pertains to constants in the sphere of human experience that sustain intelligibility, coherence, and consistency. As J. L. Austin argues, the language of fiction is intelligible precisely because it is "parasitic" upon ordinary use (Austin, 1960: 22). Fish argues as much by describing such expressions as "real workaday world", "normal circumstances," and "ordinary usages," all of which are variously used to describe the contents of realist, naturalistic, historical fiction, as merely referring to the world of experience with which we most commonly identify.
} 
explored the characters' experiences “through the medium of large canvasses, minutely detailed to give a sense of richness, conveying a picture of a definite period in history" (ibid). The audience of literary narratives had grown increasingly impatient with allegorical tales and epic parables, "whose outlandish nature" they were forced to decode "into everyday terms" (82). Instead, they demanded a story bearing closer resemblance to the real and the everyday, "with characters broadly imitating the speech of people, with situations broadly resembling real situations in the world and with events tending to follow the logic that they would in real life" (ibid).

"Scene," for example, "clearly attempts to imitate the space and time inhabited by events and characters" (64). Dialogue presented in a realist narrative should provide the reader with a "reasonable approximation of the time-scale in which a character makes the utterance" (ibid). As Ronen (1997: 283) points out, a novel not only provides a narrative trajectory to carry the reader through a story, it also provides description to represent or approximate an actual historical circumstance.

What realist narratives accomplish, then, is to present speech-acts within larger contexts of meaning. As Bruner notes, "people do not deal with the world event by event or with text sentence by sentence" (Bruner, 1990: 64). Rather, sentences are interpreted according to contexts of practice, or goal-oriented situations. As Cobley puts it, what narratives importantly accomplish is "representation of the world for a purpose" (222). It is only by locating an utterance within a scene and by locating the scene within a larger context of practice that an adequate interpretation can even begin. 


\section{Literature Review}

This section will review the scholarly studies in the various fields or areas of inquiry either directly or indirectly bearing upon my project. I have organized this section according to general themes of inquiry.

\section{A. Intercultural Communication}

The field of intercultural communication can boast of a vast body of literature. The field was pioneered by Edward T. Hall, a former diplomat in the American Foreign Service. Hall's extensive experience in numerous foreign cultures afforded him insights into effective cross-cultural communication $(1959,1981, \& 1990)$. As a result, the field has maintained a decidedly pragmatic interest in intercultural communication, focusing largely on the facilitation of diplomacy, trade, and immigration. Standard texts in the field include those of Everett Rogers \& Thomas Steinfatt (1999), Milton Bennett (1998), Larry Samovar \& Jack Mills (1998), Samovar \& Richard Porter (1994), H. Ned Seelye \& Alan Seelye-James (1995), William Gudykunst (1994), Gudykunst and Young Yun Kim (1988 \& 1997), and Judith Martin \& Thomas Nakayama (1997). There is a plethora of case studies examining intercultural experiences, which I will not review here. What I wish to point out, though, is the largely empirical approach to a very practical inquiry. There seems to be very little appreciation for theoretical inquiries into understanding between cultures. 


\section{B. On Language, Utterances and Meaning}

Although language is a very broad topic, my project will draw from certain studies of language so as to give some clarity to the notion of utterances. An influential philosophers of language, John Austin (1962) examines different types of utterances, such as primary, performative, and evaluative utterances. Austin also explores misapplications, "misinvocations", and "misexecutions", which give rise to misunderstanding. His student, John Searle, has carried Austin's project further, developing a wide-ranging and meticulous theory of the speech act, which examines the different components and aspects of expression, meaning and utterances (1969). Searle's theory offers an analytical framework to make sense of the hazy and often confusing phenomenon of language. Charles Taylor explores speech activity, the role of background understanding in communication, and problematizes the notion of intelligibility (1995). Maeve Cook (1994) examines the pragmatics of Habermas's theory of communicative action, exploring his understanding of speech acts, validity claims, and meaning. Donald Davidson has written an influential philosophical account of language (1981), wherein he explores the character of utterances and the problem of translatability between conceptual schemes.

\section{Practical Rationality, Moral Interpretive Schemas and Moral Experience}

Practical rationality has been a topic of philosophical preoccupation at least since the time of Aristotle, who explores the notion of phronesis in his Nicomachean Ethics and Politics. The contemporary moral and legal philosophers who have written about practical rationality are many. However, again, my thesis will only draw from a pertinent 
selection of such writings. These include John Searle (2001), who provides a wonderfully lucid examination and critique of the classical Aristotelian model of rationality. He also explores the basic structure of intentionality, action, and moral meaning, as well as the logical structure of moral reasons. The Oxford legal philosopher Joseph Raz has published a number of essays exploring moral meaning and practical rationality. These have been collected in two separate volumes (1993 \& 1997). Habermas (1993) provides his own account of practical rationality to reinforce his discourse theory of ethics. Charles Taylor (1995) also provides an account of practical rationality, which very strongly resembles that of MacIntyre. The studies that influence my own project are those that provide a teleological account of practical rationality. These include studies by G. F. Schueler (2003), Robert Koons (2000), and James Tomberlin (2000). However, other studies are critical of the teleological account, arguing that such accounts do not leave much room for human agency. These include studies by Frederic Schick (1991) and Hugh McCann (1998). While I accept certain of their criticisms leveled against the teleological account of practical rationality, I do not accept the general thrust of their alternative account.

\section{Narrativity}

There are two basic areas of narrative theory. The first of these concerns the narrative conception of the self and culture. Studies in this area include those by Clifford Geertz (1977) W. J. T. Mitchell (1981), Joseph De Rivera and Theodore R. Sarbin (1998), Jerome Bruner (1987, 1992, \& 2002), Jordan B. Peterson 1999), and Donald Spence (1984). A number of studies examine the narrative at work in autobiography. 
These include John Shotter and Kenneth Gergen (1989), Sidonie Smith (1987), Janet Varner Dunn (1982), Philippe Lejeune (1989).

The second area explores the narrativity of literature, historical writings, and film. The contributions to literary studies include those by Todorov (1981), Genette (1983 \& 1990), Martin (1986), Mieke Bal (1998), and Philip John Moore Sturgess (1992). The relationship between narrative and historiography has been explored by Hayden White (1975 \& 1987) and Donald Polkinghorne (1988). Walter Fisher (1987) has developed a "narrative paradigm" to explore narrative rationality in drama and literature and Joseph Kupfer (1999) examines the ethical structures in the narratives of popular film.

\section{Chapter Breakdown}

In Chapter Two, I will provide a discussion of the theoretical framework and methodology of the present thesis. The theoretical framework will discuss moral experience and practical rationality, the narrative conception of culture, moral discourse between cultures, and speech-act theory. The section on methodology will cover the basic approach to my analysis of Brick Lane and will highlight some minor difference between Fish's approach and my own. Chapter Three is the longest chapter of the present work. It is a speech-act reading of Brick Lane, focusing on cultural roles and their attendant speech-acts. The extended length of the chapter is due in part to the imperative to take into account narrative contexts of justification, only through which the meaning and moral significance of a speech-act can be adequately grasped. Chapter Four will explore the importance of narrative contexts of justification in much greater detail. It will be argued that speech-act theory stands to gain from an appreciation of the socially 
embodied narratives constitutive of social traditions and practices that cannot be defined in institutional terms. The argument concerns the legitimating source of the noninstitutional speech-act. Finally, the conclusion will review the arguments developed in the course of the present thesis and offer some reflections on the relevance of speech-act theory for the debate over humanism and anti-humanism. It ends with a brief discussion of policy implications for multicultural societies. 


\section{CHAPTER 2: THEORY AND METHODOLOGY}

\section{Theory}

In this section, I will locate my central argument within a certain nexus of ideas that informs the particular approach I have chosen for the present thesis. I will examine how moral experience, practical rationality, culture, moral discourse between cultures, and narrativity have been conceptualized and problematized by key thinkers. In developing a theoretical framework that is distinctly my own, I will at certain points either expand upon a certain idea or set of ideas, or offer a different way to conceptualize the same phenomenon. Where an ongoing debate is relevant, I will briefly summarize that debate and state my own position vis-à-vis those of others.

\section{A. On Moral Experience and Practical Rationality}

In his 1971 book, Against the Self-Images of the Age: Essays. on Ideology and Philosophy, Alasdair MacIntyre presents a series of essays exploring moral language and the character of moral experience. These essays are, in part, a response to the neoKantian ethics that prevailed in many philosophical quarters at the time. They were also written as a sort of philosophical interrogation of certain contemporary methods of the social sciences, particularly of sociology and anthropology, which MacIntyre believed were in dire need of considerable philosophical support in many domains. Among those domains was the attempt to understand the moral utterances made by members of alien cultures. In an essay entitled, "Rationality and the Explanation of Action," MacIntyre 
takes up the question of why, in different cultures just as often as in one's own, a noticeable gap frequently exists between beliefs and actions.

MacIntyre first addresses a persistent standpoint on this matter, one derived from a much older generation of anthropologists, according to whom the gap between beliefs and actions could be attributed to irrationality. Insofar as a moral agent's actions diverged from his or her beliefs, that individual was thought to be irrational. And, insofar as the members of a culture collectively exhibited patterns of behavior diverging from commonly held beliefs, the culture as a whole was thought to be irrational. MacIntyre's essay challenges that thesis, arguing instead that rationality lies at the heart of every culture, although what is constitutive of rationality will differ from culture to culture. Hence, a different explanation must be sought to account for the gap between beliefs and actions.

Although he himself does not arrive at a full explanation of this problem in the essay, MacIntyre reconceptualizes the problem in a manner that I find especially useful. His first order of business is to probe into the character of ethical "beliefs". He argues that ethical principles are the products of historical circumstances and that they are often codified and elevated to the level of a canon, thereafter being preserved through what he calls "tradition," a concept that is central to MacIntyre's moral philosophy and to which I will return shortly. Once canonized, however, ethical principles run the risk of becoming divorced from the ongoing flow of historical circumstances; that is, they are liable to recede into the realm of folkloric irrelevance. Although practical rationality-the operative logic that governs the actions of a moral agent at the level of conscious experience-might be informed by the prevailing canons of a given culture, it will also 
be informed by the actual circumstances in which an agent happens to be situated. Moreover, actions are just as often informed by the emotional and psychological 'climate', so to speak, which itself is a product of historical circumstances. To take an obvious set of examples, we might consider how dismal economic circumstances, war, or political revolution might influence practical rationality in ways that a canon of ethical principles might not. Hence, practical rationality and formal codes of ethics need to be distinguished from one another. To be fair, there are examples of some communities whose members live every jot and tittle of their daily lives according to a comprehensive code of ethics. These might include certain monastic orders, for example, which make no distinction between divine law and morality. However, it would be exceedingly presumptuous to assume that a canon of ethics, whether held to be of divine extraction or not, is the chief source of normativity in everyone's daily life. Though he does not say it in so many words, MacIntyre draws a distinction between formal "beliefs," or the doctrines one might be raised to uphold from childhood, and the actual convictions that govern the actions of a moral agent.

MacIntyre's interest concerns that gap between actions and beliefs that, in time, becomes "institutionalized so that there is a systematic discrepancy between the norms dominant in the culture and the characteristic behavior of agents in that culture" (256). Aided by philosophy, the task of the social sciences is to furnish an explanation for this systematic discrepancy. It is a question of what lies at the heart of practical rationality. MacIntyre himself provides just such an explanation in his 1984 study of ethics, After Virtue. 
After Virtue introduces a number of key concepts concerning practical rationality that are of considerable importance for the present thesis. The first of these is the concept of intelligibility, which MacIntyre describes as "the most basic distinction of all embedded in our discourse and in our practice" as human beings (209). If we are able to identify a particular occurrence as an action, we do so by placing it "under a type of description which enables us to see that occurrence as flowing intelligibly from [an] agent's intentions, motives, passions and purposes" (ibid). When we are unable to identify an occurrence as an intelligible action, even if we might recognize that there was genuine human agency behind it, we are liable to be ...intellectually and practically baffled. We do not know how to respond; we do not know how to explain; we do not even know how to characterize [it] minimally as an intelligible action; our distinction between the humanly accountable and the merely natural seems to have broken down. And this kind of bafflement does indeed occur in a number of different kinds of situation; when we enter alien cultures or even alien social structures within our own culture, in our encounters with certain types of neurotic or psychotic patients...but also in everyday situations.

(MacIntyre 1984: 209-210)

MacIntyre then offers an example of how one might be baffled by an utterance:

I am standing waiting for a bus and the young man standing next to me suddenly says, 'The name of the common wild duck is Histrionicus histrionicus histrionicus.' There is no problem as to the meaning of the sentence he uttered: the problem is, how to answer the question, what was he doing in uttering it?

(MacIntyre 1984: 210)

As MacIntyre points out, there could be a number of possible answers to the above question. If it were to appear, for example, that the young man had been randomly repeating this utterance to every passing stranger, he might very well be thought to have been suffering from some form of madness. If it were revealed that the young man had just been advised by his psychotherapist to overcome an acute case of bashfulness by 
randomly talking to strangers about perfectly random topics, his utterance would then perhaps be at least somewhat intelligible. If it turned out that he had mistakenly assumed that he was speaking to a friend from the library, who had earlier asked him about the name of the common wild duck, then his utterance would be perfectly intelligible. In each case, the attempt to render the utterance intelligible is an attempt to locate that utterance within a personal narrative.

The intelligibility of human purposes and of speech acts is impossible to secure without some or other context of justification. That context of justification can best be understood as a narrative continuum. As MacIntyre puts it,

[W]e render the actions of others intelligible in this way because action itself has a basically historical character. It is because we all live out narratives in our lives and because we understand our own lives in terms of the narratives that we live out that the form of narrative is appropriate for understanding the actions of others.

(MacIntyre 1984: 212)

The question might be posed as to what gives rise to an individual's personal narrative. A personal narrative, after all, cannot be generated in a contextual vacuum. Moreover, it might also be wondered as to what the relationship is between the narrative of an individual and the larger cultural context in which that individual happens to be situated. Just as a moral utterance requires a narrative context for its intelligibility, so too does a personal narrative require an even larger context for its own intelligibility. Here is where the concept of a tradition comes into play. Every personal narrative is informed and shaped by the pre-existing narratives that prevail in whatever context an individual happens to be situated. Nobody's personal narrative can "start literally ab initio"; rather, one plunges “in medias res, the beginnings of [one's] story already made for [one] by what and who has gone before" (215). The particular moral outlook that I as an 
individual acquire will be shaped by the particular social circumstances that I encounter during my moral development. And how I develop my moral outlook will be influenced by those around me who have already faced the same or a very similar set of social circumstances. Just as I inherit a language, so too do I inherit a moral outlook, which "constitute[s] the given of my life, my moral starting point" and which gives my life its "moral particularity" (220). MacIntyre conceives of a tradition as the into which we are thrust at birth and which provides us with our initial moral and conceptual framework for making sense of the world and for acting in the world. ${ }^{10}$

The concept of a tradition is also central to the hermeneutic philosophy of HansGeorg Gadamer, upon whose work MacIntyre's own philosophy is heavily indebted. ${ }^{11}$ According to Gadamer, the hermeneutic situation consists of being "thrown," in Heidegger's sense of the term, into "a history or set of stories that we did not start and cannot finish, but which we must continue in one way or another" (Warnke, 2002: 79). That history or set of stories provides the direction for our future action. Gadamer, too, conceives of this history as narratives that establish the conditions for the possibility of action. Narratives are constituted by "specific vocabularies, plots, and sets of issues and insofar as we are 'thrown' into the narratives, their languages and trajectories necessarily provide the contours for our understanding of them" (80). Moreover, insofar as

\footnotetext{
${ }^{10}$ It should at this point be noted that MacIntyre's concept of a tradition does not preclude the possibility of free will. He argues that, although our being born into a tradition does limit the possibilities for action, traditions establishe the conditions for the very possibility of action itself. Our being born into a tradition implies that we are in certain respects teleologically bound, but that within the realm of possibilities established by that teleology, the number of possibilities is infinite. For a fuller account of MacIntyre's conception of free will, see After Virtue, 215-216.

${ }^{11}$ See for example MacIntyre's essay, "On Not Having the Last Word: Thoughts on our Debts to Gadamer," in Malpas, Arnswald, \& Kertscher (2002).
} 
narratives or traditions are the source of normativity in our lives, they can be said to exercise a certain degree of normative "authority". ${ }^{12}$

The philosopher John McDowell has developed a very similar notion, which he refers to as our normative "second nature". McDowell developed this notion to account for the character of judgments in the scientific enterprise. Scientific rationality "evolves historically within communities into which we are socialized and shaped through a matrix of language, practice, and individual and corporate experience" (Watcherhauser, 2002: 60). Notwithstanding the scientific community's commitment to cold, disinterested objectivity, science can only function through an epistemological framework in which justification is guided by the scientist's normative second nature. Although McDowell does not specifically have in mind moral experience and moral psychology, I find his notion of a normative second nature to be especially helpful in understanding practical rationality.

My own view on the question of practical rationality is that we cannot assume that a particular canon of ethics is sufficient to understand either actions or moral convictions. In addition to the obvious fact that a canon of ethics may not even exist in an agent's life, ethical principles are liable to be misinterpreted when abstracted from the cultural, historical contexts that gave rise to those principles in the first place. ${ }^{13}$ Moral discourse that proceeds via such abstraction treats ethical principles in an unduly objectivist manner and neglects the original lived experiences of which such principles are but a linguistic

\footnotetext{
${ }^{12}$ Gadamer's use of the term "authority" has earned him some notoriety among critics who see in his philosophy a license for neo-conservativism. See for example Habermas (1988), Caputo (1987), Code (2003), and Eagleton (1983: 61-64). Although this matter has little bearing upon my argument, I do regard the accusation as badly lacking in merit. For an account of the relationship between hermeneutics, ethics, and politics in Gadamer's philosophy, see Warnke (2002), which evaluates the charge of conservatism. ${ }^{13}$ Simpson also offers a brief discussion of this point (2001: 38-39).
} 
expression. I believe MacIntyre and Gadamer's descriptions of traditions and narratives place an appropriate emphasis upon the deeply contextual character of moral utterances.

The question of interpreting the moral utterances by members of alien cultures is rendered all the more problematic in yet another respect, namely, the ambiguity surrounding the notion of culture. MacIntyre does not offer a well-developed account of culture, although his use of the term suggests something more fluid and ephemeral than the conventional view that regards culture as a merely ethnic, linguistic, or national marker. Gadamer seems more comfortable with the term "tradition" than he does with "culture," as when he speaks of "communication between traditions" (Watcherhauser, 2002: 65). In attempting to problematize moral understanding between cultures, then, we are left with the vexing question of what exactly we mean by "culture," a notoriously elusive notion for which no "final vocabulary" will likely ever be found.

\section{B. A Narrative Conception of Culture}

The present thesis demands a theory of culture that does justice to my inquiry into moral understanding. I will attempt a modest, but viable account of culture that should adequately sustain my primary argument. This account builds on the conception of culture developed by the eighteenth century German philosopher, philologist, and theologian, Johann Gottfried von Herder (d. 1803). Simpson (2001) provides an informative account of Herder's conception of culture, culled from Isaiah Berlin's Vico and Herder and Herder's own Reflections on the Philosophy of the History of Mankind and Sämtliche Werke. The following summary of Herder's views is based on that account. 
Herder maintained that, at the most basic level, a culture constitutes a community with a distinct identity and collective consciousness. The members of a culture are bound by the unique set of social and political situations they collectively encounter. The binding fabric of a culture, however, is language, through which the members of a culture communicate intelligibly with one another. Herder's view of language may be described as a type of "linguistic holism," in which, "each and every cultural product (both sayings and doings) has its meaning determined by the entire system of significations from which it emerges and to which it gives expression" (Simpson: 2001, 28). For an understanding of any one part, knowledge of the whole is requisite. And, for an understanding of the whole, knowledge of the constitutive parts is equally requisite. Each culture is, then, in a way, hermetically sealed off from one another since each represents a distinct community of "intersubjective meanings" to which only its members have access (29). Moreover, such "systems of meaning" are "rooted in social practices and projects" that generate and sustain normativity. It is only through their unique set of circumstances that the members of the culture can understand each other's actions and utterances. Intelligibility is thus a binding characteristic between the members of a culture. Simpson describes this as a "mutually reinforcing intelligibility" that underwrites "a system of interexplicable practices" (ibid). Those who participate in the same "field of practices" may be said to "share in a common sense of the good" (ibid).

Simpson then goes on to describe Herder's theory of the "health" of a culture. Although this part of Herder's conception of culture has its merits, it seems less persuasive and of much less importance to my inquiry. What I wish to retain from Herder, however, is his description of culture in terms of community, communication, 
situations, and a norm-guided orientation toward "the good". The literary critic Stanley Fish has developed a theory of communication, according to which mutual understanding can only take place within what he calls "interpretive communities" (1981). As he puts it, ...communication occurs within situations and that to be in a situation is already to be in possession of (or to be possessed by) a structure of assumptions, of practices already understood to be relevant in relation to purposes and goals that are already in place...

(Fish 1981: 318)

The particular group of individuals who find themselves in a common situation, who are committed to the same set of practices, whose actions are governed by the same "structure of assumptions," and who are thus able to communicate intelligibly with one another, are described by Fish as members of an "interpretive community". The notion of interpretive communities, I believe, illuminates what is fundamentally constitutive of cultures. The emphasis upon situations and practices in establishing a common basis for mutual intelligibility is helpful in salvaging the notion of culture from those conceptions of culture as grand, totalizing systems that maintain an absolute grip on one's life. Although Herder describes cultures in terms of situations, practices, and purposes, he still treats culture in a totalizing manner. His notion of culture as a Volk, or a people united by a national language and collective sense of purpose, does not allow for those situations and practices that, on the one hand, can claim a large membership, but whose cultures, on the other, cannot be described as a whole way of life. We can speak, for instance, of the culture of a particular institution, such as a corporate workplace, or the culture of a particular event, such as a sports game, without suggesting that members of those cultures all share a common way of life. What Herder does not account for, then, are 
differences within a community and the misunderstandings, moral or otherwise, that might take place between individuals purportedly belonging to the same culture.

David Carr, in his book, Time, Narrative, and History (1986), similarly argues that narrative is a temporal structure inherent in our way of living and acting. The temporality of human experience and action is configured and reflexively structured, as if by a character discovering his or her place in a story. Stories, he insists, are not just forms of discourse, but our fundamental mode of being. He argues that the basic feature of the temporal structure of active experience is the purposive or means-end character of action. An understanding of action requires that we consider the narrative context of justification, internal to which is a set of logical relations that govern practical reason. Carr takes the view that

the events of common experience and actions undertaken collectively are constituted when the members of the group gather together sequences of events or sub-actions by interpreting them through a narrative structure comprising beginning, middle, and end. The group itself is constituted as the unity of a temporally extended [set] of experiences and actions.

(Carr, 1986: 78)

It is precisely these experiences and actions that form the basis for mutual intelligibility and communication.

The present thesis employs a conception of culture as being generated out of situations, with some experience common to a collectivity that serves as the basis for mutual intelligibility. In addition, I find that the theory of narrativity I have just outlined most convincingly explains how that experience is managed and how the practices to which an individual is party are ultimately rendered meaningful. Cultures, according to this conception, are the intersubjectively sustained and "mutually reinforced" narratives that we live out in our daily lives. The particular set of practices or situations in which 
we are implicated is precisely what endows the members of a culture with a common sense of direction and meaning, a norm-guided orientation toward "the good". Herder, for example, refers to "the values and goals that are distinctive of a people" as being "conceptually connected with that people's center of gravity" (Simpson, 2001: 39). I would equate Herder's notion of a culture's center of gravity with the teleological pull of a narrative situation; the particular norm-generating vision of the good that guides and binds the members of a culture with a common outlook or point of view.

Identity, according to this argument, is merely a question of the character one plays in any given narrative situation. ${ }^{14}$ If $\mathrm{I}$ am correct in arguing that cultures are best understood as collective narratives, then discourse between cultures should be reconceived as discourse from rival narrative perspectives. Hence, whereas Barnett \& Kincaid (1983) contend that all communication is intercultural communication, I would modify that idea to suggest that all communication is inter-narrative communication. This argument, of course, quite categorically precludes the possibility of impartiality, an objective moral standpoint, and ideal speech situations. It is to this issue that I now turn.

\section{Moral Discourse Between Cultures}

My inquiry into moral understanding between cultures will work between two very different paradigms for moral discourse. The first of these paradigms is the program of discourse ethics developed by Jürgen Habermas, which I have taken from his Moral Consciousness and Communicative Action (1990) and his subsequent Justification and

\footnotetext{
${ }^{14}$ MacIntyre makes this argument in extended discussion concerning personal identity (1981: 213-222). In some instances, an agent will play a particular character or role, the script for which has already been written. In other instances, an agent can, if he or she so chooses, influence his or her own narrative. As he argues, "we are never more and sometimes less than the co-authors of our own narratives" (213).
} 
Application: Remarks on Discourse Ethics (1993). This program of discourse ethics is based on a cognivitist theory of moral universalism and impartiality. It is a revisionist approach to the Kantian tradition of moral philosophy, recognizing a grave error in Kant's belief that monological deliberation can arrive at a universal and impartial moral point of view. By contrast, discourse ethics accepts the role of language and intersubjectivity in structuring individual thought and consciousness. It seeks to locate a universal moral point of view through a procedural process of "practical deliberation and reasoned agreement among all those potentially affected by a proposed norm of justice" (Habermas 1993: xxiii). Habermas's famous "U” proposition maintains that a proposed norm cannot be regarded as universal and impartial

[u]nless all affected can freely accept the consequences and the side effects that the general observance of a controversial norm can be expected to have for the satisfaction of the interests of each individual.

(Habermas 1990: 93)

The conditions under which moral discourse can take place, however, must be such that no relevant opinions or perspectives are suppressed or excluded, whether intentionally or unintentionally, especially in cases of an asymmetry of power. Hence, Habermas insists that moral discourse must take place in what he calls the "ideal speech situation".

Habermas acknowledges the formidable, if not wholly impossible, obstacles in establishing the ideal speech situation, some of which may be attributed to the counterfactual epistemological assumptions upon which the ideal speech situation is based. Perhaps the most obvious of these is ensuring that all relevant perspectives are not only respected, but actually recognized and understood by all parties engaged in the communicative encounter. He seeks to overcome this problem by advocating a model of 
general and reciprocal role-taking, in which all parties grasp each other's point of view.

By incorporating such a model into his program of discourse ethics, Habermas

...builds the moment of empathy into the procedure of coming to a reasoned agreement: each must put him- or herself into the place of everyone else in discussing whether a proposed norm is fair to all.

(Habermas 1990: xiii; emphasis in the original)

It should be noted that Habermas's program for discourse ethics was developed to locate a universal and impartial moral point of view between individuals of a common lifeworld, the contours of which may be gauged by the intersubjectivity that sustains the collective consciousness of those individuals. Although he recognizes the challenges of intercultural understanding, in which "rival conceptions [and] conflicting standards of rationality clash" (1993: 104), he seems equally confident that his discourse ethics can locate a universal and impartial moral point of view between members of different cultures (or lifeworlds, to use his own terminology).

The second paradigm for moral discourse between cultures is taken from Alasdair MacIntyre, which may be found in his Whose Justice? Which Rationality? (1998). Unlike Habermas, whose moral philosophy works within a revised Kantian framework of moral universalism, MacIntyre rejects the possibility of a perspective or standpoint that resides outside of all context and from which one could undertake an impartial evaluation of rival and competing moral claims. He presents a moderate form of neo-Aristotelian contextualism and historicism, which maintains that every moral standpoint is rooted in a particular historically situated tradition. Even modern liberalism, which formally rejects tradition as such, itself bears all the marks of a tradition. What distinguishes one tradition from another is the particular rationality through which the adherents of a tradition sustain their ethical perspectives and communicate with one another intelligibly. 
MacIntyre's rejection of the Enlightenment claim to a super-rationality that stands beyond all context has led him to espouse a thesis of radical untranslatability. According to this thesis, moral meaning cannot be translated from one rational context to another. ${ }^{15}$ No language has the descriptive resources to creatively articulate or reproduce the moral meanings of an alien culture. ${ }^{16}$ However, whereas Simpson's postmodern anthropologists forsake the possibility of understanding alien cultures, MacIntyre believes that moral understanding is possible by being born again in another culture. Put simply, MacIntyre believes that to grasp the moral point of view of the cultural other, one must in effect become the cultural other. That is, moral understanding requires hermeneutic access to the cultural other's moral experience. This entails not only learning the languages of the alien culture, but also the practices and experiences that shape the meaning and use of those languages. This effort to understand the cultural other MacIntyre refers to as acts of "creative empathy".

My project will traverse a middle path between these the extreme paradigms presented by Habermas and MacIntyre. Although Habermas maintains that moral discourse must proceed on the condition that each party engaged in the moral communicative encounter grasps each other's perspective, he has very little to say about how exactly all parties are to achieve this empathetic foothold in each other's "role".

\footnotetext{
${ }^{15}$ A different version of the untranslatability thesis is presented by Homi Bhabha (1994). As he puts it, "In the act of translation the 'given' content becomes alien and estranged; and that, in its turn, leaves the language of translation Aufgabe, always confronted by its double, the untranslatable - alien and foreign" (164).

${ }^{16}$ As will become obvious in the methodology section of this chapter, I do not accept the untranslatability thesis in toto. Although it seems reasonable to argue that moral meaning in its exact formulation cannot be wholly reproduced in another linguistic, social, and cultural context, it seems somewhat outlandish to argue that absolutely nothing of that meaning can be translated at all. Translation, it seems reasonable to argue, is only a matter of the degree of perfection. If we rule out the possibility of a perfect translation, we have not thereby ruled out the possibility of a partial translation. It should also be borne in mind that MacIntyre's untranslatability thesis, based in large part on the subjective character of intercultural moral experience, can never actually be proven or disproven by way of rational argument.
} 
Given the centrality that reciprocal role-taking plays in his discourse ethics, it is remarkable that Habermas should have so little to say about how perspectives are to be commonly shared. MacIntyre, on the other hand, sets such incredibly high standards for moral discourse that he effectively renders understanding between cultures virtually impossible for those who do not have the luxury of becoming anthropologists. What is significant about these two paradigms, however, is the central role that both accord to empathy. Despite being a contextualist, MacIntyre strongly believes in the possibility of empathy. And Habermas, who is committed to a Kantian theory of moral universalism, is left with no choice but to accommodate empathy into his paradigm. Thus, accepting the assumption by these two radically different thinkers that empathy is not only possible, but also necessary for moral understanding, the present thesis proposes the study of narratives as a viable empathetic approach to advancing moral understanding between cultures.

\section{Background to Speech Act Theory: Austin, Searle, and Fish}

The philosopher of language J. L. Austin (d. 1960) was the first to highlight the many different functions to which the utterance of certain sentences might be directed. As he observes in his posthumously published How To Do Things With Words (1975), utterances can be divided into two distinct classes. The first of these is comprised of what he calls constative utterances, or utterances that only convey information. To issue a constative is merely to say something. By contrast, performative utterances are those that both convey information and constitute the performance of an act. To issue a performative is to do something. A readily familiar example of a performative utterance 
to which Austin repeatedly refers is that of a priest who performs the rites of marriage. The very utterance of the words, "I hereby pronounce you man and wife," constitutes the act of formally uniting two individuals in the contractually binding institution of matrimony. Other examples include a national leader uttering the words, "I declare war," or when an umpire utters the words, "You're out," or when a lawyer utters the words, "Objection, your Honor." In each case, the act in question is performed only by the utterance of certain socially and institutionally agreed-upon words and phrases; hence, the term 'speech-acts'. Austin notes that constatives are falsifiable, while performatives are not. It is possible, for instance, to falsify the utterance, "X and $\mathrm{Y}$ are married," if in fact $\mathrm{X}$ and $\mathrm{Y}$ are not married. However, it is not possible to falsify the utterance, "I hereby declare you man and wife," if uttered by a priest or a justice of the peace who had just performed the rites of marriage upon $\mathrm{X}$ and $\mathrm{Y}$.

Austin further distinguishes three dimensions to performative utterances in his analysis of speech-acts. He notes that the particular sense with which a performative is uttered will define the character of the act itself, along with the meaning or significance the performative holds in the particular context in which it is uttered. For this reason, he first identifies what he calls the locutionary act, which is "roughly equivalent to uttering a certain sentence with a certain sense and reference" (Austin, 1975: 109). Put simply, a locutionary act is the act of communication itself. Second, he identifies what he calls illocutionary acts, which are "utterances [that] have a certain (conventional) force" (ibid). Illocutionary acts include the above-mentioned examples of the acts performed by the priest, the national leader, the umpire, and the lawyer. Third, Austin identifies the perlocutionary act, which is "what we bring about or achieve by saying something" 
(ibid). Perlocutionary acts may best be understood as the social and institutional effects intentionally set in place by the utterance of a performative. So, for instance, in complaining to another party about his or her actions, I might be intending to bring about a sense of guilt or remorse, at least. Thus, in the utterance of a single sentence constituting a speech-act, it is possible to discern three types of action. It is not the case, however, that every speech-act will necessarily entail each type. It may very well be the case, for example, that upon hearing X utter the words, "I forgive you," Y replies by saying, "I don't accept your forgiveness." In such a case, although X performed the locutionary act, the failure to yield the desired perlocutionary effect in Y renders the speech-act as a whole a categorical failure. Austin describes successful speech-acts as "felicitous" and unsuccessful speech-acts as "infelicitous". The success or failure of a speech act rests squarely upon what he refers to as "felicity conditions". It bears noting that Austin's discussion of felicity conditions spans the greater part of How To Do Things With Words. For the purposes of the present thesis, what follows is a very brief account of felicity conditions based on the discussion of speech-acts by Austin and also that of Crystal (1987: 121).

Felicity conditions are of multiple types. One such type is the set of 'preparatory' conditions that have to be in place for the speech-act to be successful. For example, the utterance of the words, "I pronounce you man and wife," can only be valid as an act of uniting two individuals in matrimony if and only if they were uttered by someone with the requisite institutional authority. Moreover, these words could not be uttered to random strangers on the streets with the intention of uniting them in marriage. Rather, it must be the case that the two individuals being married must have made the formal 
decision to marry and they must also have acknowledged the authority of the priest who performed the rights of marriage. Preparatory conditions are not necessary for all speechacts, such as apologizing, promising, or thanking.

There are also procedural or process conditions that have to be met for the speechact to be successful. If, for instance, a priest were to utter the words, "I hereby declare you man and wife," only thereafter to utter the words, "If anyone present knows a reason why this man and this woman should not be joined together, speak now or forever hold your peace," the latter utterance would be met with bafflement for not abiding by the institutional procedures for the performance of the rites of marriage. In other cases, only very simple expectations must be obtained. The utterance of the words, "I forgive you," would presumably not be followed by a barefaced display of spite and contempt, but rather by a demeanor of understanding and kindness.

The third type of felicity condition involves sincerity. Speech-act verbs such as forgive, apologize, and vow are successful only if the speaker is sincere in employing them as performatives. Other speech-act verbs, such as believe and affirm, can only be employed successfully if the speaker is not being deceitful.

It can be argued that, ordinarily, people have an intuitive grasp of the felicity conditions that render a speech-act successful. Only in rare, awkward, or special situations will the meaning of a speech-act be brought into question. For example, the request, "May I have an extension on the deadline for my thesis?" would not be felicitous unless the following conditions were to obtain: 1) the speaker is actually in the midst of writing a thesis; 2) the speaker has a reason for asking for an extension; and 3) the request is directed toward an individual endowed with the requisite institutional authority 
to grant an extension. In the event that these conditions do not obtain, "a special interpretation of the speech act has to apply" (Crystal, 121). It may be the case that the speaker had mistakenly directed the speech-act to the wrong individual. It may be the case that the speaker mistakenly assumed that there was a deadline, when in fact there was no such deadline. It may be the case that the speaker was merely attempting to make a joke or that the speaker had temporarily gone mad. In such cases, the crucial distinction to be borne in mind is the failure of the speech-act to accord with conventionally established felicity conditions.

Curiously enough, after taking such pains to distinguish between constatives and performatives, Austin then throws the whole distinction into question. In Lecture XI of How To Do Things With Words, he examines several constative utterances and considers how their truth or falsity is to be evaluated. He observes that, although constatives purportedly concern questions of fact, they function within contexts of meaning and, like their performative counterparts, also require felicity conditions to be successful. Only when constatives are abstracted out of their original contexts of meaning can they be judged in terms of truth or falsity. Such judgment is only possible because what is being evaluated is the literal, propositional content of a statement. However, such abstraction is liable to result in a mistaken judgment concerning truth or falsity, as becomes obvious when vastly different contexts of meaning are entertained. "It is important," Austin points out, to take into consideration "the speech-situation as a whole" (138). The fallacy behind evaluating decontextualized constatives lies in our instinctive tendency to "discuss such utterances in terms of meaning as equivalent to sense and reference and so get confused about them" (139). Once it becomes clear that "what we have to study is not 
the sentence but the issuing of an utterance in a speech situation," there can no longer be any doubt that "stating is performing an act" (ibid). Put simply, to issue a constative is to issue a performative. The difference lies only in our mistaken assumption concerning those external referents about which we feel confident enough to make objective pronouncements. To put it another way, there is no such thing as a neutral statement concerning matters of fact. As will be discussed shortly, the very notion of "fact" is highly problematic in speech-act theory.

The famous example Austin offers to prove his equation between constatives and performatives is the sentence, "France is hexagonal" (143). The question of its truth or falsity, as it turns out, depends on the standpoint of the evaluator. As Austin says, "I can see what you mean by saying that it is true for certain intents and purposes. It is good enough for a top-ranking general, perhaps, but not for a geographer" (ibid). The question of truth or falsity, therefore, is always relative to the intents and purposes of the speaker. "It is essential," Austin says, "to realize that 'true' and 'false', like 'free and unfree', do not stand for anything simple at all, but only for a general dimension of being a right or proper thing to say as opposed to a wrong thing, in these circumstances, to this audience, for these purposes and with these intentions" (144-145). Whereas objectivist and pragmatist philosophers of language are likely to evaluate truth and falsity according to "what works" (by implication, an exceedingly facile theory of the pragmatics of language), Austin proposes an alternative mode of evaluation, one in which truth and falsity depend on "what act you were performing in what circumstances" (ibid). Put simply, Austin draws the equations between truth and felicity, on the one hand, and falsity and infelicity on the other. 
In his essay, "How To Do Things With Austin and Searle," Stanley Fish interprets Austin's argument to mean that "it is only in relation to dimensions of assessment that judgments of truth and falsity, adequacy and inadequacy, are possible" (1980: 198). Fish provides a more detailed interpretation of the original distinction between constatives and performatives:

Constative language is language that is, or strives to be, accountable to the real or objective world. It is to constatives - to acts of referring, describing, and stating - that one puts the question, 'Is it true or false?' in which true and false are understood to be absolute judgments, made independently of any particular set of circumstances. Performative language, on the other hand, is circumstantial through and through. The success of a performative depends on certain things being the case when it is uttered; performatives therefore are appropriate or inappropriate in relation to conditions of utterance rather than true or false in relation to a reality that underlies all conditions.

(Fish 1980: 198)

Building upon Austin's example of France and the question of its hexagonality, Fish argues that even the seemingly brute facts about which we make objective pronouncements are the products of our discourse and dimensions of assessment. "France" as on object of description is "produced" through the discourse of the geographer, the military strategist, the historian, the politician, the economist, etc. The conclusion to which Fish is driven is that nobody can claim access to some neutralist language or medium of description, "unmediated by social or conventional assumptions," that can provide an account of the "facts" as they "simply are" (199).

According to John Searle in Speech Acts: An Essay in the Philosophy of Language (1969), each dimension of assessment provides a particular framework for the governance of speech-acts. Searle's study is a meticulous and lengthy examination of Austin's notion of felicity conditions, which Searle refers to as the "rules" of illocutionary acts. He argues that, because speaking is "a rule-governed form of 
behavior," a theory of language is therefore also a theory of action (17). In a given situation, the socially and institutionally agreed-upon conventions for language constitute the very framework for meaningful, intelligible action. Searle confirms Austin's ultimate equation between constatives and performatives, insisting that there cannot be two separate and distinct studies for the analysis of the meaning of sentences and the analysis of the performance of speech-acts. He puts the point as follows:

The speech act or acts performed in the utterance of a sentence are in general a function of the meaning of the sentence. The meaning of a sentence does not in all cases uniquely determine what speech act is performed in a given utterance of that sentence, for a speaker may mean more than what he actually says... Therefore, it is in principle possible for every speech act one performs or could perform to be uniquely determined by a given sentence (or set of sentences), given the assumptions that the speaker is speaking literally and that the context is appropriate. And, for these reasons, a study of the meaning of sentences is not in principle distinct from a study of speech acts.

(Searle, 1969:18)

In developing a painstakingly detailed taxonomy of speech-acts, along with an equally painstaking analysis of their basic structures and the rules that govern their performance, Searle in effect develops an account of practical reason. He takes care to point out, however, that our grasp of the rules of language and of action is not always consciously acquired. An agent will speak and behave according to a set of rules, "even though the agent himself may not be able to state the rule and may not even be conscious of the fact that he is acting in accordance with the rule" (42). There are two important indicators of "rule-governed as opposed to merely regulative behavior," the former of which provides language and action with some viable degree of constancy or stability (ibid). The first of these indicators is that, despite our lack of a conscious knowledge of the established rules of language and action, we are nonetheless able to detect deviations from those rules. The second indicator is that these rules sufficiently guide speaking and 
acting in new situations, such that a chain or continuity of intelligibility is maintained across time and circumstance.

Searle distances himself from Paul Grice's account of meaning, which does not provide any connection between what an agent does when uttering a sentence and what the sentence means in the agent's original language. ${ }^{17}$ A proper analysis of illocutionary acts "must capture both the intentional and conventional aspects and especially the relationship between them" (45). One of the "extraordinary properties" of human communication is that, "[i]f I am trying to tell someone something, then...as soon as he recognizes that I am trying to tell him something and exactly what it is I am trying to tell him, I have succeeded in telling it to him" (47). When we perform illocutionary acts, our success rests on whether or not we get our audience to "recognize what we are trying to do" (ibid). However, the "effect" is neither a change in one's beliefs, nor a response in the form of either a verbal utterance or a more extended mode of physical action, but rather the mere recognition or understanding on the part of the hearer of the utterance of the speaker. It is precisely this outcome that Searle terms the illocutionary effect. ${ }^{18}$ The theory of illocutionary acts may be succinctly put as follow: "the speaker $S$ intends to produce an illocutionary effect $I E$ in the hearer $H$ by means of getting $H$ to recognize $S$ 's intention to produce $I E "(47)$.

\footnotetext{
${ }^{17}$ As Searle puts it, "[o]ne might say that on Grice's account it would seem that any sentence can be uttered with any meaning whatever, given that the circumstances make possible the appropriate intentions. But that has the consequence that the meaning of the sentence then becomes just another circumstance" (45). In other words, Grice does not identify an anchoring mechanism to account for constancy and intelligibility.

${ }^{18}$ The notion of illocutionary effects should not be confused with perlocutionary effects, which consist of an official change by the standards of a given institutional structure. The notion of illocutionary effects should also not be confused with the effects tradition in mass communication studies. The former takes into account the quintessentially human medium of culture. The latter, by contrast, does not take into account the socially and culturally agreed-upon conventions for language and action. Given its derivation from strict behaviorism, the effects tradition provides a stimulus-response model of communication, which, at best, amounts to a very weak and largely unconvincing explanation of action.
} 
Searle's analysis of illocutionary acts is by no means intended to be exhaustive.

His aim is merely to "unpack what constitutes understanding a literal utterance in terms of (some of) the rules concerning the elements of the uttered sentence and in terms of the hearer's recognition of the sentence as subject to those rules" (47-48). The various examples he entertains are hypothetical scenarios as they are likely to arise in a familiar social circle, which again indirectly underscores the fact that the rules governing language and action are relative to social and cultural contexts. However, Searle insists his study of speech acts also has cross-cultural purchase. That is, although he believes that speech-acts have particular applications in different cultures, the basic categories of speech-acts and their underlying structures are the same in every culture. What differs from culture to culture is the particular set of governing conventions only. Searle's view on this matter warrants extensive quoting:

Different human languages, to the extent that they are inter-translatable, can be regarded as different conventional realizations of the same underlying rules. The fact that in French one can make a promise by saying "je promets" and in English one can make it by saying "I promise" is a matter of convention. But the fact that an utterance of a promising device (under appropriate conditions) counts as the undertaking of an obligation is a matter of rules and not a matter of the conventions of French or English. Just as in the above example, we can translate a chess game in one country into a chess game of another because they share the same underlying rules, so we can translate utterances of one language into another because they share the same underlying rules. It ought...to be regarded as an extraordinary fact, one requiring an explanation, that sentences in one language can be translated into sentences in another language (39).

And this, by implication, suggests that if an utterance in one particular language is intertranslatable, then so too is action inter-translatable. The value of speech-act theory is that it can be applied to multiple cultural contexts to "unpack" the social and cultural conventions that govern the performance of illocutionary acts. This is precisely what Fish accomplishes in "How To Do Things With Austin and Searle," where he unpacks 
the illocutionary acts performed by the characters in William Shakespeare's Coriolanus. What renders this essay especially interesting is that Fish applies speech-act theory to a literary work. This innovative use of speech-act theory forms the basis of my methodological approach to the interpretation of moral utterances.

\section{Methodology: How to do things with Stanley Fish}

Coriolanus is the eponymous play about a legendary Roman leader from the $5^{\text {th }}$ century $\mathrm{BCE}$, whose pride and will to absolute autonomy results in his own tragic death. Coriolanus personally leads several battles and establishes for himself a reputation as a fearless warrior and competent leader. However, from his record of success he develops an extremely arrogant attitude toward others, even his own people, eventually resulting in a debilitating case of megalomania. He is unhappy being merely a head of state, as he is bound by the state's regulative and constitutive rules. However, Coriolanus seeks to transcend this institutional dependency. He is determined to achieve full autonomy, such that he will not be subject to a public system of evaluations, which he regards as so many worldly shackles weighing him down and preventing him from achieving his rightful glory. Coriolanus aspires to justify his actions not according to a public set of criteria and public procedures of inquiry, but from a higher realm of pure essences to which, he believes, he alone has access. In a word, what Coriolanus seeks to achieve is divinity. However, the lesson of the play is that such an aspiration is a delusional fantasy, for even a head of state is dependent upon the regulative and constitutive rules of the institution from which he derives his authority. In the end, Coriolanus's megalomania costs him both his sanity and his life. 
Fish is observes that Coriolanus is a play about speech-acts. The institution of the state thrives on the performance of certain illocutionary acts from the standpoint of certain institutional roles. In challenging his very own speech-act community, Coriolanus attempts to an appeal to his own categories of understanding, frames of reference, and system of evaluation. However, that challenge inevitably fails and Coriolanus is in the end reclaimed by the community. In the tension between Coriolanus and his own people, the play becomes a story about the speech-acts constitutive of the community: what is challenged is reaffirmed and reasserted. Hence, Fish applies speechact theory to unpack the dominant conventions that govern language and action in the play. In doing so, Fish writes what he calls a "speech-act history" of Coriolanus.

In Chapter Three, I will be adopting Fish's innovative application of speech-act theory in my own speech-act reading of Brick Lane. The goal of my analysis is twofold. First, whereas Fish analyzes the speech-acts constitutive of a formal, institutional setting, I will analyze the speech acts constitutive of an informal, non-institutional setting. I will examine specific speech-acts constitutive of the Bengali community of Brick Lane by applying Searle's model of illocutionary acts. This model, a structural account of the types of rules that govern illocutionary acts, is comprised of the following elements: the propositional content, the preparatory conditions, the sincerity condition, and the essential condition that determines the other conditions (Searle, 64-71). Like Fish, what I hope to uncover are the regulative and constitutive rules that govern illocutionary acts. It is important to emphasize that my analysis will hardly be exhaustive. It is simply not feasible nor purposeful to provide a complete account of each and every speech-act and their regulative and constitutive rules. Rather, my analysis is driven by the more modest 
aim of examining certain key speech-acts that may be said to define the identities or social roles of certain key characters in the story. Just as Fish provides a speech-act history of Coriolanus, so, too, will I provide a speech-act history of the central characters of Brick Lane. In particular, I will be focusing on the character of Nazneen, who, like Coriolanus, attempts to abandon her speech-act community.

Secondly, because I will analyze informal, non-institutional speech-acts, I am committed to identifying the source of legitimation from which the non-institutional speech-act derives its illocutionary force. Hence, my analysis will move beyond that of Fish by attempting to locate the non-institutional speech-act within its context of justification. It will be my contention that that context of justification is the socially embodied narrative constitutive of the Bengali culture portrayed in Brick Lane (a point that will be more fully developed in Chapter Four). It is precisely this socially embodied narrative from which the members of the Bengali community derive their respective social roles and their normative orientation. Furthermore, in my analysis, I will be committed to answering the following questions: What cultural mechanisms sustain the social roles of the Bengali community? To what extent are social roles and the conventions that govern language and action firmly entrenched in non-institutional settings? What price does one pay for membership in a speech-act community? What price does one pay for challenging one's social role or a set of established conventions? In referring to the regulative and constitutive rules that govern the performance of an illocutionary act, I am arguing that membership in a given speech-act community requires that one play what Searle describes as an "illocutionary game". I will be inquiring into what it means to be a player in an illocutionary game and what rules one 
must follow to be a player. When regarded in terms of a game, the notion of a legitimate "move" becomes not only all the more intelligible, but vital to our appreciation of the internal, unwritten, and largely intuitive scheme or structure through which the members of a culture communicate with one another. As I will argue in Chapter Four, that scheme or structure is identical to a culture's morality. Hence, a legitimate move, according to this argument, constitutes a legitimate moral utterance.

It is at this point important to acknowledge that my use of speech act theory to interpret moral utterances moves beyond the limits of the theory explicitly sanctioned by Searle. In the second chapter of Speech Acts, Searle argues that moral utterances are not readily "assimilable" to the "distinction between brute and institutional facts" (50). That is, moral utterances can neither be said to be objective statements, nor can they be said to be the products of our discourse. In fact, the question of moral utterances is entirely circumvented by Searle, who insists that speech-act theory has nothing to say on the matter and that moral philosophers will have to address the question of moral utterances through a different philosophical paradigm. This is precisely where I would respectfully disagree with Searle. Moral utterances, I believe, cannot but be assimilable to the speech-act paradigm, which engages with the local, the temporal, the contextual, the relative. Like MacIntyre, I maintain that

...the subject matters of moral philosophy at least-the evaluative and normative concepts, maxims, arguments and judgments about which the moral philosopher enquires - are nowhere to be found except as embodied in the historical lives of particular social groups and so possessing the distinctive characteristics of historical existence: both identity and change through time, expression in institutionalized practice as well as in discourse, interaction and interrelationship with a variety of forms of activity. Morality which is no particular society's morality is to be found nowhere. 
This line of argument admittedly runs against the grain of the Kantian tradition of moral philosophy, which insists on locating the moral in some timeless, universal realm of objective rules. By contrast, I hold the position that moral utterances are the products of our discourse; that they are nothing more than institutional, discursive phenomena. Building upon Fish's contention that meaning is produced through discourse, I likewise maintain that morality is also a product of the narratives that manages our experiences in situations and practices. It is precisely this argument that I hope to vindicate in Chapter Four. 


\section{CHAPTER THREE: A SPEECH-ACT READING OF BRICK LANE}

"What could not be changed must be borne. And since nothing could be changed, everything had to be borne. This principle ruled her life. It was mantra, fettle, and challenge." - From the opening chapter of Brick Lane

The above quote somberly illustrates the central theme of Brick Lane and the life of its central character, Nazneen Ahmed. The novel begins by relating the story of Nazneen's birth - a story Nazneen hears repeatedly from her mother as a child and which she herself will eventually share repeatedly with her own children. As the story goes, immediately after she was born, Nazneen stopped breathing, leaving her family to think that she had died. Nazneen's mother was a stubborn fatalist, who always assumed the worst and insisted that every event, including the worst, was the will of God. Hence, rather than attempting to save her daughter, Nazneen's mother left the poor newborn "to her fate". That is, her mother believed she had left matters in God's hands. She had not bothered to call a midwife to prepare for a successful birth, insisting instead that if the birth were successful, it would have been God's choice. According to this logic, hiring a midwife is not only superfluous and a waste of money, but also an affront to the will of God. As it turned out, however, just as her family had thought that Nazneen had died, she unexpectedly began breathing again, much to everyone's surprise. Now, her mother believed, God had willed that Nazneen should live.

The theme of fatalism informs the cultural backdrop of not only Nazneen's personal life, but of Bengali culture generally. When Nazneen eventually moves with her husband to the United Kingdom, she settles into the Bengali community in London's East End district of Brick Lane. The very same cultural attitudes that had governed her life 
during her youth are reproduced in her new community. That community can rightly be described as a speech-act community, replete with a constitutive set of social roles, each of which is defined by certain key obligations and speech-acts. The community itself is governed by a fixed system of conventions to which the members of the community must appeal for the felicitous performance of their speech-acts.

However, Brick Lane does not attempt to merely reproduce the social and cultural conventions constitutive of Bengali culture. It does not narrate a conventional life. Nazneen's story is, in fact, highly out of the ordinary. Like Coriolanus, Nazneen attempts to abandon the conventions of her speech-act community so as to eventually exclude herself from its membership. What follows is a speech-act reading of Brick Lane. It will focus on certain key characters in the novel. These include Nazneen herself; her overbearing husband, Chanu; the equally overbearing Mrs. Islam; Nazneen's disreputable close friend, Razia; and Nazneen's two daughters, Shahana and Bibi. The analysis will explore the central characters' social roles and the speech-acts that define those roles. As mentioned in the previous chapter, membership in a speech-act community can be likened to being a player in a game, the "game of illocutionary acts," as Searle calls it (1969: 55). Although the members of a speech-act community are intuitively able to play the illocutionary game, they do so "without any explicit formulation of the rules" (ibid). A speech-act analysis therefore seeks to "set out the conditions for the performance of a particular illocutionary act" (ibid). Hence, in the following analysis, I will attempt to identify the conditions for the performance of various illocutionary acts. While the analyses of certain speech-acts are taken directly from Searle and while certain others are based on Fish, I have in other cases had to develop my 
own analysis for other speech-acts. My analyses, however, like Fish's, are based on Searle's model (1969: 66-67).

A key point to bear in mind is that membership in a speech-act community requires communicating through an operative stock of speech-acts. One maneuvers one's way through a community by appealing to its speech-acts and its governing conventions. It is also important to bear in mind that infelicities of whatever kind are dealt with through yet other speech-acts. The illocutionary game is unending and, hence, to ensure that the game will continue its proper course, the community collectively appeals to existing mechanisms and the operative stock of speech-acts to deal with infelicities. However, those mechanisms do have limits, beyond which one runs the risk of transmuting from a player to a non-player. In Nazneen's case, she is actively driven to become a non-player.

One of the aims of the following analysis is to trace Nazneen's evolution from willing player to unwilling player and, eventually, to transgressive non-player. My speech-act reading of Brick Lane will be organized mainly thematically, but will still follow a basic chronological order. It should be emphasized at this point that what follows promises to be a fairly light and straightforward analysis. The main theoretical analysis will be saved for Chapter Four.

The present chapter is divided into two parts. Part One will introduce the main characters, their social and cultural roles, and the speech-acts characteristic of those roles. It will be primarily concerned with the conventional and the felicitous. Part Two will be concerned primarily Nazneen's transformation. It will focus on the unconventional and 
the infelicitous. The significance of Part Two concerns the limitations and boundaries of Nazneen's speech-act community, which she will eventually manage to overcome.

\section{Part One}

\section{A. Nazneen \& Chanu}

Monica Ali begins her novel by opening a window on to the culture of the Bengali community of Brick Lane. Before even describing the internal rules of normative conduct, she describes the consequences of violating those rules. We are to understand that both conformity to the rules and the particular internal mechanisms culturally sanctioned to deal with breaches of normative conduct are very much constitutive and salient aspects of this particular moral culture. Nazneen has been drafted into a certain social role, namely, that of a wife in a working-class, Bengali Muslim household. As such, there are certain virtues by which she is expected to abide. She must be a "good worker," who attends to certain household duties, such as cleaning and cooking. According to the rules of this moral culture, "[a] wife could be reasonably beaten," for failure to attend to her culturally prescribed duties (9). Nazneen's principle virtue, at least in the eyes of her husband, is that she is an "unspoilt girl" from "the village" (ibid); that is, she is sufficiently naïve, submissive, and dutiful. She can be told what to do and can be reproached for not doing something precisely as she is told or even reproached at random to remind her of her station in life. She is, at times, reproached for nothing more than being shy and hesitant. Stories are told of women in the community who are violently beaten by their husbands and of other women still who discover that 
their husbands have other wives besides them. It is, in fact, customary for a wife to feel grateful that she has not been made a co-wife.

Nazneen's inferior status in life is epitomized by the supremely degrading and strikingly symbolic task of having to regularly cut the corns from her husband's feet, cut his finger nails, cut his hair, pluck the hair from his ears, clip the hair from his nose whatever it takes "smarten him up". Such tasks Chanu could certainly assume himself, but are given to his wife only to underscore her sense of duty and obedience before her husband. There are, moreover, other symbolic acts of submission she routinely performs. It is customary, for example, for Nazneen to walk a step or two behind her husband when out in public. When he walks, she walks. When he stops, she stops. She covers her hair, bows her head, lowers her gaze, and does not speak unless spoken to. When on those rare occasions she does speak, going so far as to actually express a personal opinion, it only excites dismissive laughter from her husband, according to whom his wife is incapable of any independent, critical thought. For the young Bengali housewife, servility is of the essence.

Chanu himself is the epitome of the Bengali husband. He is extremely proud of himself and of his accomplishments, which are not all that many and do not strike the reader as exactly worthy of much pride in the first place. Chanu routinely speaks of his many "certificates" to highlight his great learning and status as an educated man. He is perpetually obsessed with status and respectability, the supreme ideals in the moral culture of his community. These are the goods or the telos to which the actions of the Bengali husband are ultimately oriented. With high status and respectability, one reserves the right look upon others with condescension and scorn. Chanu is also forever 
exercising authority over his wife for the mere sake of exercising authority over his wife. The exercise of authority is, more often than not, an end in itself and, hence, certain actions and utterances must be understood to serve no purpose other than to emphasize his authority, status, and self-worth.

Ali provides the reader with a sense of the general structure of expectations in which Chanu's actions and utterances are most at home. Early in the novel, for instance, Chanu takes special care to mention his education, which consists of a Bachelor of Arts degree "from a British university". We are never actually told in what or which university. Chanu will, throughout the course of the novel, repeatedly point to his academic credentials to underscore his superior status in the community, given that most of its members consist of "uneducated", "illiterate", and "close-minded" "peasants" "without ambition" (14). We are to understand that Chanu has none of these contemptible qualities. He goes so far as to describe himself as an "intellectual," insisting that the intellectuals of the community "must stick together" (16). The point here is not to ascertain whether Chanu fits his self-description. Rather, because he believes he does, this is the role he plays when before his wife, who is made to believe that he exemplifies in the extreme one who is educated, urbane, and possessed of considerable will and ambition. Chanu's role is not one to which she will continue according unquestioning respect. For the moment, however, the relationship between Chanu and Nazneen is one of a mutual reinforcement of each other's roles and personal narratives. Their relationship fits something of a master-slave dialectic in that each is at once both definitive of and impossible without the other. As we will see, when Nazneen abandons her role, Chanu is no longer able to retain his. 
Nazneen serves, moreover, as a guaranteed audience or disciple, before whom Chanu can exercise his wisdom and reinforce his image of himself as a bona fide intellectual. Whether Nazneen understands anything he says is entirely beside the point. That she generally does not understand his many pompous quotations from "Chaucer or Dickens or Hardy" (21) reinforces her own self-image as a simple, uneducated housewife and his image as an urbane intellectual. Expressing his contempt for the "rubbish" he is sent from correspondence school, Chanu declares his preference for Shakespeare, which he refers to as, "English literature at its finest" (62). He uses the occasion to bolster his pride by his patronizing insistence that even Nazneen has "heard of William Shakespeare. Yes, even a girl from Gouripur [the poor village in which Nazneen was brought up] has heard of Shakespeare" (ibid). Chanu quotes at length from Shakespeare's plays, though he knows Nazneen understands not a word of what she hears. He uses such occasions not only to highlight his great learning, but also to emphasize the futility in her desire to learn English.

On another such occasion, when riding together on a public bus, Chanu remarks on the physique of the African bus driver, expounding upon the roles of "[c]ommerce and natural selection" in ensuring that only the fittest slaves survived the ordeal of slavery (67). Even this sort of talk, however, is largely unintelligible to Nazneen, who is humbly ignorant of such history. For she, like most housewives in her community, was only given an elementary education. She invariably responds to Chanu's history lessons with the passive concession, "If you say so, husband" (ibid). Chanu is able to confidently, even unthinkingly, pontificate on end precisely because he knows that his wife will 
humbly assent to whatever he says. His speech-acts are felicitous because they bring about the desired perlocutionary effect.

Nazneen does not feel that Chanu actually speaks to her when he engages in his many rambling monologues. She feels, rather, that she is "only part of a larger audience" to whom his monologues are actually directed (24). Whenever she inquires into what it is he does in his supposedly important job, she is not given a straight answer. "But whenever she asked what he did he gave such a long reply that she got lost in it and although she understood the words, they got together in such a way that their meaning became unclear, or she became confused by them" (26). When Nazneen inquires into whether a particular sari is nice or not, Chanu replies by quoting a passage from David Hume concerning "relations of ideas" and "matters of fact". He is fully aware she will have no clue as to the meaning or relevance of such a passage. This betrays even further her feeling that Chanu does not actually speak to her; that his utterances are directed to some imaginary audience, which he merely superimposes upon her. The role Nazneen plays in their domestic illocutionary game is hardly that of an engaged and engaging interlocutor. Precisely because Chanu's utterances are directed to an imaginary audience, one intended to appreciate the profundity behind his quoting of such intellectual luminaries as Hume and the like, what Nazneen hears is not meant to be understood, but rather to reinforce in her mind an image of her husband as a distinguished man of great learning. Her inability to understand anything he says is, furthermore, intended to underscore her inferiority.

There is one speech-act in particular that is definitive of Chanu's identity: "It is lucky for you that you married an educated man" (27). Chanu will on multiple occasions 
throughout the novel, in some variation or another, insist that it is lucky for Nazneen that she married an educated man. It is his favorite utterance and, in performing it, he defines who he is. The multiple recurrence of this utterance warrants an inquiry into its performative function. The following is my speech-act reading of what I will call a boast:

\section{Boast}

$\begin{array}{cl}\text { Types } & \text { Propositional Content } \\ \text { of } & \text { Preparatory Conditions } \\ \text { Rule } & \text { Sincerity Condition } \\ & \text { Essential Condition }\end{array}$

\author{
Some act, property, quality, etc. $E$ related to $C$. \\ $E$ reflects creditably on $C$ and $C$ would like others \\ to believe that it does. \\ Both $C$ and $N$ value $E$ positively. \\ Counts as a positive evaluation of $E$.
}

The above speech-act analysis is based on Fish's analysis of praising (Fish, 1980: 209). The object of the praise, of course, is different, but the propositional content remains the same. Fish is keen to observe that the felicity of the speech-act of praising requires the complimentary speech-act of accepting praise. In the moral culture to which Chanu and Nazneen belong, a boast also requires for its felicity the complimentary speech-act of assenting to that boast. Based on Fish's analysis of accepting praise, the following is my speech-act analysis of assenting to a boast:

$\begin{array}{cl} & \text { Propositional Content } \\ \text { Types } & \text { Preparatory Conditions } \\ \text { of } & \text { Sincerity Condition } \\ \text { Rule } & \text { Essential Condition }\end{array}$

Assenting to a Boast

Some act, property, quality, etc. $A$ related to $C$. $A$ benefits $C$. Both $C$ and $N$ believes $A$ benefits $C$. $N$ feels appreciative of $A$.

Counts as an expression of acknowledgement or recognition of $A$.

Just as certain speech-acts are definitive of Chanu's identity, so, too, are certain speechacts definitive of Nazneen's identity. The speech-act of assenting to her husband's boasts is in part definitive of her social role, as exemplified by her passive concessions. By performing a speech-act repeatedly, she confirms and reconfirms the social role into which she had been drafted. 
This particular cultural conception of husband-wife relations is, of course, unexceptional. Similar such relations, it can be reasonably argued, may be found in other cultures as well. It is to the point, however, to emphasize the particular rules and pragmatics that one would have to observe, not just to be intelligible, but also to be regarded as a particular type of player within this particular cultural setting. Actions and utterances within this setting are liable to be infelicitous when they fail to take into account the social and cultural conventions and the larger structure of expectations definitive of the community. This point is all the more significant to bear in mind, as Nazneen will later violate the rules of normative conduct in such a manner as to be decidedly unintelligible to Chanu. How he deals with unintelligible behavior, that is, the behavior of one who transmutes from a player into a non-player, becomes a rather telling commentary on the limitation and fragility of this particular local morality.

\section{B. Mrs. Islam}

The reader is also introduced early in the novel to the elderly Mrs. Islam, whom Chanu refers to as "respectable" (13). Chanu describes most Bengalis as uneducated, simple villagers, whose fate in life is to work menial jobs. Few of these Bengalis, he insists, will ever hold a book in their hands. They have generally been fated to the immigrant "predicament" and are thus doomed to misery and failure. Mrs. Islam, by contrast, plays the role of a respectable individual in the community. She wields great power over both men and women. She holds such power that, even in Nazneen's own home, she can issue commands. Nazneen can be ordered to sit down or to go make tea or to stop being fidgety. Mrs. Islam visits whomever she wills, always dispensing advice, 
whether it is sought from her or not. The illocutionary force of such advice and commands, of course, derives solely from her social status. The following is Searle's analysis of the speech-act of advising:

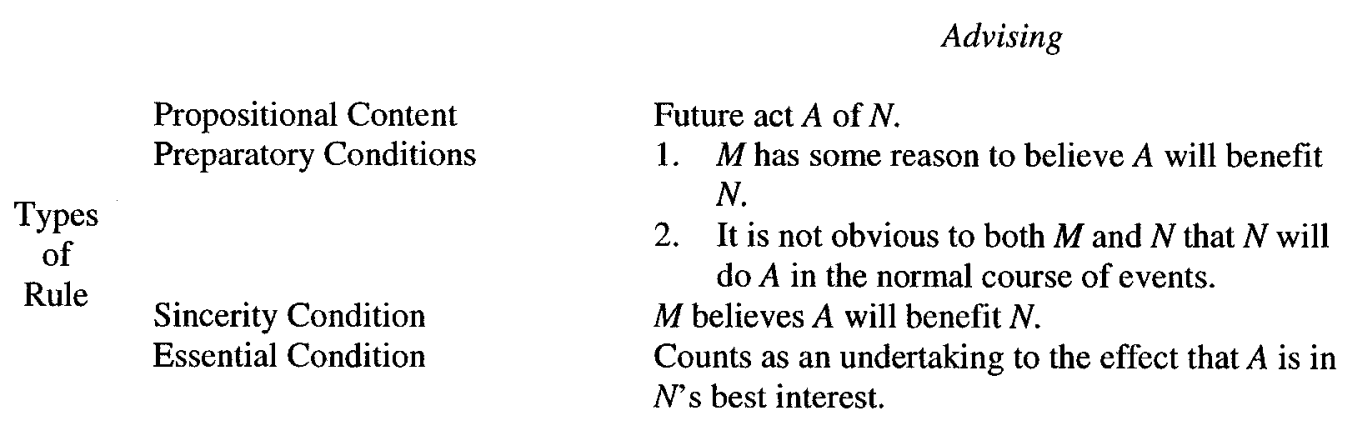

(Searle, 1969: 67)

And the following is my own analysis of a command:

$\begin{array}{cl} & \text { Propositional Content } \\ \text { Types } & \text { Preparatory Conditions } \\ \text { of } & \\ \text { Rule } & \text { Sincerity Condition } \\ & \text { Essential Condition }\end{array}$ Commanding An instruction $p$ issued to $N$.
3. $M$ assumes authority over $N$. 4. $N$ accepts the authority of $M$. None. Counts as an undertaking in so far as $p$ is a realistic instruction achievable by $N$.

Both speech-acts require for their felicity something akin to Nazneen's concession to her husband's boasts. Mrs. Islam's authority is such that she can issue commands and advice and expect that they will both be rendered felicitous. Just like Chanu and Nazneen, there are speech-acts constitutive of Mrs. Islam's identity and their felicity likewise thrives on the inferior social role of the party to whom such speech-acts are directed. On those occasions when the other party does not conform to his or her social role, the speech-act of advising or commanding is, of course, rendered infelicitous. On such occasions, Mrs. Islam is compelled to turn to other speech-acts to reassert her authority and restore order. On one occasion, for example, Mrs. Islam declares that she will take Nazneen's own baby for a couple of hours to entertain her niece. Mrs. Islam issues a rather 
straightforward command: "You can collect him in a couple of hours. Give him a feed now, and we'll go" (59). Nazneen, however, refuses, insisting that the baby will feed later. This defiance does not at first even register with Mrs. Islam, who is not accustomed to having her authority challenged. Mrs. Islam repeats her command: "You better do it now. I'm ready to go" (ibid). Again, Nazneen refuses: "He's staying here. With me" (ibid). Mrs. Islam cannot believe what she hears and, with the illocutionary force of a threat, challenges Nazneen to repeat herself. Nazneen is, in effect, given the opportunity to steer the situation back to a culturally sanctioned course. In this case, however, she resists:

Nazneen trembled, but the warmth of [her baby's] body against her chest fired her resolve. "He's staying here." She could have added something to soothe. Something to show her respect. She could have said, I'll bring him later. He's not well today. Another day, I'll bring him. He'll be in good hands with you. All she said was, "He's staying here."

Nazneen's response is issued in the form of a declaration, the sort of speech-act that cannot possibly have any felicity conditions, precisely because Nazneen's social role deprives such a speech-act of any illocutionary force. Mrs. Islam does not persist, but instead passes judgment upon Nazneen, declaring that, "The white people, they all do what they want. It's nobody's business. [...] They do what they want. It is a private matter. Everything is a private matter. That is how white people live" (59-60). This judgment functions as a form of censure, the force of which again derives from Mrs. Islam's social status: 


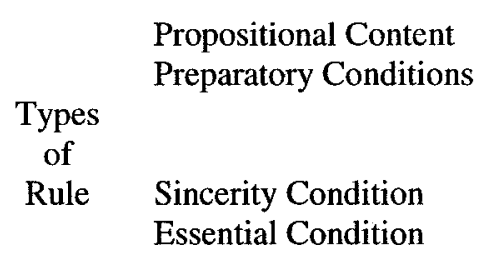

\section{Censuring}

A negative judgment $p$ concerning $N$.

1. $M$ has evidence (reasons, etc.) for the truth of $p$.

2. It is not obvious to both $M$ and $N$ that $N$ knows

(does not too to be reminded of, etc.) $p$.

$M$ believes $p$.

Counts as an undertaking to the effect that $M$ produces an actual state of affairs.

The above analysis of censuring is mine. Mrs. Islam's censure is a speech-act that requires for its felicity a certain illocutionary effect, namely, that Nazneen acknowledge the sort of damage she is bringing upon her reputation by behaving like the muchdespised white people. A certain reality has, in effect, been produced by her censure. Although Nazneen's breach of conduct is hardly as revealing as her later dramatic defiance before Mrs. Islam, the above scenario does provide a window, albeit a modest one, on to the cultural mechanisms instituted to deal with such breaches. Nazneen's refusal is at this point still intelligible to Mrs. Islam. The latter is able to classify her disrespectful behavior according to existing moral categories. Nazneen has not as yet defied intelligibility and Mrs. Islam, despite her sense of offense, still retains her social station of authority. Neither party's social role has been subverted.

On another occasion, after Nazneen reveals that her husband is suffering from an ulcer, Mrs. Islam replies, "There is no need to tell me. I know how it is. I get to know these things" (41). Despite the inferior status to which women in the community have been fated, the older and more respectable Mrs. Islam plays the surprising role of a matriarch. "All the young people," she says, "they come to me. Everyone knows that what they say to me stays in confidence. But if you do not wish to speak, I do not wish to hear" (ibid). In the Bengali community, gossip is an extremely powerful mechanism of social control. As one of Nazneen's friends puts it, "Once you get talked about, then that's it. Nothing you can do" (38). The pressures faced by a wife to conform to 
culturally instituted patterns of social behavior are hardly limited to the domestic context. Although the motives vary, the entire community collaborates to guarantee that certain social roles, especially that of young women, are strictly maintained. Mrs. Islam's power is bolstered by the fact that all gossip eventually finds its way to her. She herself can, moreover, be the source of much gossip, including the kind that can destroy one's community standing. Hence, the considerable illocutionary force of her warnings and threats. Mrs. Islam will, in the course of the novel, perform certain apparently innocuous speech-acts, such as requests, the actual illocutionary force of which translates into warnings and threats. ${ }^{19}$ The felicity of such speech-acts rests on a general acknowledgment of not only her respectable status, but the power she wields to preserve or destroy one's standing. It is only by membership in the community and by abiding by a particular social role that Mrs. Islam's speech-acts can have any perlocutionary or illocutionary effects at all. As we will see later, Nazneen can defy Mrs. Islam only up to a certain point, beyond which she risks effectively excluding herself from the community.

\section{Razia}

Another key figure in the novel is Razia, the miserable wife of a lowly factory worker who is unable to support his own family. Razia's status in the community is the very opposite of that of Mrs. Islam. Her family is poor, which in itself counts against her standing. Razia also refuses to dress in traditional clothing, preferring instead to dress like the much-despised white people. She even crops her hair short like a man. She does not observe all of the traditional forms of cultural etiquette associated with her social

\footnotetext{
${ }^{19}$ See Searle's discussion concerning how the propositional content of a single utterance can function as different speech-acts depending on the context (1969: 58-59).
} 
role. Her children are, moreover, wayward youths, thus bringing considerable shame and embarrassment upon her family name. Because of her behavior and because of her family's many predicaments, Chanu classifies Razia as an unrespectable character - yet another role from among the stock of established social roles in the community. One can be unrespectable and yet remain a community member, much like an untouchable at the bottom of the caste system. Although Chanu does not explicitly forbid Nazneen from seeing Razia, he asks her to keep Razia's lowly status "in mind" (56).

When she visits Nazneen, Razia often complains that, despite her husband's daytime and nighttime jobs, she is forced to buy everything second-hand for her family. She threatens to seek out a job to earn extra money. She claims that her husband not only keeps her "locked up inside," but that he will surely kill her if she dares get a job. "That's the sort of man he is. For hours, for days, he says nothing at all, and when he speaks that's the kind of talk I get" (86). Razia insists that her complaints against her husband are due solely to the suffering of her children.

On one occasion, Razia suggests that she will follow in the footsteps of Jorina, whose husband is also unable to earn enough money to support the family. Much to the scandal of the community, Jorina is forced to work in a local garment factory. For a woman to work is to bring considerable shame and embarrassment upon her husband, whose role it is to be the sole breadwinner in the family. In response to Razia's suggestion, Nazneen evokes the stern and unforgiving opinions of Mrs. Islam and the greater community, warning Razia of the consequences of malicious gossip. The following is Searle's analysis of a warning: 


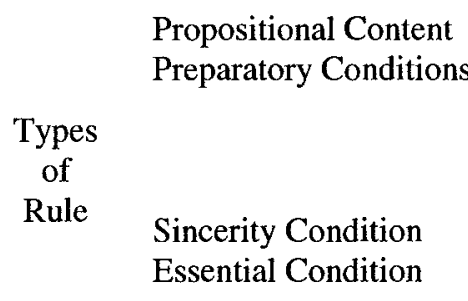

Propositional Content

Essential Condition
Future event or state, etc., $E$.

1. $N$ has reason to believe $E$ will occur and is not in $R$ 's best interest.

2. It is not obvious to both $R$ and $N$ that $E$ will occur.

$N$ believes that $E$ is not in $R$ 's best interest.

Counts as an undertaking to the effect that $E$ is not in $R$ 's best interest.

(Searle, 1969: 67)

Community opinion, as mentioned earlier, functions as a very powerful mechanism of social control and induces considerable fear in those most likely to bear the brunt of its negative judgments. The illocutionary force of Nazneen's warning cannot be easily brushed aside. Razia therefore responds by asking with comparable force, "Will the community feed me? Will it buy footballs for my son? Let the community say what it will. I say this to the community," upon which she expresses her sense of contempt with a flick of her fingers, a moral utterance that permits of little ambiguity (66). Although, formally speaking, Razia's expression of contempt constitutes a speech-act, it is a speechact generated from the standpoint of a personal narrative and not that of a social role. That is, it cannot be said to derive from the community's operative stock of legitimate speech-acts. Her expression of contempt requires for its felicity a departure from the established conventions, which she has no choice but to dutifully observe when in public. Contempt she can only express in private, for no reason other than that the exacting price of community membership requires drawing from the operative stock of recognized speech-acts to navigate one's way through the community.

Despite her poor reputation, Razia's status as a community member is evidenced by those rare encounters with other community members, such as Chanu, who is forced by tradition to observe a basic code of courtesy. On one such occasion, Chanu 
unexpectedly finds that Nazneen has company in the notorious person of Razia, upon which he his forced to greet her. "He paused when he saw Razia, then offered a salaam that appeared to include her only by accident" (88). The following is Searle's analysis of the speech-act of greeting:

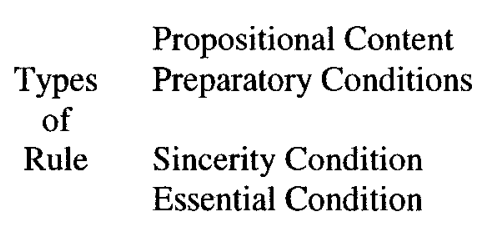

\author{
Greeting \\ None. \\ $C$ has just encountered (or been introduced to, \\ etc.) $R$. \\ None. \\ Counts as courteous recognition of $R$ by $C$.
}

(Searle, 1969: 67)

Commenting on the speech-act of greeting, Fish makes the following rather illuminating remarks:

What strikes us immediately is how little, relative to other speech-acts, greeting commits us to. One who greets commits himself neither to a proposition, nor to a desire, not to a position in a line of authority and dependence, but simply to being a member of the (speech-act) community whose conventional means of expressing courtesy he is now invoking. Greetings is the bottom line of civility; it has no content except the disposition to be civil; it is an act we perform even in the company of our enemies, signifying that the differences dividing us finally depend on something we share. We can say of someone, "I'll never ask him for anything again," or "I'll never rely on his promises," and still be understood to have commerce with him; but if we say "I will not even say 'hello' to that man," it is understood that we will have nothing to do with him at all.

(Fish, 1980: 214)

Quite uncomfortable in this situation, Chanu brings himself to engage in a mild, albeit affected, tête-à-tête:

He cleared his throat and with great formality inquired about Mrs. Islam, her health in general, her hip in particular, and the continuing good fortune of her sons. Razia made brief, polite replies but sprawled over her chair in a manner unbecoming to a Bengali wife. His inquiries exhausted, Chanu stood ill at ease as if waiting for an invitation to be seated. 
Two contrasting speech-acts are performed. On the one hand, by felicitously greeting each other, Chanu and Razia both grudgingly acknowledge each other's existence and confirm that they are both members of the same speech-act community. However, within the boundaries established by that greeting, Razia brazenly flouts the conventions by which a housewife is expected to abide. Although expressed through silent gesture, her unbecoming demeanor nonetheless communicates a clear and unambiguous message with resounding force. It is a speech-act performed, again, from the standpoint of an individual narrative, but whose perlocutionary effect cannot be escaped. Even in her nonconformism, however, Razia is still parasitic upon the dominant norms to make herself understood. Her behavior is intelligible precisely because it appeals to existing conventions. That she should choose to express her dissent by intentionally flouting the expectations of the community is a strong indication that she is still very much imprisoned within its moral and symbolic universe. The nonconformist is thus forced to submit to a basic degree of conformism. So long as one remains trapped within the socially established role of the rebel, one is still intelligible and therefore manageable by the other members. As we will see, however, Nazneen's supreme achievement is to defy even the role of the rebel and, therefore, to defy intelligibility itself.

\section{Shahana and Bibi}

The interaction between Chanu and his daughters, Shahana and Bibi, reveals a great deal about the speech-act conventions that govern language and action in the Bengali family. Both daughters were born in England and, although raised at home according to Bengali norms, they are also socialized in school and the larger British 
society according to very different cultural norms. They are hybrid creatures, as second generation members of diasporic communities tend to be. Chanu wishes to instill in his daughters a sense of tradition, or at least of continuity with tradition. However, their Western values and attitudes represent a threatening departure from that tradition and a test for the boundaries of the community, its norms and moral matrix. The value of examining the interactions between Chanu and his daughters lies precisely in the emphases he places upon culturally sanctioned social roles, their constitutive speech-acts, and the conditions under which those speech-acts can be rendered felicitous. Chanu's cultural conservativism is, for the purposes of the present analysis, highly illustrative of the conventions of which he is so representative. Ali uses several scenes to introduce the reader to father-daughter relations, which cannot fail to be of value for speech-act analyses.

We learn that beatings are regularly administered to Shahana, the senior of the two daughters, who almost invariably earns Chanu's wrath by her refusal to conform to her assigned social role. From Shahana's insubordination, it is routine for Nazneen to instinctively "divine a flogging ahead" (127). When, for example, Chanu tries to teach his young daughters Rabindranath Tagore's "My Golden Bengal," they follow him only with the starkest indifference. Shahana recites with an insolent apathy, the audacity of her insolence being compounded by the laziness in her posture. Such behavior only manages to excite Chanu's indignation, perhaps unsurprisingly, given his temperament. Chanu at first issues a command to his daughter to sing, a speech-act intended not only to get his daughter to recite the poem in a proper manner, but also to exercise his parental authority. When the desired perlocutionary effect does not materialize, Chanu's 
command, of course, goes infelicitous. However, the ensuing situation is not beyond Chanu's control, for he still has at his disposal certain speech-acts designed to bring about the sort of perlocutionary effects he seeks to achieve. Chanu issues a warning in the form of the following utterance: "Tell the little memsahib that I am going to break every bone in her body" (ibid). Ali does the reader the favor of detailing the conventions established for the intelligibility of this type of utterance:

Chanu never addressed his threats directly to his elder daughter. Nazneen was the preferred intermediary or, if a new and particularly lurid threat had been invented, Bibi would be chosen. "I'll dip her head in boiling fat and throw her out of that window. Go and tell the memsahib. Go and tell your sister." Bibi could be relied upon to convey the message word for ringing word, even though Shahana was rarely more than a couple of feet away.

Thus, a threat issued to one daughter is expressed as a command issued to another. The following is my speech-act reading of a threat:

$\begin{array}{cl} & \text { Propositional Content } \\ \text { Types } & \text { Preparatory Conditions } \\ \text { of } & \text { Sincerity Condition } \\ \text { Rule } & \begin{array}{l}\text { Essential Condition } \\ \end{array}\end{array}$

\section{Threat}

Future event or state, etc. $E$.

1. $C$ has reason to believe $E$ will not occur.

2. It is not obvious to $S$ that $E$ will not occur.

None.

Counts as an undertaking to the effect that $C$ seeks to bring about $E$.

Although issued as a response to the infelicity of his command, his speech-act of a threat is designed to restore the situation to a particular course. Failing this, Chanu can, of course, resort to violence. However, there are established steps before that extreme point is reached. That is, there are speech-act options to which one can resort to ensure that the family saga will run its prescribed course.

On another occasion, Chanu comes home with a surprise gift, which excites much interest on the part of Nazneen and the girls.

"Don't I always do as you ask? I got it." He beamed at Nazneen. The girls stuck their heads out from the bathroom. "Come on," he called to them. "See 
what I have got for your mother." [...] "You know, when I married your mother I thought I was getting a simple girl from the village and she would give me no trouble." He was playing the fool for them. Rolling his eyes and puffing his cheeks. "But she is the boss woman now. Anything she says, your father goes running off and does it...

As it turns out, Chanu has managed to buy a computer and a sewing machine. As he sets these up, he declares before his daughters, "It is lucky for your mother that I am an educated man" (ibid). Chanu's favorite speech-act is again uttered with total obliviousness to his wife, but is this time directed toward his daughters. Just as he was oblivious to his wife's reaction, so too is he oblivious to his daughters' reaction. Unlike Nazneen, though, Shahana and Bibi have inherited different cultural values, leading them to question the indifference and general lack of awareness with which Chanu interacts with them. "If Shahana had been a boy, would it be different? Bibi he barely noticed. He talked to her, but how surprised he would be if answers started coming back" (137). Chanu's recursive utterance is again directed toward an imaginary audience, which he superimposes on whichever family member happens to be nearby and willing to indulge him. Its felicity rests on their passivity.

In another incident, Chanu reveals to his family the wonders of the Internet, inviting them to suggest some keywords to be entered into a search engine. He speaks with his standard pedagogical tone, as though his family were entirely ignorant of what has by now become household knowledge. To this, Shahana retorts in English that both daughters go online at school, a remark clearly intended to undermine Chanu's sense of intellectual complacency. She further expresses her absolute lack of interest by declaring that a Bengali website Chanu has just brought up is, "Bor-ing" (143). Chanu then brings up another Bengali website and asks, "Who wants to take a look?" Although fully aware 
that Shahana has no interest, he is determined to bring about a certain perlocutionary effect, namely, Shahana's going up to the monitor, even against her will, to observe whatever website he has brought up. Chanu's goal is not to inspire any interest in his daughter, but merely to exert his authority over her, even if through the guise of a tempting offer that everyone knows is feigned. What he performs is the speech-act of a command in the form of an offer. When Shahana refuses to comply with her father's will, rendering his command infelicitous, Chanu reacts with an uncontrollable outburst of fury.

The regularity of such speech-acts is a telling commentary on the role Chanu plays within his family. While he perpetually seeks to secure for himself a respectable status from the rest of the community, he concurrently strives to maintain some basic sense of status and self-worth in his own home. The authoritative Bengali husband and father was, after all, the role into which he had been drafted and which he is determined to fulfill. Hence, his seemingly random and curious speech-acts, which function as veiled expressions of commands and threats aimed at exerting his will. It is Shahana's refusal to indulge her father that not only renders his commands infelicitous, but also, by exciting his fury, reveals the central importance of such commands to Chanu's identity. For an infelicitous command is tantamount to the undermining of that identity.

However, not all of Chanu's commands, veiled or explicit, go infelicitous. When Shahana does not have it within her to challenge his will, for even the memsahib herself is given every now and then to periodic moments of fatalism and resignation, she is made to perform such degrading tasks as fetching Chanu's slippers, even though they are a few feet away, and then putting them on his feet, which he lifts for her in a lordly manner. 
Chanu gives his daughters tasks for the sake of giving them tasks, for nothing more than to instill in them a sense of duty and respect. Respect for one's parents, much like respect for one's husband, is a central virtue in the Bengali family, even if that respect must be forced out of unwilling children who feel no genuine respect in the first place. It is precisely because sincerity is not an intrinsic property of commands that, when issued by Chanu, they assume a highly performative function.

When Chanu decides—and is it only Chanu who could decide—to take the family on a sightseeing tour of London, he forewarns the girls of the requirement that they enjoy themselves. At one point during the tour, he asks them, "How do you like your holiday so far?" (210). Given Chanu's requirement that his daughters enjoy themselves, it is curious that he should ask such a question. The following is Searle's analysis of the speech-act of questioning:

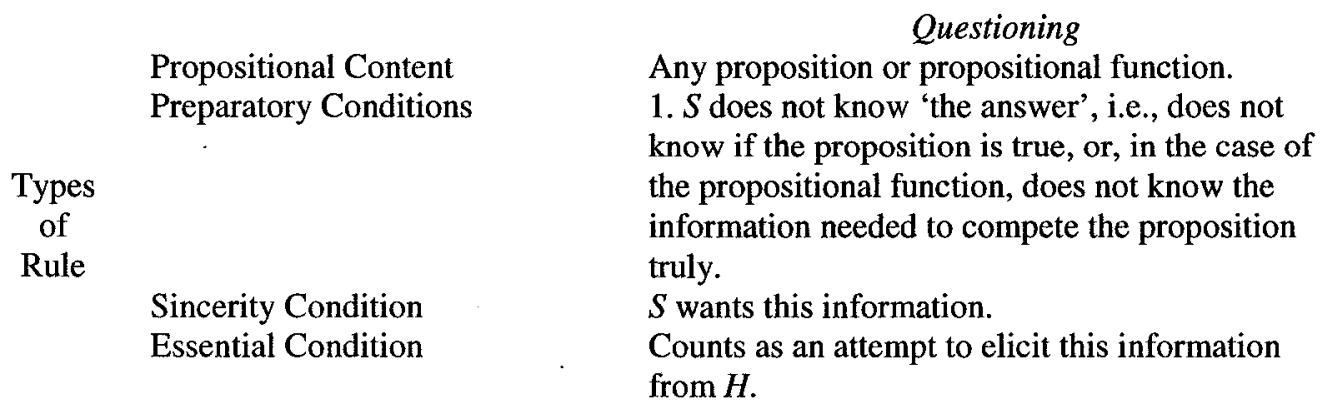

(Searle, 1969: 66)

Unlike commands, one of the felicity conditions for the speech-act of questioning entails that the listener perceives sincerity on the part of the speaker. A question is not a question if the speaker is not sincerely seeking information. Chanu is, of course, not seeking any information. His question functions as the speech-act of a threat, designed to yield a certain response from his children. It is tantamount to guaranteeing the answer in advance. For anything other than the correct answer would quite predictably excite 
Chanu's ire. Precisely because sincerity is missing from his utterance, what appears to be a question again serves a purely performative function. It serves as yet another tool to ensure that the family saga will run its proper course.

\section{E. Fatalism}

Perhaps the most prominent theme of Brick Lane is the fatalistic mindset that plagues the Bengali community generally. The opening quote of the present chapter starkly illustrates the sort of defeatist mentality inherited not only by Nazneen, but by Bengali women and men generally. These women and men are the unwitting heirs of a traditional system of fixed social roles, out of which they are given no hope or expectation of escape. Nazneen performs her duties without demur precisely because to do otherwise would be entirely beyond the realm of possibilities afforded by her social role. Worse, though, her imprisonment within that role is solidified by her religious beliefs, according to which every outcome is the result of the will of God. To assert one's will is tantamount to challenging God himself - the most egregious kind of transgression and one that inevitably provokes shock and offense in the community. The powerful, if often latent, current of fatalism in the social psychology of the community further clarifies the larger structure of expectations of the community and the moral import of certain key speech-acts. Although it would be misleading to suggest that the psychology of fatalism somehow nullifies desire and intentionality, that psychology nonetheless plays a considerable role in influencing practical reason.

Nazneen, for example, rationalizes her very presence in England by a circular appeal to fatalism. She is in England because that is just what happened to her and 
"[a]nyone else, therefore, was here for the same reason" (47). She rationalizes the boredom and meaningless of housewifery by insisting that all she can do is to sit and wait, though for what she does not know. She rationalizes all her troubles by invoking the principle of fatalism to account for her past. She interprets her arranged marriage to Chanu-the diminutive, balding man of grotesque habits and unexceptional character, for whom no woman could rightly feel much pride or enthusiasm—as a scheme devised by her father to get rid of her. "He just wanted to be rid of me, she thought. He wanted me to go far away, so that I would not be any trouble to him. He did not care who took me off his hands. If I had known what this marriage would be, what this man would be...!" (69; italics in the original). Nazneen is not able to actually contemplate an alternative to this if-then scenario, for she remains trapped within a fatalistic narrative in which misery and suffering are the ultimate telos to which her life is ultimately oriented. When she finds herself in a deeply troubling situation, Nazneen chooses not to do anything to remedy that situation. "It was her place to sit and wait. Even if the tornado was heading directly towards her. For her, there was nothing else to be done. Nothing else that God wanted her to do. Most of the time she did not want to run, but neither did she want to sit still. How difficult it was, this business of sitting still" (69-70).

Nazneen recalls how, as a child, she learned this defeatist mentality from her mother's many stern and dispiriting lessons about the role of women. Nazneen's father, for example, would disappear for several days at a time and for reasons that were never made known. When Nazneen once inquired into her father's whereabouts, her mother became instantly troubled. "Look! Now my child is asking where he goes" (53). For there are certain things that women are not meant to know and questions they are not 
meant to ask. This point was made in terms so clear and emphatic that Nazneen has since never been able to forget them: "If God wanted us to ask questions, he would have made us men" (ibid). Such attitudes her mother was apt to repeatedly instill in her daughter. Nazneen was taught that she should not want anything from life. Women should neither ask for anything, nor expect anything. By not asking, they are less likely to be disappointed.

Disappointment, however, was the defining property of her mother's life. Nazneen recalls one occasion in particular, during which she found her mother weeping for no apparent reason. Her mother was often given to similarly inexplicable moments of sadness and suffering. From a distance, Nazneen observed her mother confiding to Auntie Mumtaz, who, being a woman, understood the suffering of women. "We suffer in silence," her mother insisted (70). Nazneen ponders over the possible cause of this suffering, only to discover her mother's conviction that there is no escaping fate:

"We are just women. What can we do?"

"They know it. That's why they act as they do."

"God has made the world this way."

"I told him I will not go back."

"That's what you said."

"If he carries on this way, that's it."

"You said it last time as well."

"What else can I do?"

A young Nazneen, still in the dark concerning the source of her mother's anguish, is driven to the conclusion that the answer lies in her being a woman. She romanticizes the day when she, too, will become a woman and finally discover the wellspring of this mysterious suffering: "She looked forward to that day. She long to be enriched by this hardship, to cast off her childish baggy pants and long shirt and begin to wear this 
suffering that was as rich and layered and deeply colored as the saris that enfolded Amma's troubled bones" (71). Nazneen, of course, is not given the option of choosing her social role, but is, rather, its unwitting heir. The telos to which she believes her life has been fated accounts for the manner in which she interprets her past and anticipates her future. Her actions are intelligible only in the light of her social role, from which her individual personality, largely undeveloped throughout the greater part of the novel, generates little, if any, striking departures. An adequate understanding of this role, then, is impossible without an appreciation of the psychology of fatalism characteristic of not just Nazneen, but also, to varying degrees, the members of the community generally.

The plea, "What else can we do?," is a speech-act oft-repeated throughout the novel by multiple characters, indicating just how effectively the sense of fatalism grips the community. During times of hardship, it becomes a standard refrain to ask, "What else can we do?" Although framed in terms of a question, this speech-act does not conform to Searle's analysis of questioning, for its felicity does not entail that the questioner actually seek any information. Rather, it thrives on the mutual recognition of the futility of challenging a divinely determined course of events. This peculiar speechact is expressed sometimes in the form of a question and sometimes in the form of an assertion, but its illocutionary force and moral import generally remains the same.

Even Chanu himself, who cares not to pray and generally maintains a rather bitter attitude towards dutiful religious observance, is himself often given to the creed of fatalism. However, the specific invocation of this principle does not always constitute the same speech-act and the underlying intentions can vary considerably. When Nazneen implores Chanu to help her sister, Hasina, who has run away from an abusive husband 
and is now living on her own in Dhaka, he at first responds with sarcasm. He asks whether she would like to bring her entire village back to Brick Lane, a cruel remark betraying his contempt for the stereotype of the immigrant. Sensing Nazneen's offense at this remark, Chanu attempts to console her by invoking the creed of fatalism as a normative principle. He argues that, "Sometimes we just have to wait and see. Sometimes that's all we can do" (40). Whereas the creed of fatalism is generally invoked to underscore the futility of challenging what has already been written, fatalism is now invoked to actively thwart and discourage another party's intentions and to absolve oneself of responsibility.

In a later incident, Hasina has written from Dhaka informing Nazneen that she has been taken under the wing of a respectable property owner and is thus safe for the time being. Hasina has expressed much enthusiasm about her promising new situation. Chanu responds to this news by asking, "What did I tell you? Sometimes we must sit and wait" (45). Chanu now invokes the principle of fatalism as a source of encouragement. In yet another incident, Nazneen reveals to Razia that Chanu "cannot accept one single thing in his life but this: that my sister should be left to her fate. Everything else may be altered, but not that." To this, Razia asks, "What can we say against fate?" Nazneen realizes that she cannot challenge fate, for to do so would not only violate her personal beliefs, but also those on which the community as whole rests. "I am not saying anything against it." (46). Hence, notwithstanding its central importance in the community, the creed of fatalism is not given universal and uncritical assent. Both the invocation and acceptance of fate are, formally speaking, speech-acts. What follows are my analyses of invoking and accepting fate, respectively: 


$\begin{array}{cl} & \text { Propositional Content } \\ \text { Types } & \text { Preparatory Conditions } \\ \text { of } & \text { Sincerity Condition } \\ \text { Rule } & \text { Essential Condition }\end{array}$

Propositional Content

Types
of

Rule Sincerity Condition

Essential Condition
Some past, present, or future act, property, quality, etc. $E$ related to $N$.

$N$ accept $E$.

$C$ accepts $E$.

Counts as an expression of acknowledgement or recognition of $E$.

\section{Accepting Fate}

Some past, present, or future act, property, quality, etc. $E$ related to $N$.

$N$ perceives sincerity in $C$.

$N$ accepts of $E$.

Counts as an expression of acknowledgement or recognition of $E$.

Unlike promises and requests, both the invocation and acceptance of fate commit the speaker and the listener to very little except a mutual recognition of the futility of challenging fate. Just as praising requires for its felicity the acceptance of praise, so, too, does the invocation of fate require for its felicity the acceptance of fate. Two remarks are in order here. First, the invocation of fate is liable to be infelicitous if the party to whom it is directed does not perceive sincerity on the part of the speaker. That perception itself derives from an adequate grasp of the speaker's personal history. Without the perception of sincerity, suspicion of the sort Nazneen feels toward her husband is but a liable outcome. Second, despite the perception of sincerity, a speaker's personal history can still have a considerable impact upon the moral import of the invocation of fate, for the invocation of fate can serve to actively thwart a particular course of events. It can be invoked to explain the past, interpret the present, and predict the future, and almost invariably in discouraging terms. So long as Nazneen earnestly surrenders to fate, Chanu has at his disposal a powerful speech-act with which to exert his will and ensure that she conforms to her culturally sanctioned social role. It will be another of Nazneen's 
principal achievements to eventually break free of the social role in which she is imprisoned by fate.

\section{Part Two}

\section{A. Crisis and Disruption}

When their infant son Raqib is struck with a serious illness, Nazneen and Chanu do not hesitate for one moment to take him immediately to the hospital. Raqib remains under intensive care for several days and, during this time, Nazneen virtually loses her grip on reality. She refuses to leave the hospital and Chanu is forced to bring food and other necessities for his wife. Nazneen, whose concern for her son trumps all other family considerations, actually issues commands to Chanu and with a dismissive sense of contempt to boot. Chanu humbly does as he is told and is careful not to aggravate Nazneen in the slightest. His relationship to her in this time of crisis has profoundly changed, indicating just how fragile their respective social roles really are. After the crisis is over, Nazneen returns home with Raqib and rather seamlessly resumes her former role.

Nazneen's transmutation from player to non-player is impelled by her realization that, had she not taken her son to the hospital upon learning of his illness, he would surely have died. Her mother, however, whose practical reason was, for the duration of her life, governed by her unquestioning faith in the will of God, would have foregone the option of taking the baby to the hospital in favor of letting God decide whether he was to live or die. That is, her mother would have dealt with the situation in precisely the same manner in which she had dealt with Nazneen when the latter was herself a baby. 
Utterly horrified by this realization, Nazneen thereafter regards fate in drastically different terms. Her evolving understanding of her own situation, her grasp of her own narrative, is no longer fixed within the rigid teleological framework to which she had previously given her unquestioning allegiance. Contrary to the inherited role she now inhabits, Nazneen acquires something strikingly anomalous for a woman in her situation: a cynical and skeptical attitude toward fate. Given the central importance of fate in the worldview of Nazneen's community, it is a rather telling development when one of the community's least likely members throws into question one of the foundational moral pillars on which the community rests. Nazneen, in effect, undergoes a volte-face, after which she will never be the same.

While pondering over the determination with which she had saved her child-a determination her mother would have considered a blasphemous affront to the will of God—Nazneen begins to notice in the very simplest of actions that fate is not what she had formerly thought it to be. Fate is not a binding force that thwarts her own will, her own desire and intention. She notices in the act of drawing on a notepad that she can, in fact, do as she wills. "I move my pen. This way. That way. Began an elephant and turned the back legs to a horse. Nobody else here. Nobody else moving this pen" (100). The discovery of the power of her own will begins a transformation in her practical reason, which, in time, will no longer be contained by the established conventions. Although no utterance or action can derive from pure individual will—for the will requires for its expression conventions of one kind or another-it is imperative to now be attuned to the degree to which Nazneen's personal will plays an increasingly significant role in the determination of the meaning of her speech-acts. 
The exercise of her personal will, however, is a strange and confounding experience. She does not immediately acquire a grasp of how to interpret the world around her in a coherent and unified sense, at least now that she has allowed the germ of individuality and self-determination to sprout within her. Nazneen at first interprets the death of Razia's husband as her own fault for saving her baby's life: "Raqib was meant to die, but she had forced Death away. Death was forced to choose again. 'Be gone from me!' she shouted. 'Be gone! Back to hell, where you belong.' And with these words, banished the jinni that had danced, briefly, spitefully, through the room and into her head" (101). Thus, the genesis of individuality is already thwarted by oppressive feelings of fear. $^{20}$

The emotion of fear is complemented by that of guilt, the manipulation of which also functions as an effective mechanism of social control and supplements the invocation of fatalism to uphold the social roles constitutive of the community. Nazneen's growing discontent toward the community may go unnoticed by others, but it cannot escape her own conscience, which returns with a vengeance to haunt her and ensure that she purges herself of symbolic acts of defiance. In one scene, after having suffered doubts about the moral correctness of questioning fate, she interprets the fumes emitted by a public bus as guilt-cum-punishment:

...there was this shapeless, nameless thing that crawled across her shoulders and nested in her hair and poisoned her lungs, that made her both restless and listless. What do you want with me? she asked it. What do you want? it hissed back. She asked it to leave her alone but it would not. She pretended not to hear, but it got louder. She made bargains with it. No more eating in the middle of the night. No more dreaming of ice, and blades, and spangles. No more missed prayers. No

\footnotetext{
${ }^{20}$ As it turns out Raqib, does later die, though this does not prove to be a setback to Nazneen's transmutation out of a fatalistic mindset. For the purposes of the present analysis, his death does bear any significance.
} 
more disrespect to my husband. She offered all these things for it to leave her. It listened quickly, and then burrowed deep into her internal organs.

Intermittent punishment by guilt indicates that Nazneen is still very much a player, as her moral conscience, however much at odds it may stand against the larger community, is still parasitic upon that community for the management and understanding of her moral experience. There are, in fact, certain speech-acts whose illocutionary force thrives on certain emotions, guilt being among them. It is precisely because guilt is an object of manipulation that certain of Mrs. Islam's speech-acts are virtually guaranteed to be felicitous.

The above point is all the more significant to bear in mind given MacIntyre's shrewd observation that "[i]n every culture emotions and desires are norm-governed" and that " a particular type or degree of emotional reaction or of aspiration to fulfill a desire is justified in such and such a range of situations when exhibited by such and such a type of person filling such and such a particular type of social role" (1988: 76; emphasis in the original). ${ }^{21}$ Although MacIntyre is not here specifically referring to guilt, it should nonetheless be observed how remarkably well guilt fits this description. It greatly illuminates our understanding of speech-acts and their relation to the emotions. For it is only when Nazneen regards herself as bound by fate to fulfill her role as the passive, submissive, and utterly unobtrusive housewife that guilt maintains such a powerful grip on her conscience. When she eventually transmutes into a non-player, that is, when she effectively escapes the social role into which she had originally been drafted, guilt ceases to imprison her. It is at that point that those speech-acts that prey upon guilt for their

\footnotetext{
${ }^{21}$ For a similar elaboration of this point, see Martha Nussbaum's chapter, "Emotions and Human Societies," in Nussbaum, 2001: 139-173.
} 
felicity lose their illocutionary force. That she should become immune to the force of such speech-acts will be an indication that she has managed to overcome guilt, or at least to have reconstituted her emotions in such a way that they are not governed by the norms of the community. For the moment, however, her emotions are structured such as to render her a community member who can still be manipulated by the likes of Chanu and Mrs. Islam through their signature speech-acts.

\section{B. Restoration of Order}

Despite the time that has passed since the death of Raqib, Nazneen still conforms to her duties as a housewife. In the evenings, for instance, she clips the hair from her husband's nose. When Chanu issues his threats and commands to his daughters, when he beats Shahana with whatever object is within immediate reach, Nazneen does nothing but quietly sympathize with the girls and wait until the violence is over. She emits no sign of protest against these beatings, accepting them for the moment as conventional conduct that she and her children must patiently endure. As Nazneen cuts his corns, Chanu talks of his plan to take the girls back to Bangladesh, where they might be saved from the cultural impurities of British society. Nazneen evinces a regression back to her former attitude of submission to fate: "They would go. Or they would stay. Only God would keep them or send them. Nazneen knew her part, had learned it long ago, and rolled the dead skin around in her palm and sat quietly, waiting for the feelings to pass" (130).

When her sister Hasina's situation again becomes precarious, Nazneen implores her husband to consider bringing her to England. Chanu responds again with sarcasm and derision, invoking as before the insulting image of bringing Nazneen's entire village 
to England. In an effort to protect Hasina's honour, Nazneen has so far refrained from disclosing to her husband the shameful situation in which her sister has plunged. All Nazneen can emphasize before Chanu is the seriousness of Hasina's situation, though without delving into any actual detail. When Nazneen realizes the futility of her efforts, Chanu asserts, with stern authority, his plans for the family. "We are going there. I have decided. And when I decide something, it is done" (130; emphasis in the original). What Chanu issues is not so much an assertion, but what in speech-act theory is classified as a declarative utterance. The following are speech-act analyses of asserting (Searle's) and declaring (mine):

$\begin{array}{cl} & \begin{array}{l}\text { Propositional Content } \\ \text { Pypes } \\ \text { of } \\ \text { Rule }\end{array} \\ & \begin{array}{l}\text { Sincerity Condition } \\ \text { Essential Condition }\end{array}\end{array}$

$\begin{array}{cl} & \begin{array}{l}\text { Propositional Content } \\ \text { Types } \\ \text { of } \\ \text { Rule }\end{array} \\ & \begin{array}{l}\text { Sincerity Condition } \\ \text { Essential Condition }\end{array}\end{array}$

\section{Asserting, Affirming, Stating (that)} Any proposition $p$.

1. $C$ has evidence (reasons, etc.) for the truth of $p$. 2. It is not obvious to both $C$ and $N$ that $N$ knows (does not too to be reminded of, etc.) $p$. $C$ believes $p$. Counts as an undertaking to the effect that $p$ represents an actual state of affairs.

(Searle, 1969: 66)

\section{Declaration}

Any proposition $p$.

1. $C$ has evidence (reasons, etc.) for the truth of $p$. 2. It is not obvious to both $C$ and $N$ that $N$ knows (does not too to be reminded of, etc.) $p$. $C$ believes $p$. Counts as an undertaking to the effect that $C$ produces an actual state of affairs.

As will be discussed in more detail in the subsequent chapter, the difference between an assertion and a declarative lies in their respective essential conditions. An assertion is felicitous insofar as its performance represents an actual state of affairs. However, a declarative is felicitous in so far as its performance produces an actual state of affairs. The illocutionary force of a declarative, of course, rests on the station of the speaker. Some people can produce a certain state of affairs, while others cannot. By virtue of the 
power accorded to him by tradition, Chanu can issue declaratives and thus to produce a certain reality. In this case, he produces a state of affairs against which Nazneen is all but powerless.

\section{Discovery of alternative social roles}

We learn that Nazneen acquires her understanding of life beyond the community through "[t]he television, the brief exchanges at the few non-Bengali shops she entered, the dentist, the doctor, and teachers at the girls' schools" (ibid). However, Nazneen's greatest sources of information about the world beyond her community are her own daughters, who "demanded to be understood" (ibid). Nazneen is forced to appreciate their starkly different attitudes, which they have acquired from school, among other sources. It is through her interaction with them that Nazneen's develops an appreciation for a worldview other than the one in which she had been raised. The more she learns of life beyond the community, the greater her realization of the limitations of her own worldview.

On one occasion, Nazneen comes to discover the different lives she could lead, if only she were free of the limitations imposed on her by inherited social role. Staring in the mirror while dressed in an elegant sari, she realizes that her dress is what defines her and imprisons her in a certain identity:

Suddenly, she was gripped by the idea that if she changed her clothes her entire life would change as well. If she wore a skirt and a jacket and a pair of high heels, then what else would she do but walk around the glass palaces of Bishopgate and talk into a slim phone and eat lunch out of a paper bag? If she wore trousers and underwear, like the girl with the big camera on Brick Lane, then she would roam the streets fearless and proud. And if she had a tiny, tiny 
skirt with knickers to match and a tight brown top, then she would-how could she not?-skate through life with a sparkling smile....

The utter ephemerality of her identity had never struck Nazneen in quite this way before. Her role was one out of which there was initially no hope or even idea of escape. The realization that she could enter into a new life just as easily as changing her clothes manages to deal a further blow to that sense of fatalism that had hitherto governed her life. "For a glorious moment it was clear that clothes, not fate, made her life. And if the moment had lasted she would have ripped the sari off and torn it to shreds" (201). The sari is no longer a mere item of clothing she can take for granted. For Nazneen, the sari now has meaning; it signifies and represents a cultural identity, replete with prescriptions and proscriptions for behavior, thought, and feeling. Although this moment of enlightenment does not last, it marks yet another step in the evolution of her selfhood and reveals a great deal about the cultural tradition to which she had been an unwitting heir.

In another incident, Nazneen notices that even the way one walks can define who one is. In a subway station, she notices a "young woman in high-heeled boots and jeans, a denim jacket pegged on her fingers and slung over her shoulder" (334). Nazneen becomes fascinated by the manner in which this woman's "footsteps rang like declarations" (ibid). She ponders the significance of something so seemingly banal and ordinary as the manner in which one walks. "How much could it say? One step in front of the other. Could it say, I am this and I am not this? Could a walk tell lies? Could it change you?" (ibid). Much like dress, the manner in which one walks reveals for Nazneen both the ephemerality of one's identity and the ease with which one could shift from one identity to another. This observation further emboldens her suspicion that 
attitudes are inextricably woven into social roles and that to escape the submissive attitudes to which she had become accustomed, she would have to escape the social role in which she is currently imprisoned.

\section{Coercion and Control}

When Mrs. Islam decides to pay a surprise visit, Chanu is naturally delighted, given his preoccupation with respectability and good company. This time, Mrs. Islam appears in an affected state of failing health, as revealed by her dramatic application of various medications and her equally dramatic expressions of hardship and suffering. When Mrs. Islam inquires into whether Nazneen will be sending her girls to a local Islamic school, which in this case has been established by a charitable endowment from Mrs. Islam herself, Nazneen insists that she will in fact be sending her girls. To this, Mrs. Islam replies, "I am a sick woman now. Very, very sick. Anyone can say anything to me. They know how weak I have become. You tell me, 'Yes, they will go,' but you do not send them. But to sick old women it is possible to say anything." The following is my analysis of reproaching:

$\begin{array}{cl}\text { Types } & \text { Propositional Content } \\ \text { of } & \text { Preparatory Conditions } \\ \text { Rule } & \text { Sincerity Condition } \\ & \text { Essential Condition }\end{array}$

\section{Reproaching}

Some past, present, or future act $E$ related to $N$. $E$ reflects negatively on $N$ and $N$ would not like to be associated with $E$.

Both $M$ and $N$ value $E$ negative.

Counts as a negative evaluation of $N$.

Reproaching is, of course, distinct from censuring in its essential condition. While the latter produces a state of affairs, the former does not. There is no perlocutionary effect in the act of reproaching. As a speech-act, however, the felicity of reproaching thrives on 
the emotion of guilt. Insofar as Nazneen is immersed in her social role, Mrs. Islam is thus able to force a certain course of events.

Chanu had, in the past, expressed his utter disgust at the very idea of sending his girls to an Islamic school. "Do they call it an education? Rocking around like little parrots on a perch, reciting words they do not understand" (140). However, in the presence of Mrs. Islam, he betrays a very different attitude. "Yes, my wife will send them. I remember your husband. He was the most respectable-type man. One time we thought of doing some business. Jute industry. Import-export sort of affair" (140). This attempt at one of his signature speech-acts, however, goes infelicitous. Mrs. Islam has little interest in indulging Chanu, whose sycophancy only manages to further entrench his subordinate status. Before Nazneen can amend the situation by giving her assurance that she will send her daughters, Mrs. Islam interjects with a very noteworthy remark:

You do as you please. I tell my sons-Mrs. Ahmed [Nazneen] always does as she pleases, I don't interfere. I tried to look after her son, loved that child like my own, but she slapped me down and I don't interfere. [...] Only I can tell you this. A sick woman still has ears. If you think I have gone deaf, let me tell you my ears are good. I hear what goes on.

Had Razia been the one to remark about still having ears, it would have constituted a warning, especially given her lowly status. Razia cannot be said to wield the power to destroy anyone's standing, as she herself has no standing. Mrs. Islam, however, holds one of the highest community stations and wields the power to destroy the standing of others. From her standpoint in the present situation, her words thus constitute a threat. The difference again lies in the essential condition. A warning counts as an undertaking in so far as a future event or state of affairs is not in a party's best interest. However, a threat counts as an undertaking to the effect that a party is actually moved to bring about 
a particular event or state of affairs. There is no evidence that Mrs. Islam is concerned with Nazneen's best interests.

Mrs. Islam's periodic visits are later impelled by other, more serious motives. Much to her dismay, Nazneen discovers that Chanu had purchased the computer and the sewing machine through a loan from Mrs. Islam. Chanu has since put Nazneen to work on the sewing machine, which preoccupies her for a good portion of her waking hours. She receives orders in her home from a local garment factory, which employs unskilled and otherwise unemployable immigrant women for meager pay. However, the money Nazneen earns she is not allowed to keep. Chanu saves it all for the trip home, leaving nothing for Nazneen except that which she surreptitiously keeps for herself. Worse, though, a good portion of the money she works so hard to earn is needed to repay Chanu's debt to Mrs. Islam.

Each time Mrs. Islam drops by to collect her money, Nazneen has little choice but to comply and hand over a portion of what she has been saving to the matriarch. The situation is not one of Nazneen's design, of course. It was not her decision to have borrowed money in the first place. Yet, Mrs. Islam regards Nazneen as bound to her husband and to the community. Mrs. Islam therefore claims certain rights over Nazneen, to whom she can issue threats and commands with increasing illocutionary force.

Despite her growing sense of aversion for Mrs. Islam, Nazneen nonetheless treats her with the respect due to an elder. That Nazneen is an adult, with children of her own, is immaterial to Mrs. Islam and immaterial to the illocutionary game through which they interact with one another. When Mrs. Islam refers to Nazneen as a child, to whom she can confer words of wisdom and admonition, Nazneen must accept her designation and at 
least put on the appearance of listening patiently and respectfully. When Nazneen insists that she, too, is showing signs of aging, Mrs. Islam brushes the remark aside, declaring that Nazneen is "just a child." Mrs. Islam can even refer to Nazneen as a "good girl" for fetching her medicine. That Nazneen should choose to endure such humiliating treatment-humiliating for her, since she has grown increasingly disaffected with her inherited social role and with their moral culture, generally—is testimony that she is still a community player.

On another occasion, Nazneen runs into Mrs. Islam at a halal meat shop. At first, she has the impulse to evade the matriarch. However, upon realizing that evasion is out of the question, Nazneen decides to straightforwardly greet Mrs. Islam according to the established customs. She intends to render this encounter as normal as possible by appealing to the existing stock of speech-acts definitive of polite and friendly encounters. She thus extends a greeting and inquires into Mrs. Islam's health. Mrs. Islam, however, dismissively brushes that greeting aside: "Ah, to be young again and walk around in a dream" (312). For Mrs. Islam is fully aware that Nazneen is engaging in mere formalities and not expressing a genuine curiosity for her failing health. When Nazneen attempts again to steer the encounter toward something more polite and friendly, this time by complimenting Mrs. Islam on her appearance, she is disappointed. Twice now, Nazneen's speech-acts were infelicitous. Mrs. Islam's bluntness is such as to provoke her own desired illocutionary effect, namely, to make it clear to Nazneen that she is not going to indulge in petty formalities and that there is a very serious matter at hand. This effect Mrs. Islam can bring about by virtue of the power she retains to establish the rules of interaction. Being not only the younger party, but also a debtor, Nazneen has no 
choice but to submit to those rules. However much she may betray her growing dislike for the old woman, Nazneen's submission is evidence she is still bound by the latter's authority.

That authority is further established in two ways. First, Mrs. Islam reveals that Chanu has taken yet another loan from one Dr. Azad to pay for the trip home. Thus, Mrs. Islam indirectly reveals just how well informed she is of the secrets of the community. Even Nazneen was unaware that Chanu had sought additional financial relief. Second, she presses Nazneen to pay her debts. When Nazneen objects, insisting that " $[\mathrm{w}] \mathrm{hatever}$ we give, it's not enough," Mrs. Islam invokes a distinctly religious principle: “God always provides a way. [...] You just have to find it" (313). The will of God is thus invoked this time as a threat.

\section{E. Evolution of Selfhood}

Nazneen realizes that Chanu's decision to take the entire family back to Bangladesh will be a monumental test, not only for their daughters, but also for Nazneen herself. It is a test of Chanu's authority, which, as stated before, is constitutive of his identity. He is not, however, taking his family back merely to exercise that authority. He has genuine reasons for his decision, which concern his daughters' increasing disaffection with Bengali tradition and the widespread drug and alcohol addiction among the youth of the community. His decision will come as a big test for Nazneen, however, given that her personal narrative has been evolving in an unorthodox direction. This much Nazneen understands rather starkly when she takes stock of her recent past and comes to grips with the reality of her adultery. 
Nazneen is, at first, able to carry on her adulterous affair without much trouble to her conscience. She is only slightly aware of her infidelity when she changes the sheets afterwards. Otherwise, she tries earnestly to fulfill her social role as the ever-dutiful Bengali housewife, even going so far as to convince herself and her daughters that Chanu is a man of integrity and great learning, entirely worthy of respect and admiration. She is able to lead a double life rather seamlessly, at least until the sense of sin she has until now been repressing returns with a vengeance.

During one sleepless night, she decides to wash some clothes in the kitchen sink. At first, she remembers something Mrs. Islam had told her concerning the benefit of rubbing one's temples so as to avoid tension. Nazneen then thinks that she has not been experiencing enough tension and that she has been neglecting her family. But with the sudden thought of her infidelity, she is overpowered by the horrifying realization of the enormity of her behavior, upon which she becomes violently ill. Her mother's voice returns to haunt her, imploring her never to forget that, "God sees everything. He knows every hair on your head" (235). The voice that had played so decisive a role in shaping Nazneen's worldview now stands as a barrier to the new direction in which she has been leading her life. The conflict between her personal narrative and the social role into which she had been drafted is taking a devastating toll.

Although she recovers from her breakdown, Nazneen does not return to her former self. She is struck every now and then with the impulse to attend to some duty, but cannot be bothered to think of what actually needs to be done. When she turns to the Qur'an for guidance, it no longer speaks to her. "She looked for familiar passages, the words that she knew would give comfort. In her panic, she could find none and the 
words on the page kept her out, hid their meanings and pushed her away" (243).

Nazneen thus becomes estranged from the spiritual foundation of her worldview.

Chanu and the girls, who are not aware of Nazneen's infidelity, worry a great deal about her condition. She has been given orders from the doctor to rest, but insists on getting up and being productive. When she eventually drifts back into her routine of cooking and cleaning, she feels like something of a ghost, with only a memory of her past, but without any sense of immanence in her social role. She has, as it were, become alienated from her former, faithful self. That much is confirmed when she acknowledges the irreversible damage she has incurred upon her soul. "Whatever I have done is done. [...] Now I have earned myself a place in hell for all eternity. That much is settled. At least it is settled. [...] A degree or two hotter, a year or two more or less. What does it matter? Good. That's it, then. That is it" (250). Now that she believes she will burn in hell, Nazneen no longer feels morally compelled to carry out her prescribed duties.

When Chanu attempts to perform his signature speech-acts, they go infelicitous. In response, Chanu self-assuredly insists upon some readily classifiable and morally acceptable reading of the situation:

"She doesn't seem to be listening."

"Oh, she is," said Nazneen, "she's listening. But she is not obeying." Chanu smiled unexpectedly, waiting for the joke to be explained. The smile lingered awhile around his lips, while his eyes scanned her face and then the room, looking for clues, for changes.

Nazneen's utterance, which does not conform to any of the dominant conventions, is simply baffling for Chanu. As mentioned earlier, a wife could, under ordinary circumstances, be very harshly chastised, if not violently beaten, for disobeying their husbands. However, Nazneen's inexplicably blasé pronouncement of disobedience does 
not excite Chanu's wrath. Instead, he finds himself concerned, without any memory of a precedent with which he might maneuver his way through a very awkward situation. Her behavior does not fit within any of the legitimate moves in their established language game. It cannot be regarded as an infelicitous speech-act, since there are no felicity conditions under which a wife can felicitously declare her disobedience. Chanu's immediate instinct is to interpret her pronouncement as a joke, thus reflecting his uneasiness over having to revise his understanding of his own wife. It is his attempt to conceive of some broader narrative context in which he can locate her utterance and thus render it intelligible. If he were successful, he would, at the very least, have rendered the situation manageable and have some idea of where he stands in this new and unprecedented situation. As it turns out, however, Nazneen was not joking and Chanu, who is at a total loss to understand what has just taken place, attempts to escape the situation by returning to a role in which he is most at home: "All right, then," he said, after a while. "I have some reading to do. Shahana! Bibi! Quick. Who is going to turn the pages for me?"' (ibid).

When Nazneen played within the rules, when even her violations of normative conduct conformed to the existing stock of recognized violations, she was dealt with according to the existing stock of culturally sanctioned mechanisms of punishment and control. However, when her violations did not conform to the existing stock of recognized violations, that is, when her behavior could not even be understood to be violations at all, despite their failure to conform to the rules of normative conduct, the existing mechanisms of punishment curiously seemed no longer to apply. Chanu finds himself helpless before Nazneen's unusual behavior. His own social role becomes 
terribly confused and badly lacking in direction. Contrary to his authoritarian temperament, he is reduced to a state of helplessness, submission, fear, and concern, precisely the state into which he had formerly been plunged during Raqib's illness. We are thus given an insight into the curious limitations of Nazneen and Chanu's social roles, of what it would take to dismantle their illocutionary game from the inside.

Nazneen is, moreover, not just disobedient before Chanu, but now begins giving him orders. When Shahana unexpectedly asks if she can attend a local Muslim celebration, Chanu is outraged at the suggestion and forbids her from attending, threatening to beat the memsahib "to a bloody pulp," such that "[b]ody parts will not be identifiable" (256). Nazneen interjects, declaring that Shahana can indeed go and that Chanu should watch what he says before such a small girl. She in effect issues a command. To this, both Chanu and the memsahib are baffled. Nazneen's command defies explanation and Chanu and Shahana look to each other smilingly, acknowledging each other's bafflement, which is again indicative of the fragility of their social roles.

When Chanu later engages in one of his signature moments of self-indulgent pedantry, gleefully declaring that Bangladesh is statistically ranked as the happiest nation on earth, Nazneen challenges him on this claim. Chanu is again baffled before his wife, pointing in defense to the facts reported in the published study from which he drew his claim. Nazneen expresses her total contempt for the report, arguing that the tribulations suffered by her sister in Bangladesh, who has been forced into prostitution just to feed herself, are proof that Bangladesh is certainly not the happiest nation on earth. Whereas Chanu had before cruelly mocked the idea of bringing Nazneen's sister to England, he 
now reverses his attitude and vows to "make a plan" (258). The following analysis is based on Searle's elaborate discussion of promising:

\begin{tabular}{cll} 
& Propositional Content & \multicolumn{1}{c}{ Promising } \\
Preparatory Conditions & Any proposition $p$ concerning future act $A$ by $C$. \\
Types & & 1. It is not obvious to both $C$ and $N$ that $C$ will do \\
of & $A$ in the normal course of events. \\
Rule & Sincerity Condition & $C$. $N$ would prefer $C$ 's doing $A$ to his not $\operatorname{doing} A$. \\
& Essential Condition & $\begin{array}{l}C \text { intends to do } A . \\
\text { Counts as an undertaking to the effect that } C \\
\text { incurs the obligation to do } A .\end{array}$
\end{tabular}

(Searle, 1969: 57-61)

This is not, of course, a vow "made by elliptical turns of phrase, hints, metaphors, etc." (Searle, 1969: 55-56). Rather, it is a quite explicit and even categorical undertaking. A few remarks are in order here. First, given the dominant belief that the assertion of one's will is not only futile but also sacrilegious, as was perhaps best exemplified by Chanu's own invocation of fate to absolve himself of any responsibility toward Nazneen's sister, it is extraordinary that he should now issue a promise to take precisely that responsibility. Promising is a highly unusual move in this speech-act community. It is a personal testimony to the power of human agency to bring about a future outcome, thereby superseding the power of fate. There are, of course, insincere promises, the sort of speech-acts whose propositional content is not supported by the incurrence of an actual obligation. Such insincere promises, much like insincere questions, hold only performative value and serve as veiled expressions of still other speech-acts. Unlike his duplicitous and self-serving invocation of fate, however, Chanu is actually sincere in his promise. Although he alone still has the power to get things done in their family, he finds himself for the first time in his life basing a major decision upon the authority of his wife. Sincere though he might have been, though, Chanu later reneges on his promise. He notices that Nazneen is again shifting back into her previous self. He therefore 
supposes that her unusual recent behavior was only the consequence of her illness, from which he expects she will sooner or later fully recover. This much is confirmed when Nazneen cuts his corns and his nose hairs again, leading Chanu to conclude out loud, "She is feeling better" (269). His words function as a declarative to the effect that matters have returned to normal. That is, Chanu produces a state of affairs in which both parties are restored to their previous roles. And if this is indeed the case, he no longer has to worry about fulfilling his commitment to do something about Nazneen's sister. Chanu attempts to maneuver back to the ordinary, predictable life to which he was accustomed and which he most prefers.

When counting the money he and Nazneen have been saving up for the trip back to Bangladesh, Chanu declares that "a wife does not keep anything from her husband" (272), prompting Nazneen to retrieve some extra money from a hiding place in the apartment. Chanu's utterance is, of course, not a mere description of a moral ideal. In this context, it functions as a command. Although it may not exert quite the same illocutionary force as it once had, it is still a legitimate move in their illocutionary game. That Nazneen should act so as to render Chanu's command felicitous is thus evidence that she is still, despite her recent history, predisposed to be a player. Although he is not totally indifferent to her feelings, as is apparent by his inquiring into whether she is happy to be going back to Bangladesh, he feels comfortable telling her how she really feels. "But of course you want to go. [...] What kind of sister would you be if you did not? Of course you want to go" (274). However baffled he might have been over her recent behavior, Chanu now feels confident that she is under his authority once again. He 
believes he has effectively domesticated his wife under an intelligible and therefore manageable narrative.

\section{F. Exclusion from the community}

Nazneen eventually develops a growing sense of her exclusion from the community; of her transmutation from a player to a non-player. She tells Razia, the untouchable of the community, of her adultery. She confirms that everything Razia might have suspected is really true. This secret Nazneen had confided on the assumption that Razia could be trusted, given her lowly status and her own embarrassing family problems. However, Nazneen cannot be sure that others have not discovered her shameful secret. When several of the housewives visit the markets as a group, Nazneen notices that two of her closest friends, Nazma and Sorupa, ignore her completely. This prompts her to consider whether she might have become the victim of community gossip:

At the time she had not realized it, but none of the women had spoken to her. Had it been deliberate? Would she find that people hurried past her in the street? [...] Only recently Hanufa had been frozen out when it was discovered she had been attending a massage course. It was un-Islamic behavior and, apparently, the imam at the Jamme Masjid had preached against that very thing.

The most extreme consequence of gossip, then, is exclusion from the community. To be a player, one must have a basic public record of conformity to a certain pattern of normative conduct. Adultery is obviously a grave breach of that pattern of conduct, next to which Hanufa's own misdeeds, if misdeeds they indeed were, pale by comparison.

Nazneen is thus justified in suspecting that she is being deliberately snubbed. Nazma and Sorupa's snubbing can be read as a speech-act in itself, even though nothing in particular 
was explicitly said. That is, their egregious silence constitutes an intelligible move in their illocutionary game. That Nazneen should instinctively turn to the existing stock of illocutionary acts from which to derive an interpretation of their behavior is an indication that such behavior is indeed a legitimate move. Snubbing is consciously performed to bring about what Searle refers to as an illocutionary effect; in this case, that the receiver of the message should register in her mind that she is now a pariah, an exile, and no longer a member of the community. The refusal to greet Nazneen is a sign that the bottom line of civility conferred upon even disreputable members no longer applies. There is no perlocutionary effect. So long as Nazneen has registered the message, there is nothing she can do to render it infelicitous. She is powerless against it.

\section{G. Incommensurability and Narrative Rupture}

Nazneen's growing sense of discomfort over Chanu's plans to take the entire family back to Bangladesh is aggravated by her ongoing infidelity. Although she had entertained the idea of creating a new life without her husband, even to the extent of "finding out about divorce" (300), Nazneen had not thought carefully and honestly about how to take her future into her own hands. This dilemma generates an endless line of questions that demand answers from a sovereign, independent self, one quite different from that afforded by her traditional social role. The tension reflects an increasing incommensurability between two distinct identities. This becomes quite apparent by her stern affirmation of her autonomy and personal will. Upon unwittingly rubbing her eyes while chopping chilies, the ferocious sensation of pain "unleashed in her an equal ferocity. Suddenly her entire being lit up with anger. I will decide what to do. I will say 
what happens to me. I will be the one. A charge ran through her body and she cried out again, this time out of sheer exhilaration" (301). Although this brief moment of selfaffirmation does not quite sever her allegiance to her original social role, it nonetheless represents a further and decisive step in the development of a self whose yearning for autonomy only sharpens its incompatibility with that role. It had hitherto been none of her business to consider any of life's major decisions, let alone those decisions that constituted a grave breach of traditional norms. The scope of decision-making afforded by her social role is limited only to those petty matters that do not interfere with the incomparably greater authority and jurisdiction accorded by tradition to her husband. Now, however, she has crafted a personal identity whose narrative structure does not accommodate absolute submission to fate and tradition.

\section{H. The Final Moments of Transformation}

When Razia inquires into what exactly Nazneen plans to do about her ongoing infidelity, Nazneen reveals just how serious the situation has become, how profoundly it has altered her understanding of who she is and what she wants out of life. She insists that the whole situation is "too difficult. It is too ridiculous" (319). Razia asks whether this is what she wants, to which Nazneen replies, "Everything goes against it. Family, duty, everything" (ibid). For to pursue one's own path in life, as Razia observes, is "the English style" (ibid). Nazneen finds herself confronting two highly contrasting moral cultures, between which she is finding herself increasingly torn. What is wholly illegitimate according to the one is perfectly acceptable by the moral standards of the other. The two moments that signal Nazneen's final transmutation from player to non- 
player and her decisive challenge to her social role, occurs in incidents involving Mrs. Islam and Chanu, respectively.

On the day prior to the family's scheduled departure for Bangladesh, Nazneen is given a final surprise visit by Mrs. Islam, who has brought along her two notorious sons. These sons are rumored to be involved in all manner of shady activities and have a reputation in the community for intimidation and violence. Such rumors do nothing to tarnish Mrs. Islam's reputation, however. The deeds of men are not counted in the community's moral register in the same manner as those of women. Precisely because they are men, the notorious reputation of Mrs. Islam's sons only serves to instill fear and respect before the matriarch. And now, Mrs. Islam has chosen to exercise her full power to extract from Nazneen a final payment before she and her family leave for Bangladesh.

Mrs. Islam presents a flat sum "to settle the debt" (330). To this, Nazneen has the audacity to challenge Mrs. Islam, insisting that, according to her calculations, the debt has been paid in full, "and some more as well" (331). Mrs. Islam persists with a curious remark: "I am an old woman now. Do as you like. The money is for the [Islamic school], but what does it matter to you? I am an old woman now" (331; emphasis added). On the surface, this remark would seem to appeal to Nazneen's sense of guilt for troubling an old woman. However, the presence of her violent sons makes it clear, to the point of absurdity, that Mrs. Islam is not really expecting pity of any kind. Sincerity is certainly not an intrinsic property of this speech-act. It is a threat expressed in the form of a reproach. When the two sons begin to violently smash up the apartment, Nazneen has the audacity to accuse Mrs. Islam of engaging in usury, a major sin in Islam. For even Mrs. Islam's reputation is liable to be tarnished if she were to become known to the 
community as a usurer. Mrs. Islam is clearly threatened, insulted, and angered by this accusation, asking Nazneen, "Do you think, before God, that I would charge interest? Am I a moneylender? A usurer? Is this how I am repaid for helping a friend in need?" (332). Nazneen does not relent and challenges Mrs. Islam to swear on the Qur'an that she has not charged interest. The one authority that not even Mrs. Islam can challenge is that of the Divine, in this case, a formidable ally, indeed. The only device left to Mrs. Islam is to threaten to reveal to Chanu the scandalous secret of Nazneen's adultery. "There are some things a wife does not want a husband to know" (ibid). Nazneen challenges Mrs. Islam on this count as well, declaring that Chanu "knows everything. He'll come home soon. Why don't you ask him?" (332). Thus, the otherwise powerful Mrs. Islam is left without any means to extract from Nazneen a final payment and is compelled to leave. Although she retains the power to prevent Nazneen from ever having a place in the community again, she can no longer exercise her authority over Nazneen directly. The force of her commands and threats have been effectively neutralized. More importantly, though, "a thought began to form. God provided a way. Nazneen smiled. God provided a way, and I found it" (333). The assertion of her will is thus no longer thought to be wholly incompatible with the will of God.

The second moment in Nazneen's final transformation occurs during the day of the family's scheduled departure for Bangladesh. Nazneen has been seriously entertaining the idea of telling Chanu at the eleventh hour that she will not be going back. This, of course, represents the ultimate challenge to Chanu's authority and would irreversibly undermine their illocutionary game. Chanu has been living in England for over thirty years now. During this time, he has managed to accomplish very little in 
terms of his career. He has neither a prestigious job nor much money to take back with him to Bangladesh, where his family and friends are expecting him to return as some sort of hero. At the very least, he will be able to save face if he returns with a happy family. Speaking to Nazneen, he makes the following remarks:

"All these years I dreamed of going home a Big Man. Only now, when it's nearly finished for me, I realized what is important. As long as I have my family with me, my wife, my daughters, I am as strong as any man alive."

Given Chanu's obsession with his status and reputation among his fellow Bengalis, he has one last opportunity, "one last dream" (342) to fulfill the social role into which he has been drafted. Chanu suspects that Nazneen might refuse to travel to back home. He is therefore unduly good-tempered before her, acknowledging with humility his own shortcomings, but insisting that he is, at the very least, "modern" and cheerfully free of "[v]illage attitudes" (343), the ultimate sign of disgrace. During the early part of their marriage, when his authority went unquestioned, the very same utterances would have qualified as speech-acts confirming his sense of self-worth. However, given his personal history, given his fear that his own wife might actually betray his dreams, what on the surface appears as a boast now constitutes a desperate plea to preserve the very last vestige of his dignity, without which the identity he has been seeking to preserve for the last thirty years will finally be robbed from him. There is, thus, no rigid illocutionary structure to which this utterance must adhere. With the authority and clout Nazneen has managed to recently acquire in their family, she now has the power to preserve or destroy her husband's reputation. If she chooses to travel with her husband, she compromises her personal ambitions, but preserves his dignity. If she pursues her personal ambitions, she will irreversibly destroy their illocutionary game and permanently ruin her standing in the 
community. For to defy one's husband on so major a family decision is to violate one of the most basic community norms. The decisive moment represents the critical point at which Nazneen is forced to choose between her inherited role and the personal narrative she has been crafting on the side. In the end, Nazneen defers to the latter and refuses to travel with her husband. Worse, both Shahana and Bibi choose to stay with their mother, forcing Chanu to return home alone, with neither money nor a family. Not only do Chanu's commands and threats go infelicitous, even his pleas concerning that which matters to him most and on which his very identity rests, namely, his reputation before the community, are now bereft of force. Chanu thus leaves for Bangladesh alone, a man without worth.

Having defied her husband and having defied Mrs. Islam, Nazneen effectively disentangles herself from her original speech-act community. Her new situation is profoundly different and utterly unconventional as compared her former place in the old community. She no longer adheres to her original social role. The speech-acts constitutive of the social setting of which she had formerly been an integral part can no longer be performed in the same felicitous manner as they once were. Nazneen now lives on her own with her two daughters. She eventually enters into a business with Razia, Hanufa, Jorina - the untouchables, exiles, and outcasts of the community-who together design chic, hybrid clothes for an urban youth market. Needless to say, not only is their line of business untraditional, the very fact that they have gone into business is itself highly untraditional. Nazneen now answers to no one and is her own boss. The social practices of which she is now a part have no counterpart in her former community. The 
conventions that govern language and action in her new context of practice are characteristically different than those by which she had previously abided.

It is instructive at this point to inquire into the sources of normativity for the one who has chosen to live a life of self-imposed exile. Recall that Coriolanus attempts to transcend the norms of his speech-act community and become something of an übermensch, "the totally autonomous self" (Fish, 1980: 219), who is the source of his own normativity. This, of course, is an impossible feat and Coriolanus is in the end reclaimed by the very speech-act community he sought to abandon. For Coriolanus has no alternative source of normativity, no alternative source of standards and conventions, whether moral or otherwise, other than those afforded by his original speech-act community. With Nazneen, however, matters are quite different. In what is perhaps the most arresting moment in the entire novel, Razia, Shahana, and Bibi surprise Nazneen by taking her to an ice-skating rink, the one activity about which she had dreamed since arriving in England. As they lace their boots, Nazneen is certainly pleased, but makes the following objection on cultural grounds: "But you can't skate in a sari" (369). To this, Razia replies, "This is England. You can do whatever you like" (ibid). Nazneen's objection had rested on a moral scheme whose normative value is now effectively obsolete.

And, with that, Razia signals the decisive end of Nazneen's shift to an alternative source of normativity and ethical justification. It is not that Nazneen is no longer Bengali. That would be a preposterous and largely meaningless assertion. It is to say, however, that Bengali tradition is no longer the sole or even the primary source of normativity in her life. She emerges victorious from her battle with conventions. 
Nazneen is quite unlike Coriolanus, who attempts to create his own world of meaning, his own moral and communicative foundations, yet who remains parasitic upon the very conventions he seeks to transcend and abandon. That dependency is precisely what renders his attempt to abandon all existing conventions an inevitable failure and explains his eventual breakdown. Nazneen, however, does not attempt to be the sole creator of her own world of meaning. She does not aspire to be the sole source of her own normativity. An überfrau she most certainly is not. She has merely shifted the source of normativity from Bengali tradition to those of the greater British culture, which does not thwart her ambitions, which does not imprison her in a demanding and oppressive social role, which does not paralyze her within a fatalistic mindset, and, most importantly, which does not torture her with feelings of fear and guilt for believing that " $[\mathrm{y}]$ ou can do whatever you like." 


\section{CHAPTER 4: NARRATIVE CONTEXTS OF JUSTIFICATION: SUPPLEMENT TO THE THEORY OF THE SPEECH-ACT}

\section{Preliminary Remarks}

In this chapter, I would like to bolster my central thesis concerning the value of studying realist narratives by analyzing certain key remarks about speech-acts by Austin, Searle, Fish and MacIntyre. In particular, I will relate Fish's remarks about institutional settings and MacIntyre's remarks about teleological sagas to my speech-act reading of Brick Lane. The argument being made in the present chapter is that the interpretation of speech-acts will necessarily be frustrated if we do not take into account the narrative contexts of justification within which the non-institutional speech-act is issued. As discussed in the introduction to the present thesis, Bruner rightly acknowledges Austin and Searle's achievement in restoring the communicative context back to discussions of meaning and in giving speech-act theory a prominent place in our understanding of language and action. However, neither Austin nor Searle provide us with an adequate account of the role of purpose and intentionality in their discussions of speech-acts. Fish has done us a great service by bringing our attention to the importance of institutional roles and settings in determining the conditions of intelligibility. In addition, he draws the useful distinction between one's institutional role and one's individual moral conscience, between which we often encounter an impairing degree of incommensurability.

Fish, however, follows Searle in relegating morality to that realm of abstract universals about which speech-act theory, or so they argue, has nothing relevant to say. I 
find considerable value in MacIntyre's moral philosophy precisely because he disabuses us of the misconception that morality is somehow distinct from the countless local particularities constitutive of a given community of meaning. By insisting that there are only local moralities and no such thing as morality as such, and by insisting furthermore that these local moralities are the very lifeblood of human communities, we are given every reason to believe that a speech-act cannot but be a moral utterance; that speech-act theory has everything to do with morality. Secondly, that MacIntyre and, following him, David Carr, should draw our attention to personal and collective narratives does a great deal to further illuminate the dynamics behind practical rationality and moral justification. Without an appreciation of the various contexts of justification in which speech-acts are performed, we are in a weak position indeed to derive an adequate understanding of the moral import of those speech-acts.

\section{Austin}

As discussed previously, throughout How To Do Things With Words, Austin argues that performative utterances can be either felicitous or infelicitous. A performative utterance is felicitous when the conditions are such that an act purporting to have been performed is actually performed. An example would be an individual who declares that a prisoner is free to go. If the individual doing the declaring wielded the requisite institutional authority to make such declarations, then the declarative would be felicitous. If, however, the individual doing the declaring were a prisoner, that is, an individual who lacked the institutional authority to free another prisoner, then the declarative would have no value whatsoever. It would be an infelicitous utterance. 
Austin then argues that even constative utterances, statements about facts, may be felicitous or infelicitous depending upon the circumstances in which the constative was issued. As mentioned before, Austin draws a parallel between constatives and performatives by virtue of the former class of utterances being issued within contexts of practice. In the present thesis, I go one step further by arguing that all performatives are inescapably moral in character. Precisely because they lack imperatival force and moral significance outside of contexts of practice, speech-acts cannot but be generated by moral considerations of some kind or other. It is also of the utmost importance to note MacIntyre's argument that practices are goal-oriented and, hence, necessarily teleological. Within teleological settings, "evaluative claims [function] as a particular kind of factual claim" (MacIntyre, 1980: 77). And, if that is indeed the case, it seems we have every reason to believe the reverse as well, namely, that statements purporting to be purely denotative in character function implicitly as evaluative claims. The speech-act theorist inquires into why an agent performs this or that speech-act and what he or she is doing in making such and such a statement. To deny the moral significance of a purportedly denotative utterance is to ignore such questions altogether.

Note that Austin's preoccupation lies only in whether speech-acts are felicitous or infelicitous, sound or unsound, fair or unfair, justifiable or unjustifiable. He acknowledges that the theory of 'meaning' is not one to which he devotes a great deal of attention (149). However, as discussed in Chapter Two, MacIntyre argues that felicity is in large measure a question of meaning and interpretation based on common contexts of practice and an appreciation of the personal narrative of the moral agent who performs a given speech-act. I would thus draw an equation between felicity and intelligibility. 
Although it is considerably more problematic to speak of the "truth" or "falsehood" of a moral utterance, it is perfectly appropriate to speak of its intelligibility or unintelligibility. The argument being made in the present thesis is that both intelligibility and felicity are functions of goals and purposes, whether individual or collective, and only in the light of which the meaning of a speech-act can be adequately grasped.

\section{Searle}

As stated before, Searle takes issue with those philosophers of language who insist upon some set of objective criteria and formal taxonomy with which to classify any given utterance. Such philosophers, he reports, argue for the necessity of objective criteria of a very specific kind: “extensional, formal, or behavioral; some way whereby, for example, by performing mechanical operations on sentences or observing the behavior of speakers," one could objectively place a particular utterance under a formal category, such as whether a statement was analytic or not (1969: 6). Searle offers a clever counter-challenge to the formalist demand for objective criteria and mechanical procedures of inquiry with which to classify a given utterance. He argues that such a challenge cannot be issued unless one already possesses some standard by which he or she might assess the validity of a proposed set of criteria and procedures of inquiry in answer to that challenge (7). In effect, Searle argues that we are, prior to our formal inquiries into meaning, already implicated in standards and conventions of meaning; that the challenge itself would not be possible except by an indirect appeal to latent standards and conventions. We cannot abstract ourselves out of those standards and conventions 
only to then demand formal, objective criteria to determine meaning, failure to obtain which would supposedly reveal our incapacity to critically determine meaning.

Searle's answer to the demands of the logical formalists is to develop an extremely detailed and nuanced account of the illocutionary structures of the speech-act. He makes a convincing argument for the necessity of attending to the various conditions and rules by which a speech-act may achieve felicity. However, in the light of the present thesis, it becomes at once clear that Searle has devoted himself to the study of speech-acts familiar to those who inhabit the same basic moral universe and who, moreover, are immersed in the same social traditions and contexts of practice with interconnected histories. The speech-acts he chooses to examine would be readily familiar to a particular audience, namely, a contemporary, English-speaking audience. Searle does not consider speech-acts from other cultures or contexts of practice with which his audience would not be familiar. To point this out, of course, is not to fault Searle, but to underscore the limitations of speech-act analyses. Such analyses rest on the audience's familiarity with the background culture, structures of expectations, and dimensions of assessment in which a particular speech-act is at home. The specific examples of the speech-acts he examines are governed by a certain set of social and cultural conventions that are culturally specific and may not necessarily extend universally to all cultures and practices.

However, that is precisely Searle's claim. As mentioned in Chapter Two, Searle argues that speech-acts assume the same basic illocutionary structure across all cultures; that "[d]ifferent human languages, to the extent that they are inter-translatable, can be regarded as different conventional realizations of the same underlying rules" (30). Searle 
is not referring here to grammatical or syntactical rules, but illocutionary rules, those social and cultural conventions that govern the use of performative language. This would suggest that, despite differences in language and culture, there is at the very least a basic set of conventions to which members of different cultures can commonly appeal irrespective of situation or context of practice in which a given speech-act is performed. This argument fails, in my opinion, to account for those cases not just of infelicitous speech-acts, but also of bafflement between those who would otherwise be interacting according to the same basic set of conventions. It is clear that MacIntyre regards bafflement of the sort he describes in After Virtue in terms of the very same infelicities to which Searle and Austin have devoted so much attention.

What is missing, then, from Searle's theory of speech-acts is some account of the narrative contexts of justification in which practical rationality is driven by reasons and purposes, thereby playing a decisive role in the determination of felicitous speech-acts. It is only when moral agents are understood to speak and act within common contexts of justification, collectively driven toward a common set of goals or goods, that speech-acts can be felicitous and intelligible. It would seem that, while Searle does indeed restore the communicative context back into discussions of meaning, he limits his analysis to a very particular set of contexts and makes a rather broad claim concerning the intertranslatability of speech-acts. If the argument of the present thesis is correct, the intertranslatability of speech-acts requires that we also direct our attention to the particular settings and narrative contexts of justification in which a given set of speech-acts can be felicitously issued. 


\section{Fish}

The particular setting analyzed by Fish in his speech-act reading of Coriolanus is the institution of the state. As Fish notes, that institution is a "game," according to which the players, or members of the institution, are accorded certain rights and privileges that derive from "the conventions that define (or constitute) the workings of the state" (202). These rules enable the members of the institution, the players in this game, to carry out such and such a set of acts by virtue of the rights accorded to their institutional role by the established system of rules and conventions. As Fish notes, "One can complain about their performance, but one cannot challenge their right to perform without challenging the institution that gives them their role" (ibid). There is no external set of impartial criteria or realm of abstract universal principles to which the members of an institution can appeal to justify this or that action. All actions are judged according to the system of rules and conventions established by the state and that constitute the state.

The first point I wish to make here is that Fish's description of the state is in equal measure a remarkably fitting description of Nazneen's community of Brick Lane, a community in which certain individuals enjoy certain key privileges, those privileges being afforded by the unwritten system of rules established by Bengali tradition. Moreover, within the community one finds the more specific institution of the family, which is defined, again, according to Bengali tradition. Although the particular form of that institution varies from culture to culture, it is an institution by virtue of the roles that members of the family are expected to play. The roles of the Bengali husband, wife, and daughter are defined by a rigid system of rules and conventions, observance of which is essential if one wishes to be regarded as a player within that game or institution. As Fish 
remarks, "one can argue with an umpire, but one cannot ignore or set aside his decisions and still be said to be playing the game" (ibid). There is, then, a necessary and basic set of rules or pragmatics by which one would have to abide if one wished to be regarded as a player.

Fish uses speech-act theory to understand the behavior of Coriolanus as a particular type of player within a particular type of game, namely, head of the institution of the state:

There are certain speech acts he is good at. He is fine at refusing and even better at promising. Both make sense. Refusing is saying "I can do (in the fullest sense of agency) without it"; and while promising involves undertaking an obligation, it is an obligation the promiser creates and discharges; when he keeps his promise, he is being true to his own word, not to the word of another. It is Coriolanus' favorite speech-act, the one by which he defines himself.

One can immediately draw a parallel between Coriolanus and the characters of Chanu and Mrs. Islam. Although not heads of state, both characters perform certain social roles particular to which are certain speech-acts definitive of their respective identities. Chanu's incessant boasting and Mrs. Islam's incessant commands cannot be read merely as expressions of their individual personalities, quirks, and idiosyncrasies. Rather, the speech-acts by which they come to be defined are performed repeatedly to affirm and reaffirm their roles within the community. The proof that these roles are well established is the ease with which both Chanu and Mrs. Islam can felicitously perform their respective speech-acts before willing and observant players. Prior to Nazneen's transformation, Chanu could trust that his speech-acts would bring about the desired illocutionary and perlocutionary effects. Likewise, Mrs. Islam could trust that her commands would do the same. Both characters bank on a tacit acknowledgement on the 
part of Nazneen concerning their traditional roles and privileges. They thrive on the assumption that she will conform to her own social role and exhibit the sort of obedience definitive of that role.

A mutual agreement, then, at least by the members of a given community or institution, is required for the felicity of a speech-act. Despite his superior status as head of state, Coriolanus must nonetheless perform all speech-acts, even his favorite, "according to the conventional rules, that is, in such a way as to acknowledge his kinship with other men" (206). By observing such rules, he "submits himself to the judgment of others" and "acknowledges... his dependence on the community and its evaluative process" (ibid). This point, of course, applies to a community's weakest members as much as it applies to its most powerful. Nazneen's original station in life is the diametric opposite of that of Coriolanus; as a young woman, she is among her community's weakest and most disadvantaged. Yet, both Coriolanus and Nazneen are ironically implicated in the same type of institutional predicament; both are bound to and dependent upon the larger community for their ability to survive in that community. Nazneen's predicament is such that when she interacts according to the dominant conventions, she indirectly confirms the legitimacy of those conventions and submits to its judgments and evaluative logic. Upon developing an irrepressible sense of contempt for the conventions of the community, she is at first unable to avoid appealing to those conventions to make herself understood.

What both Nazneen and Coriolanus have in common is an evolution in their personal narratives that merit the writing of what Fish calls a "speech-act history" of their respective characters. That history reveals for us which speech-acts are generated from 
the standpoint of an institutional role and which from the standpoint of an individual moral conscience. The tensions between these two standpoints and the dilemmas they create for one's practical reason are starkly illustrated by Coriolanus' predicament within his institutional role as head of state. As Fish puts it,

...true we may do anything we like, but if we consider ourselves members of a state rather than discrete individuals, then we are bound to the mechanism by which the state determines value, and must comport ourselves accordingly, even when the determination does not sort with our private judgments.

The demands of one's institutional role are such that intentionality is often a function of institutional responsibility. Hence, Fish's insistence that speech-act theory has nothing to say about "what is going on inside, the question of the "inward performance"" (ibid). Although one can, if one so chooses, announce one's intention by appealing to the established procedures afforded to one's institutional role, that appeal comes prepackaged, as it were, in the form of intentions readily identifiable by those party to the same institutional setting. Depending on what role one plays, only such and such a set of intentions is available for one's deployment.

Although the aforementioned remark by Fish pertains to that of an institutional setting, we can see yet again a striking parallel between the predicaments of Coriolanus and Nazneen. For Nazneen, too, plays a particular role, attendant to which is a limited set of intentions, or legitimate moves in the established language game - moves without which she cannot get by in her community. For her to announce some intention contrary to those afforded by her social role is to betray unintelligible behavior. Prior to her transformation, all that Nazneen could hope to say, think, feel, and act was limited to that set of intentions constitutive of her social role. It is only after she begins her 
transformation that Nazneen's personal intentions play an increasing role in determining the meaning and illocutionary force of her speech-acts.

Thus, I wish to respectfully disagree with Fish on the question of intentionality. Although it seems fair to say that speech-act theory cannot reveal anything concerning the personal intentions latent in the performance of a speech-act generated from the standpoint of an institutional role, speech-act theory can, and cannot but, have something vital to say about those speech-acts generated from the standpoint of one's individual moral conscience. In the interpretation of moral utterance, the task is, in part, to distinguish between these two types of speech-act. Although it is fair to say that speechacts generated from the standpoint of one's individual conscience are, in some measure, parasitic upon the conventions of this or that speech-act community, one would be liable to draw mistaken assumptions concerning those conventions if one mistook a personal speech-act for a conventional speech-act. Put simply, we cannot presume to adequately understand culture on the basis of personal behavior and vice-versa.

Having realized that their personal intentions are fundamentally incompatible with the demands made upon them by their respective social roles, both Coriolanus and Nazneen find themselves increasingly inclined to reject the established conventions of their respective communities. As mentioned above, however, Nazneen finds herself unable to get by except by appeal to the dominant conventions. Hence, even if one should choose to be a non-player vis-à-vis a particular language game-that is, even if one should choose to make moves that do not derive from the existing stock of agreedupon moves and even if one were to purport to stand outside of those conventions-it would still be necessary to appeal to certain conventions if one wished to be understood. 
That is to say, I may not be a member of your community, but unless I am to appear as a total madman, I will have to appeal to certain conventions to at least be intelligible. As Searle notes,

Standing on the deck of some institutions one can tinker with constitutive rules and even throw some other institutions overboard. But could one throw all institutions overboard? [...] One could not and still engage in those forms of behavior we consider characteristically human.

To "throw all institutions overboard" is thus to regress into unintelligibility. No matter how extreme the rebel or dissident, no matter how much one might wish to revaluate all values, if one is to remain intelligible, one must at the very least appeal to some minimal set of conventions derived from the very world against which one stands in rebellion. This is precisely the predicament into which Razia and Nazneen plunge. Despite their sense of contempt for the community, their respective identities are parasitic upon that community until such time as they are able to successfully extricate themselves from its many and elaborate entanglements.

Both Coriolanus and Nazneen face a similar challenge, namely, how to divest themselves of institutional commitments to the dominant conventions and to effectively free themselves from the obligations due to their respective communities. However, between the two of them, that challenge is subordinate to strikingly different ultimate intentions. As Fish notes, it is Coriolanus' ultimate goal to ...stand alone, without visible or invisible supports, as a natural force. He wants to be independent of society and of the language with which it constitutes itself and its values, seeking instead a language that is the servant of essences he alone can recognize because he alone embodies them. 
Nazneen, of course, does not wish to reside in her own world of meaning. She merely seeks an alternative moral culture in which the personal narrative she has been crafting in defiance of her original social role can finally be at home. What Nazneen and Coriolanus have in common, however, is their refusal to submit to the judgments of their original community. This Coriolanus hopes to sustain by appealing to a "world elsewhere," in which "essences are immediately recognized and do not require for their validation the mediation of public procedures" (217). Nazneen, on the other hand, does not need to turn to a world of pure essences. For her intents and purposes, she is able to find what she seeks in the larger British society, whose moral culture is able to accommodate her personal ambitions without impugning her for failing to live up to her former social role.

Hence, the very different outcomes between Coriolanus and Nazneen's respective attempts to defy conventions. Concerning the world in which Coriolanus seeks refuge, Fish observes that "there is no world elsewhere, at least not in the sense Coriolanus intends, a world where it is possible to stand freely, unencumbered by obligations and dependencies" (218). Rather, one can only seek refuge in some or another speech-act community, each of which, by definition, "exacts as the price of membership acceptance of its values and meanings" (ibid). This is a price Coriolanus absolutely refuses to pay, but it is one that Nazneen is gladly willing to forfeit. Given her very different ultimate intentions, all that is required of her is that she shift her allegiance from her original speech-act community to a rival community, with its rival set of constituting values and meanings. Whereas Coriolanus is paradoxically committed to challenging conventions while simultaneously refusing to appeal to any conventions to justify that challenge, Nazneen's challenge to conventions is justified by an appeal to an alternative and already 
existing set of conventions. The irony is that the disenfranchised housewife-cum-rebel succeeds where the all-powerful-head-of-state-cum-übermensch fails.

One rather powerful piece of evidence that Nazneen has in fact succeeded in her battle with conventions lies in the radically different illocutionary force of the speech-acts both she and Chanu perform before each other toward the end of the novel. Chanu's identity had, as mentioned before, rested on the speech-act of boasting, among others. One of his signature boasts, that of his being "an educated man," no longer retains its original illocutionary force following Nazneen's subversion of her social role. The force of that utterance had originally derived from Chanu's institutional authority. He had been given the right by tradition to boast before his wife and expect that his speech-act would be felicitous. However, upon subverting her social role, Nazneen effectively subverts Chanu's institutional authority as well, thereby robbing his signature speech-act of its original force. Toward the end of the novel, the propositional content of Chanu's favorite utterance is reduced to the status of a plea; again, a plea to save him from irreparable shame and embarrassment. To add insult to injury, it is Nazneen who authoritatively appropriates the propositional content of Chanu's favorite speech-act, only to reverse its illocutionary force. During one of the final moments prior to Nazneen's decisive break with the community, when Chanu's unsettling sense of impending disappointment is nearing its peak and his sense of self-worth threatens to unravel, Nazneen takes control of the situation and assures her husband that "[i]t was lucky for me that my father chose an educated man" (343). Although Chanu does not become troubled by this unprecedented appropriation of his most cherished utterance, it is very much to the point that none of the 
established conventions could render it felicitous. If anything, it fortifies a radical change in their institutional relationship.

The question of illocutionary force and the attendant institutional obligations upon those party to the same set of conventions raises an interesting question about morality and the moral significance of the speech-act. Fish does not regard institutional obligations in moral terms. The derivation of an "ought" statement from the standpoint of an institutional role is designated as "procedural," not moral. That is to say, those party to the same set of institutional conventions, "incur the obligation because they have bound themselves ahead of time to the [same] system of conventions" (202). As stated earlier, Fish follows Searle in relegating morality to that realm of abstract moral principles from which one is expected to derive the moral "ought". About the moral "ought", then, speech-act theory purportedly has nothing of relevance to say. To this, I wish to reply by appealing to one of the principal theses of After Virtue. MacIntyre's twin emphases upon, on the one hand, the situatedness of the moral agent in social traditions and practices and, on the other, the narrative, teleological character of moral consciousness, is, in part, a direct challenge to the claim that the moral "ought" necessarily appeals to some abstract realm of universal principles. MacIntyre's description of traditions and practices bears a rather striking parallel to Fish's own description of institutions and their attendant roles. The point I wish to make is that the fundamental difference between a social tradition and a formal institution lies in the official character of the latter type of community, the maintenance and perpetuation of which is guaranteed by virtue of official arrangements. A social tradition, by contrast, though not maintained by an official set of agreements, thrives according to the very 
same logic and structure as those of a formal institution. The unwritten, unofficial rules of social traditions and practices find their counterpart in the official rules of formal institutions. Hence, by identifying the social roles to which a moral agent is party and by locating those roles within the larger social traditions and contexts of practice of which those roles are a part, we are indeed able to identify the legitimating source of at least some moral "ought" statements. That is, we can discover why such statements resonate in certain settings. In such cases, to say that one ought to do such and such is merely to remark about the obligations one incurs by virtue of one's social role. ${ }^{22}$ Hence, if we cannot speak of morality as such, but only of local moralities born of traditions and practices, then it would seem that speech-act theory does indeed have much to do with not just moral utterances in general, but also and in particular with moral "ought" statements.

Given his reluctance to discuss the moral "ought", there is, I believe, an irony in Fish's telling admission of "the power of language to constitute reality" (215). For he acknowledges a kernel of truth to the phrase, "saying makes it so" (ibid). Speech-acts, after all, constitute reality in one of three ways:

1. There are those speech-acts the performance of which compels a set of words to conform to a state of affairs. These include assertions and explanations.

\footnotetext{
${ }^{22}$ This argument should not be construed as an underhanded defense of conservatism. It is intended to be an empirical description and betrays no bias in favor of any social politics. As MacIntyre argues, the enduring philosophical conundrum of deriving "ought" statements from "is" premises has admittedly given rise to a great deal of incoherent moral discourse based on hypothetical moral imperatives. Hence, the pandemic of "ought" statements that thrive purely on imperatival force, but which offer little by way of convincing logic or reasoning. MacIntyre's answer to this problem is to derive "ought" statements from roles or functions; e.g. a teacher ought to teach and a shoemaker ought to make shoes. The appeal to hypothetical imperatives, the most famous of which is Kant's categorical imperative, cannot, so Macintyre argues, be sustained through rational argument. For a complete account of this point, see MacIntyre, 1984: 51-61. My point here is that speech-act theory does indeed tell us something about the moral "ought", but only when issued between those who inhabit the same moral culture. The interpretive capacity of speechact theory is greatly frustrated when applied to moral arguments based on hypothetical imperatives, a standard item of currency in moral discourse between cultures.
} 
2. There are those speech-acts the performance of which compels a state of affairs to conform to a set of words. These include promises and requests.

3. There are those speech-acts the performance of which produces a twin outcome: a set of words and a state of affairs. This last class of speech-acts is known as declaratives.

Paraphrasing Searle, Fish notes that the power of declaratives rests squarely on the "the speaker's occupying a position of authority in an extralinguistic institution" (ibid). A certain reality is produced upon the issuing of a declarative, as is the case when an umpire yells, "strike three", but which fails to be the case when, for example, a fan in the stands yells the very same words. However, Fish is also quick to note that the strength of a declarative rests in equal measure upon the consent of those to whom a declarative is issued. A declarative is incomplete until the behavior of those to whom it is issued conforms to the established conventions. If, however, those to whom a declarative is issued refuse to conform to the established conventions, the declarative then not only loses its efficacy, but the very institution from which it had hitherto derived its power is also undermined. From this, Fish draws the sobering conclusion that "institutions are no more than the (temporary) effects of speech-act agreements, and they are therefore as fragile as the decision, always capable of being revoked, to abide by them" (215).

If this is true of institutions, it is also true, mutatis mutandis, of the social traditions and practices of which we are all a part. Speech-acts are not, after all, solely institutional phenomena. Precisely because speech-acts are also performed outside of formal, institutional capacities, we are compelled to inquire into those legitimating contexts and settings from which the non-institutional speech-act derives its illocutionary 
force. If the authority of an institution rests on the consent of its members, then so, too, does the authority of a social tradition or practice rest on the consent of its members. What, then, are we to make of "ought" statements to which one cannot attach an institutional sanction and which cannot be written off as merely procedural? From where do such "ought" statements derive their authority? It is my contention that social traditions and practices are also the effects of discourse agreements, albeit agreements greatly extended over time and sustained through collective observation and the ritual performance of speech-acts. It is into one or other set of social traditions and practices that we are born and which provides us with an initial set of legitimating speech-act conventions through which we interact in the world.

What this points to, I would argue, is the utterly ephemeral and fragile nature of morality. Far from being objective and far from being coterminous with that abstract realm of universal principles to which "ought" statements commonly appeal, morality is, through and through, a discursive phenomenon whose validity rests squarely on the consent of some or other speech-act community. Put simply, the non-institutional speech-act demonstrates the power of language to produce morality. This is not, of course, as Fish is quick to note, "to deny that a standard of truth exists" (243). It is, however, to say that standards of truth and standards of morality are always and forever local and that the validity and meaning of a moral utterance rests on purely contingent grounds. It is this lesson that Nazneen discovers and which enables her to extricate herself from her original speech-act community, from its attendant web of moral and affective entanglements, so as to migrate, metaphorically speaking, to a rival community without suffering the debilitating consequences of fear and guilt. In effect, what she 
manages to accomplish is an escape from the teleological saga in which she had been formerly imprisoned. About teleological sagas and their relevance to the present discussion of speech-acts, a review of some key remarks by MacIntyre is in order.

\section{MacIntyre}

In a chapter from After Virtue entitled, "The Virtues in Heroic Societies," MacIntyre argues that "classical" cultures_among which he includes ancient Athens, medieval and Renaissance Europe, and also those historical periods during which Judaism, Christianity, and Islam respectively flourished-were informed, shaped, and influenced by a certain stock of epics and sagas that spoke of a "vanished heroic age," to which classical cultures universally turned for an understanding of their heritage and their present situation (121). These narratives were crucial in providing a "moral background to contemporary debate in classical societies," such that moral discourse was not generally chaotic and aimless, but ordered according to the moral and conceptual scheme represented by those narratives. Thus, to understand classical cultures, MacIntyre argues, it is necessary to examine the epics and sagas of their vanished heroic ages. Although the Bengali community of Brick Lane can hardly be described as a heroic society, since it is very much a contemporary society with its own vanished past-a past celebrated by Bengalis for its own glory, achievement, and high culture and to which Bengalis turn for an understanding of their identity - the Bengali community nonetheless bears an uncanny resemblance to MacIntyre's description of heroic societies. I therefore wish to draw from that description those specific characteristics that have striking parallels in Bengali 
culture and which aid us in better understanding the dilemma into which Nazneen finds herself.

The first salient characteristic MacIntyre notes of heroic societies is that

[e]very individual has a given role and status within a well-defined and highly determinate system of roles and statuses. The key structures are those of kinship and of the household. In such a society a man knows who he is by knowing his role in these structures; and in knowing this he knows also what he owes and what is owed to him by the occupant of every other role and status.

In such a system, there is no difference between "ought" and "owe". What one ought to do is what one owes another, that duty or obligation being a function of one's social role. However, what one owes another and, hence, what one ought to do, is not left entirely up to oneself. Although each role is constituted by "a prescribed set of duties and privileges," there is also an attendant understanding of "what actions are required to perform these [duties] and what actions fall short of what is required. For what are required are actions. A man in heroic society is what he does" (ibid). In such a society, one's identity is constituted by one's actions, such that to be judged is to be judged according to one's record of conformity to one's social role. It is because certain actions play so decisive a role in "sustaining the public order" that certain virtues "merit public recognition" (123). Hence, in the heroic society, actions have a very public character and the performance of one's prescribed actions leaves one open to public scrutiny and objective moral judgment.

Moreover, in heroic societies, "morality and social structure are one and the same," such that "[e]valuative questions" become "questions of social fact" (ibid). Equipped with a determinate system of right and wrong and an equally determinate system for dealing with right and wrong, moral judgment and moral action assume a 
notably formulaic-one might even say procedural-quality. Breaches of the prescribed norms are dealt with according to a preexisting set of measures, whose seemingly universal applicability renders only the most exceptional cases actually perplexing or dilemmatic. Hence, the inhabitants of the heroic society "do not find it difficult to know what they owe one another... when confronted with the possibility of wrongdoing" (125). The vices are public categories and if one cannot be counted upon to acknowledge his or her wrongdoing, "other people are always at hand to drive home the accepted view" (ibid). There is, thus, no possibility of a private morality and private system of moral justification in heroic societies. One's moral reasoning and moral judgments are always drawn from a public pool of moral meaning and a public set of moral standards, the collective observance of which requires a "mutually interdefined" use of "evaluative expressions" (ibid).

It is in this rigidly structured moral culture that the individual who lacks an understanding of his or her social station would be woefully incapable of thriving among the other members of the culture. Such an individual would not only "be incapable of receiving recognition and response from others," he or she would have little clue as to who he or she was (124). It is due to this basic requirement of conformity to an established social role that "heroic societies commonly have a well-defined status to which any stranger who arrives in the society from outside can be assigned" (125).

In what he describes as a potentially misleading analogy, MacIntyre likens the moral culture of heroic societies to the game of chess (125-126), for chess is a game whose object and rules are fixed and unchangeable. To play the game of chess is to necessarily work toward the realization of a particular goal. One would not ask why one 
follows this or that rule or whether one has done the right thing, for example, in placing one's opponent under checkmate. Likewise, heroic societies could be described as being governed by a fixed system of rules that one would have to observe to realize the good or goods definitive of one's social role. ${ }^{23}$ In the heroic society, questions of right and wrong are situated within an overarching teleological scheme oriented toward the realization of some or other good or set of goods. In such a structure, to attempt to derive the notion of "right" or "wrong" from outside would be unintelligible or, worse, outrageous. One could not question the necessity of observing this or that rule or the necessity of realizing one's good. To even inquire into the validity of a rule or good would presuppose an external perspective and the faculty of choice. However, as MacIntyre notes, "it is only within [the heroic society's] framework of rules and precepts that they are able to frame purposes at all" (126).

This is precisely where the incongruity in the analogy to chess lies. In the heroic society, "[a]ll questions of choice arise within the framework; the framework itself therefore cannot be chosen" (ibid). People play chess for different reasons, of course, but the inhabitants of the heroic society have one reason and one reason only to live the life that they do. Unlike the players in the game of chess, the inhabitants of the heroic society lack

...the capacity to detach oneself from any particular standpoint or point of view, to step backwards, as it were, and view and judge that standpoint or point of view from the outside. In heroic society there is no 'outside' except that of the stranger. A man who tried to withdraw himself from his given position in heroic society would be engaged in the enterprise of trying to make himself disappear.

\footnotetext{
${ }^{23}$ Interestingly enough, Searle likens the analysis of the rules that govern the performance of illocutionary acts to "discovering the rules of chess by asking oneself what are the necessary and sufficient conditions under which one can be said to have correctly moved a knight or castle or checkmated a player, etc. We are in the position of someone who has learned to play chess without very having the rules formulated and who wants such a formulation" (1969: 54-55). Hence his notion of illocutionary "games".
} 
The decisive factor in securing this internal perspective and in precluding any external perspective is the belief in the ultimate power of fate. In the heroic society, "there are powers in the world which no one can control" (124). One's life is "invaded by passions," which are often perceived as "impersonal forces" and even sometimes as "gods" (ibid). Such forces and the established social rules "constitute patterns of an ineluctable kind. Neither willing nor cunning will enable anyone to evade them. Fate is a social reality and the descrying of fate an important social role" (ibid). Hence, the inhabitant of the heroic society is given from the very beginning a vision of his or her coming fate, to which he or she "moves steadily" at any given moment. If defeat lies at the end of one's life, one is given no choice but to face the inevitable, the willing acceptance of which is itself a cardinal virtue. From this, it becomes increasingly apparent that life in the heroic society "has a determinate form, the form of a certain kind of story" (124).

The epics and sagas of the heroic societies not only "narrate what happens to men and women," but "in their narrative form," they also "capture a form that was already present in the lives which they relate" (ibid). That is to say, the epic and the saga portray "a certain kind of enacted story" (ibid). Although some epics and sagas tell of characters who possess the power to "transcend the values of the saga world," it is the general attribute of most characters that they cannot achieve such transcendence (128). This thorough immersion in the narrative world of the epic or saga has a certain consequence, of course. The characters in these stories have

...no means of viewing the human and natural world except that provided by the conceptions which inform their world-view [sic]. But just for that reason they 
have no doubt that the reality is as they represent it to themselves. They present us with a view of the world for which they claim truth. The implicit epistemology of the heroic world is a thoroughgoing realism.

(129; emphasis added)

\section{Analysis}

From the above remarks about heroic societies, a striking correspondence to certain features of the Bengali community of Brick Lane becomes readily apparent. First, it is clear that, much like heroic societies, the members of Nazneen's community have been drafted into a set of social roles, each of which is constituted by a prescribed set of rights and duties. It is also clear that each member not only knows his or her prescribed rights and duties, but also the specific actions and procedures one would have to follow to fulfill those rights and duties. Chanu knows precisely what is owed to him by his wife and children, just as he knows what he owes to others by virtue of their seniority over him. His anger towards Shahana can be understood as stemming from her repeated violations of the rights he claims over her. His anger is therefore not generated from a purely personal sense of offense, but out of a perceived threat to his authority and identity. Likewise, Mrs. Islam and Nazneen are both aware of the rights the one enjoys over the other. During those moments when Nazneen resists the fulfillment of her duties and obligations, Mrs. Islam can, as it were, be counted upon to drive home the accepted view.

Secondly, it is also clear that, for the members of the community, their social structure is literally indistinguishable from and a collective embodiment of their morality. For a member of the culture to challenge a particular norm is tantamount to challenging morality itself. When, for example, Nazneen suggests that she might attend college with 
Razia, Chanu immediately rules against it, insisting that "you can't take a baby to college," because babies "have to be fed; they have to have their bottoms cleaned" (51). Chanu justifies his decision by driving home the accepted view of the prescribed duties and obligations of the housewife. Nazneen's attempt to reason with Chanu is ineffective precisely because he regards the norms of the community as incontestable moral premises. To challenge those premises would be to throw one's community membership into question. Chanu himself cannot be said to be unwilling to question the community's moral structure. Rather, it is the case that he is incapable of doing so.

Chanu's incapacity to question the basic norms of the community derives from his like incapacity to assume the perspective of an outsider. For those thoroughly immersed in the moral and affective universe of the community, assuming an external perspective is entirely precluded. The peculiarity of Nazneen's situation lies in her growing curiosity concerning the world of alternative possibilities that lie beyond the margins of the community. Having discovered different identities and social roles, she comes increasingly to regard her own community from the perspective of an outsider and is therefore driven to question and eventually challenge its most basic moral principles. Although the first generation of Bengali-Britons (a salient example being Shahana) do indeed look upon the community as outsiders, it is very much to the point that those who were born and raised in a traditional Bengali society and who later migrated to the United Kingdom retain with them the roles into which they were originally drafted and the conventions by which they have always abided. Those conventions and roles are merely reproduced in the new setting. 
More importantly, what also gets reproduced is the teleological saga that is Bengali culture. The element of fate must be seen as homologous to the narrative constitution of the community. There is, as it were, a pre-written narrative, with prewritten character roles, which every member of community is intended to fulfill, even if with utterly affected performances that betray a near-total lack of enthusiasm. Witness, for example, the flagrant displays of apathy and indifference with which Shahana fulfills her social role. It is as if the entire family were cast into a play they did not choose and out of which they could not escape, but which they performed for no reason other than that they were fated to perform it. Chanu, being the head of the household, has been fated by tradition to assume the often-unpleasant task of ensuring that every member of the family acts out her assigned role. His frequent outbursts toward Shahana indicate that the story he intends to see through to the finish is not quite moving along its prescribed course.

The movement of the family story is irrevocably thrown off course upon Nazneen's final defiance of both her husband and one of the community's most senior members, Mrs. Islam. It can be said that the community has fixed categories and attitudes for dealing with non-members. However, Nazneen succeeds in becoming a nonmember in a way that seems unprecedented and that cannot be tamed by the existing categories and attitudes. She does not transmute into a stranger, but into a non-player of a very different and unclassifiable kind. It is not that her individual actions are unintelligible. That she should refuse to travel with her husband and that she should resist the authority of Mrs. Islam are not, in themselves, unintelligible intentions. However, that she should effectively abandon her social role is indeed both unintelligible 
and unclassifiable. Her flight from the community shifts her personal narrative in a direction that has no place within the overall narrative orientation of the community. A wife who not only defies those key authority figures to whom obedience and deference are due by tradition, but who also legitimates that defiance in a principled way-that is, in a way that challenges the most basic moral principles of the community by appealing to rival moral principles-is a wife who has effectively transmuted into an unintelligible character. Just as Coriolanus challenges the very institution from which he had derived his authority, so too does Nazneen challenge the tradition from which Mrs. Islam and Chanu respectively derive their authority. In doing so, Nazneen successfully escapes the teleological saga world in which she had been born and imprisoned. This she manages by extricating herself from the community's countless moral, affective, and narrative entanglements, so as to migrate to a rival narrative universe, one in which her personal ambitions are not actively thwarted. The surest indication of her success lies in the power with which she neutralizes the illocutionary force of commands and declaratives issued by her former authority figures. Not only do those speech-acts go infelicitous, Chanu and Mrs. Islam are unable to appeal to any alternative speech-acts with which they might reassert their authority over Nazneen.

\section{Conclusion}

In conclusion, I would argue that, in the absence of formal institutions, it is imperative identify the unwritten, but equally powerful, role of collectively embodied narratives to adequately grasp the meaning and significance of the non-institutional speech-act. Conventions exist in both formal, institutional settings as well as in informal, 
non-institutional settings. Such non-institutional settings include the various social traditions and practices of which we are all a part. In the case of non-institutional settings, we are apt to inquire into why it should be the case that certain speech-acts issued by certain individuals enjoy a certain illocutionary force. We are equally apt to inquire into the legitimating, even if latent, structures from which such non-institutional speech-acts derive that force. It is my contention that the answer lies in the collective narratives that sustain social traditions and practices and account for their moral structure and teleological orientation. Hence, the study of narrative contexts of justification serve as a necessary supplement to theory of the speech-act. 


\section{CHAPTER 5: CONCLUSION}

\section{Summary}

In Chapter One, I first outlined certain crucial distinctions between humanism and anti-humanism. The most salient of these distinctions concerns the strikingly different attitudes toward human nature. Humanism thrives on the principle that there is a kernel of commonality that cuts across cultures. Anti-humanism, however, thrives on a stern skepticism to such claims, insisting that arguments concerning human nature and crosscultural commonality are only so much metaphysical claptrap, an uncritical belief in which can very easily descend into dangerously chauvinistic attitudes. Without endorsing humanism, I proposed a qualified rejection of an indiscriminate anti-humanism on the basis that in its indiscriminateness it runs the risk of regressing into precisely the sort of absolutism and essentialism to which it is purportedly opposed. I suggested that human cultures should not be regarded as hermetically sealed off from one another and that the possibility of understanding across cultures requires some basic degree of commonality. The critical question concerns how to achieve that understanding. The present thesis proposes the study of narratives as one avenue toward the achievement of that end. In particular, I proposed the study of realist narratives precisely because they afford the possibility of a rich and expansive representation of alien cultures and social practices.

In Chapter Two, I outlined the theoretical framework and methodology of the present thesis. I first reviewed MacIntyre's arguments concerning the inherent rationality of cultures and his rejection of Kantian conceptions of practical reason, according to which human beings are merely rule-following animals. By contrast, MacIntyre's 
conception of human beings as storytelling and story-living animals, or what Walter Fisher has termed homo-narrans (1987), presents a far more convincing explanation of practical reason. I further argued that cultures must be regarded as socially embodied narratives. Rather than generically regarding cultures as a whole or even partial way of life, it seems far more reasonable to turn to the social practices constitutive of a given community to locate the wellspring of cultures. On this argument, one can claim membership in as many cultures as the social practices of which one is a part. It seems to me that cultures are fundamentally teleological and ultimately rooted in goals and purposes; those goals and purposes themselves being defined by social practices.

I also argued that, between the two extreme paradigms for moral discourse laid out by Habermas and MacIntyre, their mutual emphasis upon the importance of empathy was a further justification for my contention that the study of narratives serves the purpose of cross-cultural understanding. To achieve this understanding, I proposed a speech-act reading of a realist narrative. This was motivated by my conviction that speech-acts are partly constitutive of human communities and that, to better understand a given community, it is imperative to understand its basic stock of speech-acts and the conventions that govern their performance. Moreover, I understand speech-acts as moral utterances, the basic moves in an illocutionary game. Precisely because I reject the idea of universal morality, or morality as such, it seemed to me that to inquire into a culture's speech-acts was to inquire into its basic units of moral expression. Formal inquiries that probe into formal moral principles seem a terribly inadequate way to achieve crosscultural moral understanding. 
And so, in Chapter Three, I undertook a speech-act reading of a realist novel, namely, Monica Ali's Brick Lane. This novel was chosen because of its striking parallels with Shakespeare's Coriolanus, at least as Fish approached that play with speech-act theory in mind, for it was Fish's contention that Coriolanus is a play about speech-acts, just as it is my contention that Brick Lane is, likewise, a novel about speech-acts. Nazneen's community of Brick Lane can be rightly described as a speech-act community comprised of certain social roles, each role being defined by certain speech-acts. Moreover, what Brick Lane and Coriolanus have in common is a tension between the central characters and the speech-act communities of which they are a part. In that tension, the speech-acts constitutive of their respective communities, as well as the conventions that govern their performance, are made all the more salient for the reader, thus rendering both texts ideal for a speech-act analysis.

In Chapter Four, I continued my speech-act analysis of Brick Lane by arguing that an interpretation of the non-institutional speech-act requires an appreciation of the narrative contexts of justification in which such speech-acts are performed, for it is clear that the speech-act community of which Coriolanus is a part is thoroughly institutional in character. That is, his speech-act community is comprised of institutional roles governed by a formal set of institutional rules and conventions. In formal, institutional settings, the question of illocutionary force is settled. However, in the case of informal, noninstitutional settings, it is imperative to inquire into the legitimating structures from which the non-institutional speech-act derives its illocutionary force. It is my contention that non-institutional speech-acts derive their illocutionary force from socially embodied narratives. It is from such socially embodied narratives that one derives an understanding 
of one's social role, the speech-acts constitutive of one's role, and the conventions by which those speech-acts would have to be performed to achieve their felicity. Moreover, I argued that morality is a product of discourse. This much seems clear upon examining the story of Nazneen, who comes to understand the prescriptions and proscriptions for behavior as embedded in one's social role. If morality is produced through discourse, it can just as easily be dismantled through discourse. This, I believe, indicates the utterly fragile and ephemeral nature of morality.

\section{Implications for Humanism and Anti-humanism}

What implications for humanism and anti-humanism, if any, can be drawn from speech-act theory? Is there any substance to the claim that there is an ineradicable kernel of commonality that cuts across cultures? Or is it the case that commonality of whatever kind is only accidental and not, in fact, essential? Before answering these questions, I would like to consider some remarks by MacIntyre and Charles Taylor, respectively.

In Dependent Rational Animals (1999), MacIntyre offers some rather illuminating insights concerning moral understanding between cultures. These insights concern the theory of the speech-act and go beyond the common preoccupation with illocutionary structures to emphasize the significance of desire and intentionality in the performance of intelligible speech-acts. As MacIntyre notes, there are two basic dimensions to the use of language. The first of these dimensions concerns the linguistic and semantic characteristics of language use. Every natural language, for example, has a basic stock of terms and phrases from which to compose a sentence. Natural languages also have syntactical structures according to which the composition of sentences can achieve a 
coherent, logical order. Sentences can be broken down into basic units, which can then be rearranged to compose entirely new sentences, while the syntactical structure remains the same. Just as importantly, communication in any natural language entails the creative use of definite descriptions, predicates, quantifiers, demonstratives, pronouns, indexicals, and logical connectives, all of which serve to provide language with its semantic character (29).

However, the second dimension of language use concerns its social and cultural aspects. As MacIntyre insightfully points out, it would be erroneous to contend that syntactically ordered sentences are sufficient for interaction in a given community. Knowledge of a community's basic stock of speech-acts and the conditions under which their performance can be rendered felicitous would not equip one with the competence to interact in a foreign culture. As MacIntyre argues,

The use of the sentences in speech-acts must serve some further intelligible purpose, intelligible that is in terms both of the agent's situation and purposes and of the social context. It is by uttering a syntactically ordered sentence in such a way that my utterance is some particular type of speech act, performed in such a way that it serves some intelligible purpose (not necessarily, although usually evident to observers with a knowledge of the same language) that I make my meaning known.

(MacIntyre, 1999: 30; emphasis added)

From this, MacIntyre draws a hugely important conclusion concerning the use of language. Contrary to logical formalism, which, as stated before, insists upon interpreting a given utterance according to a stable set of meanings that inhere in language itself, MacIntyre argues that

...the use of language is always embedded in forms of social practice and to understand adequately what is said on particular occasions in a given language one must have at least some of the abilities of a participant in the relevant form of social practice.... [W] here there are large differences between cultures a knowledge of how to construct sentences in some alien language unaccompanied 
by a sufficient degree of knowledge of and ability to participate with understanding in the relevant set of social practices may result in failure of communication and misunderstanding of intentions.

(MacIntyre, 1999: 30-31; emphasis added)

It need not be reiterated that the present thesis has adopted the above view of language. I have insisted upon an appreciation of the social and cultural context from which the noninstitutional speech-act derives its illocutionary force. It is precisely because I understand cultures in teleological terms - that is, as socially embodied narratives oriented toward the realization of a set of goods and from which one derives an understanding of one's social roles and their attendant prescriptions and proscriptions for behavior-that I believe culture accounts for the intelligibility and purposefulness behind the performance of a given speech-act.

MacIntyre's argument, I believe, holds interesting implications for the debate over humanism and anti-humanism. If it is the case that the use of language is necessarily parasitic upon some or other form of social practice, then it becomes impossible to appeal to a neutral medium of description or, as Wittgenstein was right to deny, a private language with which to express oneself. Our dependency upon social practices, then, would seem to challenge the anti-humanist contention against a basic commonality that cuts across cultures. For human beings are, as MacIntyre, G. F. Schueler (2003), Robert Koons (2000), and James Tomberlin (2000) variously contend, teleological creatures who act upon reasons and purposes. It is for this reason that Charles Taylor astutely maintains that

...total unintelligibility of another culture is not an option. To experience another group as unintelligible over some range of their practices, we have to find them quite understandable over other (very substantial) ranges. We have to be able to understand them as framing intentions, carrying out actions, trying to communicate orders, truths, and so forth. If we imagine even this away, then we no longer have the 
basis that allows us to recognize them as agents. But then there's nothing left to be puzzled about. Concerning nonagents, there is no question about what they are up to and hence no possibility of being baffled on this score.

(Taylor, 2002: 291)

Put simply, our mutual recognition of each other as creatures of desire, purpose, intentionality, and agency seriously throws into question the argument against a common human nature.

There is, moreover, another implication to be drawn from our dependency upon social practices. This concerns the question of the totally autonomous self. As was discussed in the previous chapters, the fatal mistake of Coriolanus lay in his determination to become an übermensch. Coriolanus aspired to live in a moral and symbolic universe of his own making. That is, he sought to become the source of his own normativity, to furnish on his own an insuperably higher set of moral standards by which he could judge the members of his own community. He saw fit to answer to no one but himself. Consider, for example, Nietzsche's remarks about the übermensch in The Will to Power:

A great man-a man whom nature has constructed and invented in the grand style-what is he? [...] If he cannot lead, he goes alone; then it can happen that he may snarl at some things he meets on his way...he wants no 'sympathetic' heart, but servants, tools; in his intercourse with men he is always intent on making something out of them. He knows he is incommunicable: he finds it tasteless to be familiar; and when one thinks he is, he usually is not. When not speaking to himself, he wears a mask. He rather lies than tells the truth: it requires more spirit and will. There is a solitude within him that is inaccessible to praise or blame, his own justice that is beyond appeal.

(Nietzsche, 1968: 505; emphasis added)

The lesson of Coriolanus (the play) is that the totally autonomous self is a dangerous

fiction. We are all, each of us, necessarily dependent upon some or other speech-act community. There is no private source of normativity, just as there is no private 
language. Speech-act theory indirectly points to our fundamentally communal, dialogical nature. Although this argument is not a basis on which to revive traditional forms of humanism, a task to which I am expressly not committed, it does suggest that there is indeed an interesting shared feature that embraces us all.

\section{Final Remarks}

\section{A. Speech-Act Analysis in the Field of Communication}

It is vital to emphasize that I have not undertaken literary criticism for the mere sake of literary criticism. Had that been my sole intention, it might have been argued that this project would have been more appropriate to the field of literary studies. In so far as speech-act theory can accomplish what I believe is its principal utility, namely, the unpacking of the social and cultural conventions that govern language and action, it seems fair to say that a cultural text to which the theory can be applied is a text worth studying if one were to seek to better understand the moral culture represented by that text. As Fish remarks,

Speech-act theory is an account of the conditions of intelligibility, of what it means to mean in a community, of the procedures which must be instituted before one can even be said to be understood. In a great many texts those conditions and procedures are presupposed; they are not put before us for consideration, and the emphasis falls on what happens or can happen after they have been met and invoked. It follows that while a speech-act analysis of such texts will always be possible, it will also be trivial (a mere list of the occurrence or distribution of kinds of acts), because while it is the conditions of intelligibility that make all texts possible, not all texts are about those conditions. Coriolanus is about those conditions... .

(Fish, 1980: 245)

Hence, a text that concerns the conditions of intelligibility is a text about communication.

It is precisely because such texts are about communication, about what it means to mean 
in a given community, that I believe a speech-act reading of such texts is entirely fitting in the field of communication.

\section{B. Policy Implications}

Finally, it is worth mentioning, even if briefly, the relevant policy implications to be derived from the present study. In the United Kingdom, for example, the works of the Anglo-Indian novelist and playwright Hanif Kureishi are distributed to foreign exchange students to introduce them to the multicultural realities of contemporary British society (Yousaf, 2000). It is my contention that a comparable policy supporting the distribution and study of narratives, whether in the form of novels, autobiography, film, or personal storytelling, would be fitting for similarly diverse societies, such as the United States and Canada. ${ }^{24}$ Canada presents an especially interesting case in point, not least because the debate over multiculturalism has in some quarters inclined in favor of a policy of interculturalism, which advocates active understanding and engagement between cultures rather than mere coexistence. ${ }^{25}$ If the main argument of the present thesis is valid, the project of interculturalism stands to benefit by an appreciation of speech-act theory and by speech-act readings of realist narratives.

\footnotetext{
${ }^{24}$ For a similar argument, see Young (1996), who argues that a communicative democracy requires an appreciation of different points of view. Young believes that the study of narratives "fosters understanding across...difference without making those who are different symmetrical..." (131). Despite her optimism concerning the value of narratives, Young remains bitterly opposed to communitarianism and equally opposed to the discourse ethics and communicative rationality of Jürgen Habermas.

${ }^{25}$ For a discussion of intercultural policy in Quebec, see Kymlicka (2001: 271-280) and Gangnon \& Tully (2001: 156-161). For more general discussions of interculturalism as an alternative to multiculturalism, see Delanty (2002: 103); Postrel (1999: 197); Durham \& Kellner (2001: 507); Kirshenblatt-Gimblett (1998: 134); Said (2001: 114-115); Aguilar-San Juan (1993: xi); Tywoniak \& Garcia (2000: xix); Cushman (2001: 578); Isin (2000: 189-202); Bernasconi (1998: 289-290); Balibar (1995: 193); Milhouse, Asante, \& Nwosu (2001); Hutcheon (1999); and Cornwell \& Stoddard (1994: 40-50). For a critical view of interculturalism, see Vincent (2002).
} 


\section{REFERENCES}

Aguilar-San Juan, Karin (1993). The State of Asian America: Activism and Resistance in the 1990s. Boston, MA: South End Press.

Ahmed, Akbar (1991). Resistance and Control in Pakistan. London: Routledge.

Ali, Monica (2003). Brick Lane: A Novel. New York, NY: Scribner.

Austin, John L. (1962). How To Do Things With Words, Urmson, J.O. and Sbisà, Marina (eds). Cambridge, MA: Harvard University Press.

Bal, Mieke (1998). Narratology: Introduction to the Theory of Narrative, Second Edition. Toronto, ON: University of Toronto Press.

Balibar, Etienne (1995). "Culture and Identity (Working Notes)," Translated by J. Swenson in John Rajchman (ed), The Identity Question. New York, NY: Routledge.

Barnett, G. A. \& Kincaid, D.L. (1983). Cultural Convergence: A Mathematical Theory. In Gudykunst, William (ed). Intercultural Communication Theory: Current Perspectives. Beverly Hills, CA: Sage Publications.

Barthes, Roland (1982). "The Reality Effect," in Todorov, Tzvetan (ed). French Literary Theory Today. Cambridge: Cambridge University Press.

Bennett, Milton J. (ed) (1998). Basic Concepts of Intercultural Communication: Selected Readings. Yarmouth, ME: Intercultural Press.

Bernasconi, Robert. " 'Stuck Inside of Mobile with the Memphis Blues Again': Interculturalism and the Conversation of Races" in Cynthia Willett, ed., Theorizing Multiculturalism. Oxford, UK: Blackwell.

Bruner, Jerome (1987). Actual Minds, Possible Worlds. Cambridge, MA: Harvard University Press.

Bruner, Jerome (1990). Acts of Meaning. Cambridge, MA: Harvard University Press.

Bruner, Jerome (2002). Making Stories: Law, Literature, Life. Cambridge, MA: Harvard University Press.

Caputo, John D. (1987). Radical Hermeneutics: Repetition, Deconstruction, and the Hermeneutic Project. Bloomington, IN: Indiana University Press.

Carr, David (1986). Time, Narrative, and History. Bloomington, IN: Indiana University Press.

Cobley, Paul (2001). Narrative. London and New York: Routledge.

Code, Lorraine. Feminist Interpretations of Hans-Georg Gadamer. University Park, PA: Pennsylvania State University Press.

Cooke, Maeve (1994). Language and Reason: A Study of Habermas's Pragmatics. Cambridge, MA: MIT Press.

Cornwell, Grant H. and Stoddard, Eve (1994). "Things fall together: a critique of multicultural curricular reform," Liberal Education: 40-50.

Cushman, Ellen (2001). Literacy: A Critical Sourcebook. Boston, MA: Bedford/St. Martin's Press.

Davidson, Donald (2001). Inquiries into Truth and Interpretation. Oxford, UK: Oxford University Press. 
De Rivera, Joseph and Sarbin, Theodore R. (1998). Believed-In Imaginings: The

Narrative Construction of Reality. Washington, DC: American Psychological Association.

Delanty, Gerard (2002). Community. London: Routledge.

Dunn, Janet Varner (1982). Autobiography: Toward a Poetics of Experience.

Philadelphia, PA: University of Pennsylvania Press.

Durham, Meenakshi Gigi, and Kellner, Douglas (2001). Media and Cultural Studies. Oxford, UK: Blackwell.

Eagleton, Terry (1983). Literary Theory: An Introduction. Minneapolis, MN: University of Minnesota Press.

Eagleton, Terry. (2003). After Theory. London, UK: Allen Lane.

Fish, Stanley (1980). Is There A Text In This Class? The Authority of Interpretive Communities. Cambridge, MA: Harvard University Press.

Fisher, Walter (1987). Human Communication as Narration: Toward a Philosophy of Reason, Value, and Action. Columbia, SC: University of South Carolina Press.

Foucault, Michel (1984). "What Is An Author?," in Rabinow, Paul (ed). The Foucault Reader. New York, NY: Pantheon Books.

Gangon, Alain and Tully, James (eds.) (2001). Multinational Democracies. Cambridge, UK: Cambridge University Press.

Geertz, Clifford (1973). Interpretation of Cultures. New York, NY: Basic Books.

Genette, Gerard (1983). Narrative Discourse: An Essay in Method. Ithaca, NY: Cornell University Press.

Genette, Gerard (1990). Narrative Discourse Revisited. Ithaca, NY: Cornell University Press.

Gergen, Kenneth. (1998). "Narrative, Moral Identity and Historical Consciousness: a Social Constructionist Account." Available online: [http://www.swarthmore.edu/SocSci/kgergen1/web/printer-friendly.phtml?id= manu3]

Gudykunst, William B. (1994). Bridging Differences: Effective Intergroup Communication, Second Edition. Newbury Park, CA: Sage.

Gudykunst, William B. and Kim, Young Yun (eds.) (1988). Theories in Intercultural Communication. Newbury Park, CA: Sage.

Habermas, Jürgen (1988). On the Logic of the Social Sciences. Translated by Shierry Weber Nicholson and Jerry a Stark. Cambridge, MA: MIT Press.

Habermas, Jürgen (1990a). Moral Consciousness and Communicative Action. Translated by Christian Lenhardt and Shierry Weber Nicholsen. Cambridge, MA: MIT Press.

Habermas, Jurgen (1990b). The Philosophical Discourse of Modernity: Twelve Lectures. Cambridge, MA: MIT Press.

Habermas, Jürgen (1993). Justification and Application: Remarks on Discourse Ethics. Translated by Ciaran Cronin. Cambridge, MA: MIT Press.

Hall, Edward T. (1959). The Silent Language. New York, NY: Doubleday.

Hall, Edward T. (1981). Beyond Culture. New York, NY: Doubleday.

Hall, Edward T. and Hall, Mildred Reed (1990). Understanding Cultural Differences. Yarmouth, ME: Intercultural Press.

Hosseini, Khaled (2003). The Kite Runner. Anchor Canada.

Hutcheon, Pat Duffy (1999). Building Character and Culture. Westport, CT: Praeger. 
Isin, Engin F. (2000). Democracy, Citizenship and the Global City. London: Routledge. Kellner, Douglas (2001). "Cultural Studies and Philosophy: An Intervention," in Miller, Toby (ed.). A Companion to Cultural Studies. Malden, MA: Blackwell.

Kirshenblatt-Gimblett, Barbara (1998). Destination Culture. Berkeley and Los Angeles, CA: University of California Press.

Koons, Robert C. (2000). Realism Regained: An Exact Theory of Causation, Teleology, and the Mind. Oxford, UK: Oxford University Press.

Kupfer, Joseph H. (1999). Visions of Virtue in Popular Film. New York, NY: Perseus Books.

Kymlicka, Will (2001). Politics in the Vernacular: Nationalism, Multiculturalism, and Citizenship. Oxford, UK: Oxford University Press.

Lejeune, Philippe (1989). On Autobiography. Minneapolis, MN: University of Minnesota Press.

Lyotard, Jean-Francois (1984). The Postmodern Condition: A Report on Knowledge. Minneapolis, MN: University of Minnesota Press.

MacIntyre, Alasdair (1978). Against the Self-Images of the Age: Essays on Ideology and Philosophy. Notre Dame, IN: Indiana University Press.

MacIntyre, Alasdair (1984). After Virtue: A Study of Moral Theory. Notre Dame, IN: Indiana University Press.

MacIntyre, Alasdair (1988). Whose Justice? Which Rationality? Notre Dame, IN: Indiana University Press.

MacIntyre, Alasdair (1999). Dependent Rational Animals: Why Human Beings Need the Virtues. Chicago \& La Salle, Il: Open Court.

Martin, Judith N. and Nakayam, Thomas K. (1997). Intercultural Communication in Contexts. Mountain View, CA: Mayfield.

Martin, Wallace (1986). Recent Theories of Narrative. Ithaca, NY: Cornell University Press.

McCann, Hugh J. (1998). The Works of Agency: On Human Action, Will, and Freedom. Ithaca, NY: Cornell University Press.

Milhouse, Virginia H.; Asante, Molefi Kete; and Nwosu, Peter O. (eds). (2001). Transcultural Realities. Thousand Oaks, CA: Sage.

Mitchell, W. J. T. (ed) (1981). On Narrative. Chicago, L: University of Chicago Press.

Nietzsche, Friederich. (1968). The Will to Power. Translated by Walter Kaufmann and R.J. Hollingdale. New York, NY: Vintage.

Peterson, Jordan B. (1999). Maps of Meaning: The Architecture of Belief. London: Routledge.

Polkinghorne, Donald (1986). Narrative Knowing and the Human Sciences. Albany, NY: SUNY Press.

Postrel, Virginia (1999). The Future and Its Enemies: The Growing Conflict Over Creativity, Enterprise, and Progress. New York, NY: Touchstone.

Raz, Joseph (1999a). Engaging Reason: On the Theory of Value and Action. Oxford, UK: Oxford University Press.

Raz, Joseph (1999b). Practical Reason and Norms. Oxford, UK: Oxford University Press.

Rogers, Everett M, and Steinfatt, Thomas M. Intercultural Communication. Prospect Heights, Il: Waveland Press. 
Ronen, Ruth. (1997). “Description, Narrative and Representation.” Narrative 5 (3): 279286.

Said, Edward (2001). Power, Politics, and Culture: Interviews With Edward W. Said, Gauri Viswanathan (ed). New York, NY: Vintage.

Samovar, Larry A. and Mills, Jack (1998). Oral Communication: Speaking Across Cultures. New York, NY: McGraw-Hill.

Samovar, Larry A. and Porter, Richard E. (1994). Intercultural Communication: A Reader. Belmont, CA: Wadsworth.

Sarbin, Theodor R. (1986). Narrative Psychology: The Storied Nature of Human Conduct. New York, NY: Praeger.

Schick, Frederic (1991). Understanding Action: An Essay on Reasons. Cambridge, UK: Cambridge University Press.

Schueler, G. F. (2003). Reasons and Purposes: Human Rationality and the Teleological Explanation of Action. Oxford, UK: Oxford University Press.

Searle, John R. (1969). Speech Acts: An Essay in the Philosophy of Language. Cambridge, MA: Cambridge University Press.

Searle, John R. (2001). Rationality in Action. Cambridge, MA: MIT Press.

Seeley, H. Ned and Seelye-James, Alan (1995). Culture Clash: Managing in a Multicultural World. Lincolnwood, Il: NTC.

Simpson, Lorenzo (2001). The Unfinished Project: Toward a Postmetaphysical Humanism. New York \& London: Routledge.

Shotter, John and Gergen, Kenneth (eds). (1987). Texts of Identity. London, UK: Sage.

Smith, Sidonie (1987). A Poetics of Women's Autobiography: Marginality and the Fictions of Self Representation. Bloomington, IN: Indiana University Press.

Spence, Donald (1984). Narrative Truth and Historical Truth: Meaning and Interpreting in Psychoanalysis. New York, NY: Norton.

Sturgess, Philip John Moore (1991). Narrativity: Theory and Practice. Oxford, UK: Oxford University Press.

Taylor, Charles (1995). Philosophical Arguments. Cambridge, MA: Harvard University Press.

Taylor, Charles (2002). "Understanding the Other: A Gadamerian View on Conceptual Schemes," in Malpas, Jeff, Ulrich Arnswald, and Jens Kertscher (eds.).

Gadamer's Century: Essays in Honor of Hans-Georg Gadamer. Cambridge, MA: MIT Press.

Todorov, Tzvetan (1981). Introduction to Poetics. Minneapolis, MN: University of Minnesota Press.

Tomberlin, James E. (2000). Philosophical Perspectives: Action and Freedom. Oxford, UK: Blackwell.

Tywoniak, Frances Esquibel and Garcia, Mario T. (2000). Migrant Daughter. Berkeley and Los Angeles, CA: University of California Press.

Vincent, Andrew (2002). Nationalism and Particularity. Cambridge, UK: Cambridge University Press.

Warnke, Georgia (2002). "Hermeneutics, Ethics, and Politics," in Dostal, Robert J. (ed). The Cambridge Companion to Gadamer. Cambridge, UK: Cambridge University Press. 
Watcherhauser, Brice (2002). "Getting it Right: Relativism, Realism, and Truth," in Dostal, Robert J. (ed). The Cambridge Companion to Gadamer. Cambridge, UK: Cambridge University Press.

White, Hayden (1973). Metahistory: The Historical Imagination in Nineteenth-Century Europe. Baltimore, MD: Johns Hopkins University Press.

White, Hayden (1987). The Content of the Form: Narrative Discourse and Historical Representation. Baltimore, MD: Johns Hopkins University Press.

Williams, Raymond (1970). The English Novel from Dickens to Lawrence. New York: Oxford University Press.

Young, Iris Marion. (1996). "Communication and the Other: Beyond Deliberative Democracy," in Benhabib, Seyla (ed.). Democracy and Difference: Contesting the Boundaries of the Political. Princeton, NJ: Princeton University Press.

Yousaf, Nahem (2002). Hanif Kureishi's The Buddha of Suburbia. New York \& London: Continuum. 